\title{
The Geological Present: A Critique of the Aesthetic Anthropocene
}

\author{
Lachlan Taylor
}

A thesis submitted in fulfilment of the requirements for the degree of Master of Arts in Art History

Victoria University of Wellington

2018 


\section{Contents.}

$\begin{array}{lr}\text { Abstract } & 2\end{array}$

$\begin{array}{ll}\text { Acknowledgements } & 3\end{array}$

Introduction $\quad 4$

Entering the Geological Present

Chapter One

The Aesthetic Anthropocene

A Power of a Higher Order 16

The Table of Bounteous Nature $\quad 30$

Restoration of Disturbed Harmonies 45

Spontaneous Arrangements of the Organic or Inorganic 58

Chapter Two $\quad 65$

Art Without Nature

$\begin{array}{ll}\text { Feeling Nature } & 67\end{array}$

Thinking Nature $\quad 83$

$\begin{array}{lr}\text { Seeing Nature } & 99\end{array}$

$\begin{array}{ll}\text { Conclusion } & 119\end{array}$

$\begin{array}{ll}\text { Bibliography } & 123\end{array}$

$\begin{array}{ll}\text { List of Illustrations } & 130\end{array}$

$\begin{array}{ll}\text { Illustrations } & 132\end{array}$ 


\begin{abstract}
.
This thesis is a response to an emergent discourse on the relationship between the visual arts and the Anthropocene. The latter-the stratigraphic designation for a new geological epoch-has accrued a popularity within the contemporary artworld that is rarely afforded to a concept from the earth sciences. The uptake in Anthropocene-themed exhibitions, publications, and think-pieces reflects the concept's promise of an art-making and art-critical methodology that may foster a revised relationship to nature in the age of climate change.

Despite the new-found fashionability of the term, this relationship between art and the Anthropocene has neither been comprehensively demonstrated, nor disproved. Consequently, the purpose of this thesis is to undertake this necessary interrogation.
\end{abstract}

Firstly, this is an engagement with the competing philosophies and intentions that have attached themselves to the Anthropocene label as it progressed from a straightforward geological statement, into a profound suite of assertions regarding the relationship of humanity to our planet. The influence of the posthumanist ecological philosopher, Timothy Morton, is a particular focus for understanding what the aesthetic theory of the Anthropocene consists of. Taken together, this theory is a promise of a new relationship with the natural world through the jettisoning of Romantic fantasies of nature in favour of an engagement with a subdiscursive, material world.

Secondly, this theory is read against ecologically conscious contemporary art works. The practices of Pierre Huyghe, Simon Starling, and Conor Clarke speak to the same concerns as the aesthetic Anthropocene. Reading these works through the lens offered by the stratigraphic concept investigates and tests the capability of the aesthetic Anthropocene for delivering its promises of an art without nature, and a new engagement with our environments.

Ultimately, the innovations of the aesthetic Anthropocene are novel, plentiful, but ultimately unconvincing. As a theory, it is beset by flaws and contradictions which undermine its applicability and critical potential. Consequently, ecologically conscious art does little to reflect the aims and aspirations of the aesthetic Anthropocene, rendering it an unhelpful tool for understanding the geological present. 


\section{Acknowledgments.}

My first thanks go to my supervisor, Roger Blackley, whose gifts of encouragement, wisdom, and patience are the only reason this thesis has ever reached completion.

I would also like to thank David Maskill, Peter Brunt, Geoffrey Batchen, and Raymond Spiteri. Your teachings during my time at Victoria University have instilled in me the vitality, importance, and great pleasure of Art History. And your continued passion for this discipline is a source of inspiration and encouragement. In particular, I want to thank Geoff, to whom I owe a great debt of gratitude for his assistance in the development of this thesis.

Thank you, Pippa Wisheart. Your tireless care and affection for this department and its inhabitants is what makes the Art History programme such a pleasure to be a part of.

Thank you to my friends and family, for your unwavering support and belief, and for extending nothing but kindness and encouragement to me throughout this process.

Finally, I must thank Anna-Marie White, Kirsty Baker, and Milly Mitchell-Anyon. You don't get to choose your officemates, so it is something of a mystery how I ended up with three of the very best. For a year of intelligence, humour, empathy, and culinary expertise, I will be forever grateful. 


\section{Introduction. \\ Entering the Geological Present}

In the early months of 2017, the environmental desks of a number of global newspapers grew agitated over a sixteen-year-old can of preserved meat (fig. 1). The unopened SPAM, having descended some 4,947 metres to rest in the aphotic depths of the Mariana trench, had been photographed by a US National Oceanic and Atmospheric Association remote submarine. ${ }^{1}$ The photograph of the SPAM can was featured in stories by the Guardian, the Los Angeles Times, and the Washington Post that concerned the detection of alarming levels of toxic pollutants in the deepest reaches of the ocean. The can itself, however, functioned as a signifier for so much more than the presence of POP and PCB chemicals in the Pacific.

This individually innocuous container of gelatinous ham operated as an aluminium metaphor for the extent of our environmental depravity. 'Is there no place we won't trash?' asked Mariel Garza in the LA Times. ${ }^{2}$ In the Guardian, Damien Carrington posited in his subhead-centimetres above the photograph of the canthat 'nowhere is safe from human impact'. ${ }^{3}$ The sinister import with which both writers imbued the can was hardly misplaced. Their sentiments reflect the growing acceptance-as distinct from awareness-that the environment which nourished our species for millennia may not be quite as harmonious or eternal as we have previously imagined.

As the material consequences of anthropogenic climate change are gradually more seen, felt, and experienced by humanity, our long-held ideas about nature are appearing increasingly untenable. Ideals of the pristine, the wild, and the primitivecultivated in the crucible of Romantic thought and affirmed by Romantic aesthetics-

\footnotetext{
${ }^{1}$ Damian Carrington, “"Extraordinary” Levels of Pollutants Found in 10km Deep Mariana Trench,' the Guardian, accessed 10 March 2017, https://www.theguardian.com/environment/2017/feb/13/extraordinary-levels-of-toxic-pollutionfound-in-10km-deep-mariana-trench.

${ }^{2}$ Mariel Garza, 'There's a Garbage Patch at the Bottom of the Ocean. Is There No Place We Won't Trash?' the Los Angeles Time, accessed 10 March 2017, http://www.latimes.com/opinion/opinionla/la-oe-spam-pollution-mariana-trench-20170213-story.html.

${ }^{3}$ Carrington, “"Extraordinary” Levels of Pollutants Found in 10km Deep Mariana Trench'.
} 
now stand at odds with the realities of a total physical environment defined by the ubiquitous signs of destructive human interaction. Mounting stratigraphic evidence suggests that the scope of humanity's telluric influence justifies the transition into a new geological epoch: the Anthropocene. ${ }^{4}$ The simplicity of the idea belies its radical implication: to live in the Anthropocene is to live in a new geological present, effectively, to live in a new world. Proponents of the concept argue that, if we truly are moving into a new epoch, then as a species we will have to challenge and renegotiate our existing relationships with industry, ecology, and the very idea of nature.

While the idea of the Anthropocene began as a stratigraphic proposal, it rapidly left the earth sciences to become a fixation of the humanities and the visual arts. This evolved concept, what might be called the aesthetic Anthropocene, is no longer just a question of geology. Rather, it is a complex network of statements about an epistemological and ontological revolution in the relationship between humanity and our physical environments - an assertion that the world has so drastically changed that conceptions of ourselves as a species and the environments we occupy must change with it. Of central importance to this thesis, contemporary art has been championed as a vehicle for encouraging and manifesting this revolution. These are no small claims. Yet despite the magnitude of such a pronouncement, the Anthropocene is more often invoked as a meaningless catch-all for collating environmentally adjacent artistic practices, rather than the fulfilment of this promise.

Does this mean that the term is critically useless-a novel concept but one lacking in any real substance or rigour? This thesis is an attempt to answer that question, not by dismissing the aesthetic Anthropocene out of hand, but by taking it seriously. To give this idea its due, it is necessary first to establish what the theory of the aesthetic Anthropocene comprises. The question of the concept's critical worth and theoretical integrity can then be addressed by employing the theory as a lens through which to read contemporary art. 
In the first chapter of this thesis I draw together and analyse the varied concepts and philosophies that form the aesthetic Anthropocene. While the epoch began as a straightforward geological proposition, the Anthropocene quickly took on what Jeremy Davies notes in The Birth of the Anthropocene (2016) 'a variety of incompatible meanings, each implying different concepts and commitments' . Charting the evolution of the concept, from its initial postulation by atmospheric chemist Paul Crutzen at the turn of the millennium to its current popularity within the humanities, reveals the intersections and incompatibilities of these commitments. ${ }^{6}$

As the idea of the Anthropocene left the earth sciences, it shifted from a strictly scientific proposal to a concept with wider ethical concerns for the humanities. Consequently, the term has attracted an array of criticisms which are equally important for understanding the term's operation as its proclaimed potential. ${ }^{7}$ Finally, the supporters of the concept within the visual arts make a number of claims as to the promise of the Anthropocene for contemporary art. Primarily, this is the potential to disrupt, resolve, or even merge the epistemological binary of nature and human culture that has-in no small way-contributed to the ecological crises of the Anthropocene. Contrasting this promise with the reality of the term's current usage is what prompts the central question of this thesis.

A number of texts have begun to grasp at what an aesthetic Anthropocene may represent. ${ }^{8}$ However, as of writing, the only comprehensive aesthetic theory of Anthropocene thought has been produced by the ecological philosopher Timothy

\footnotetext{
${ }^{5}$ Jeremy Davies, The Birth of the Anthropocene (Berkeley: University of California Press, 2016), 41.

${ }^{6}$ Davies, The Birth of the Anthropocene, 42.

${ }^{7}$ These are best articulated in Andreas Malm and Alf Hornborg, 'The Geology of Mankind? A Critique of the Anthropocene Narrative', The Anthropocene Review 1, no. 1 (2014): 62-69, accessed 15 July 2017, http://journals.sagepub.com/doi/abs/10.1177/2053019613516291. Malm and Hornberg contend that the Anthropocene is an uncritically universalist construct that designates blame to an entire species for the effects of climate change, despite the fact that its causes can be primarily attributed to a privileged few.

${ }^{8}$ Heather Davis and Etienne Turpin (eds), Art in the Anthropocene: Encounters Among Aesthetics, Politics, Environments and Epistemologies, (London: Open Humanities Press, 2015) and Jamie Kruse and Elizabeth Ellsworth (eds), Making the Geologic Now: Responses to Material Conditions of Contemporary Life (New York: Punctum Books, 2012) currently stand as two of the best examples of attempts at an aesthetic Anthropocene reader.
} 
Morton. ${ }^{9}$ On account of this high profile among proponents of the Anthropocene, and his affinities with the philosophical underpinnings of the concept, Morton forms the central pillar of the aesthetic Anthropocene. Crucially, Morton identifies the very idea of nature-as it emerged in the Romantic period-as the fundamental obstacle that an aesthetics of the proposed epoch must navigate:

The idea of nature is all too real, and it has an all too real effect upon all too real beliefs, practices, and decisions in the all too real world. True, I claim that there is no such 'thing' as nature, if by nature we mean some thing that is single, independent, and lasting. But deluded ideas and ideological fixations do exist. 'Nature' is a focal point that compels us to assume certain attitudes. Ideology resides in the attitude we assume toward this fascinating object. ${ }^{10}$

Morton argues that this Romantic fixation, 'in all its confusing, ideological intensity ... ironically impedes a proper relationship with the earth and its lifeforms' ${ }^{11}$ Nature, operating as a cultural sign and metonymic structure of alterity-the absence of civilisation-is suspended in a paralytic binary that allows humanity to simultaneously revere and defile the material world. Morton details a tension between a desire for dominance over nature, and an impulse to preserve it, wherein the latter desire washes humanity's hands of the first. ${ }^{12}$

Morton builds this concept into an aesthetic theory through his assertion that the Romantic myths of nature are preserved in contemporary ecological aesthetics. He terms the process through which these fantasies flourish and endure in art as ecomimesis-an umbrella term for an array of representational techniques by which artists attempt to pose an unmediated view of the natural world to their audience. Ecomimetic art and writing 'insists that we are "embedded" in nature' as a 'surrounding medium that sustains our being'. ${ }^{13}$ To this end, Ecomimesis is both

\footnotetext{
${ }^{9}$ Morton began this project in Ecology Without Nature: Rethinking Environmental Aesthetics (Cambridge: Harvard University Press, 2007), which was then continued in The Ecological Thought (Cambridge: Harvard University Press, 2010), Hyperobjects: Philosophy and Ecology after the End of the World (Minneapolis: University of Minnesota Press, 2013), Dark Ecology: For a Logic of Future Coexistence (New York: Columbia University Press, 2016), and most recently, Humankind: Solidarity with Nonhuman People (New York: Verso, 2017).

${ }^{10}$ Morton, Ecology Without Nature, 20.

${ }^{11}$ Morton, Ecology Without Nature, 2.

${ }^{12}$ Morton, Ecology Without Nature, 5.

${ }^{13}$ Morton, Ecology Without Nature, 4.
} 
'objectively generalised and subjectively particular' — concretising an opaque idea of Romantic nature through specific references to space, climate, and time. ${ }^{14}$ Yet, in doing so, it constantly draws upon the notion of an eternal, unchanging nature, inherited from Romantic sources as a cultural paean for a pristine-and ultimately non-existent-natural world. ${ }^{15}$

The inverse of ecomimesis is dark ecology, a mode of thought and aesthetics developed by Morton that champions the values of contradiction, irony, dynamism, and grief. ${ }^{16}$ It is an expression of the experience of living with climate change, an idea so vast that he describes it as a 'hyperobject': something real yet incomprehensible due its vast scale and multitudinous forms. ${ }^{17}$ Symbolised by the Ouroboros-the snake that devours its own tail-artworks that embody the principles of dark ecology foster a sense of complicity in the Anthropocene and its attendant climate crisis: responsibility for its causes and solutions. For Morton, dark ecology is the means by which we may strip nature from art, nullifying one half of the nature/culture dichotomy and producing a 'more honest ecological art [that] lingers in the shadowy world of irony and difference'.

What remains underneath, in the wake of nature's absence, is informed by the philosophical basis of the Anthropocene concept. Davies states of the potential epoch:

The idea of the Anthropocene puts all [biogeochemical forces] on the same ontological plane. Humanity, in this epoch, does not absorb or command some merely passive nature, issuing orders from a central throne to the dull physical substance that surrounds it. On the contrary, human societies are only the most vigorous and distinctive among an irreducibly various array of altered forces. ${ }^{18}$

While not explicitly stated, Davies is drawing on an emergent body of interrelated philosophies that seek to move away from the anthropocentrism of humanist philosophy. Specifically, these posthumanisms-which include speculative realism,

\footnotetext{
${ }^{14}$ Vince Carducci, 'Ecocriticism, Ecomimesis, and the Romantic Roots of Modern Ethical Consumption,' Literature Compass 6, no. 3 (2009): 633.

${ }^{15}$ Ibid.

${ }^{16}$ Morton, Dark Ecology, 7.

${ }^{17}$ Morton, Dark Ecology, 11.

${ }^{18}$ Davies, The Birth of the Anthropocene, 73.
} 
new realism and materialism, and Object-Oriented Ontology (OOO)—comprise a broad project to reject what their protagonists charge as the logical fallacy of Kantian/Hegelian correlationism:

By 'correlation', we mean the idea according to which we only ever have access to the correlation between thinking and being, and never to either term considered apart from the other. [...] Correlationism consists in disqualifying the claim that it is possible to consider the realms of subjectivity and objectivity independently of one another. Not only does it become necessary to insist that we never grasp an object 'in itself,' in isolation from its relation to the subject, but it also becomes necessary to maintain that we can never grasp a subject that would not always already be related to an object. ${ }^{19}$

Although they offer distinct approaches, and come at the issue from different backgrounds, posthumanisms generally wish to assert the primacy of the material and real over the linguistic and constructed. As such, they offer the aesthetic Anthropocene a philosophical foundation for asserting the existence of something to be found beneath the blanket of Romantic nature. Posthumanism provides a logic for a real, material, nonhuman world to be revealed by a dark ecological aesthetic.

Brought together, the idea of a new epoch, Morton's concepts of ecomimesis and dark ecology, and posthumanist philosophy, form a theory of the aesthetic Anthropocene. This theory promises a kind of active, ecological reading of contemporary art, wherein the fallacious rendering of ecomimetic nature is stripped back to reveal a truthful nonhuman. The purpose of this theory is to promote a kind of art that fosters a more realistic, sustainable, and ultimately symbiotic relationship with the nonhuman world that surrounds us. The dream being that in removing nature from a binary at the centre of human experience, we might better understand our place in a changing planet. In doing so, the proponents of the aesthetic Anthropocene hope to encourage a different course, averting the looming ecological catastrophes of climate change. 
If the aesthetic Anthropocene is to represent a form of ecological methodology for the visual arts, then it must be able to produce a productive and sustainable reading of contemporary ecological art. To that end, the second chapter of this thesis applies the aesthetic Anthropocene to the practices of three artists whose works attend to issues of climate change, ecology, and the influence of human societies on the physical environment. Each artist speaks to these issues in different ways, and consequently, each exposes a different aspect of the aesthetic Anthropocene. Rather than immediately adopting a cynical stance-attempting to undermine the theory from the outset-I will give the concept its due by applying it without reservation, in the intention of testing its critical potential.

The French artist Pierre Huyghe (1962-) has produced a body of work that is difficult to define. He has worked in an array of traditional, object-based media including photography, video, and sculpture. But his most interesting and critically successful projects come from within a conceptual framework. These have taken the form of gallery-space interventions, and the construction of living, ecological systems possessed of indeterminate agency. ${ }^{20} \mathrm{~A}$ discussion of an artwork from this latter category occupies of the first third of this chapter.

For $d O C U M E N T A$ (13) (2012), Huyghe converted the composting area of Kassel's Karlsaue park into an unknown, unknowable environment of shifting ecological circuitry. The work, Untilled (2011-12), described by Amelia Barikin and Victoria Lynn's as 'radically indeterminate', was at once a site of entropy and creation, populated by markers of the human and nonhuman:

Two dogs roamed the grounds. One, a white Ibizan hound with a dyed fluorescent pink leg, was named Human. Psychotropic, medicinal and aphrodisiac plants flourished amidst the undergrowth: datura, peyote, marijuana, and opium poppies. Flowers were pollinated by a hive of bees living on a sculpture of a reclining nude. A human was present, repeating endlessly the role of a gardener. ${ }^{21}$

${ }^{20}$ Amelia Barikin, Parallel Presents: The Art of Pierre Huyghe (Cambridge: MIT Press, 2012), 3.

${ }^{21}$ Amelia Barikin and Victoria Lynn, Pierre Huyghe (Victoria: TarraWarra Museum of Art, 2015), 37. 
The sum total of Untilled is an uncertain equation. And that uncertainty is entirely the point. Far from the surety and stability of Romantic, ecomimetic nature, Untilled offered an alternative vision of the nonhuman world punctuated by the dark ecological values of contingency and ambiguity.

Huyghe's work closely aligns with a posthumanist thread that benefits Untilled's reading through the lens of the aesthetic Anthropocene. Object-Oriented Ontology—developed by the philosopher Graham Harman and supported by Morton-treats objects as the primary constituents of the world. ${ }^{22}$ The central thesis of $\mathrm{OOO}$ is that all objects 'distort, caricature, or inadequately translate the other' objects around them..$^{23} \mathrm{OOO}$ thought celebrates the unknowability of sub-discursive objects, their strangeness and indifference to humanity. Untilled, punctured by opaque relationships between ambiguous objects, is a perfect marriage of Morton's disruption of Romantic nature and OOO posthumanism.

A second posthumanism, and a second way of reading the aesthetic Anthropocene, is explored in the work of English artist Simon Starling (1967-). Starling's practice reframes artistic processes and histories, forcing subjects to be viewed and thought of in different contexts. This much is evidenced in his 2005 Turner Prize winning work, Shedboatshed (Mobile Architecture No. 2), which saw the artist convert a wooden shed into a boat, sail it $8 \mathrm{~km}$ down the Rhine, and then reconstruct it as a shed at the other end. Dieter Roesltraede describes Starling's practice as the 'lowering of the veil that serves to keep the artwork's essential enigma intact' ${ }^{24}$ Starling removes the mystery from alchemical transformation of material into value that takes place in art.

Starling's work often attends to the materials of artmaking, and the cultural, economic, and environmental politics that underpin their use. In his photographic sculptures-works that sit at the threshold of the two media-Starling interrogates the relationship between capital, labour, and the environment. A discussion of the works, One Ton II (Five handmade platinum/palladium prints of the Anglo American

\footnotetext{
${ }^{22}$ Cox, Jaskey, and Malik, Realism, Materialism, Art, 21.

${ }^{23}$ Graham Harman, The Quadruple Object (Alresford: Zero Books, 2011), 44.

${ }^{24}$ Dieter Roelstraete, 'Survey,' in Roelstraete, Janet Harbord, and Francesco Manacorda, Simon

Starling (London, New York: Phaidon Press, 2012), 87.
} 
Platinum Corporation mine at Potgietersrus, South Africa, produced using as many platinum group metal salts as can be derived from one ton of ore) (2005, Vancouver: Rennie Museum) and The Nanjing Particles (After Henry Ward, View of C.T. Sampson's Shoe Manufactory, with the Chinese Shoemakers in working costume, North Adams and vicinity, circa 1875) (2008, North Adams: Massachusetts Museum of Contemporary Art) demonstrates this interplay and its interruption of ecomimetic forms of photographic practice.

In bringing matter to the forefront of the gallery experience, Starling's photographic sculptures force the viewer into a confrontation with their own participation in systems of oppression and environmental destruction. Significant to this thesis, his attention to the qualities of matter aligns with posthumanist, new materialisms. Unlike OOO, which finds all meaning in objects, materialists turn to biogeochemical properties and forces. ${ }^{25}$ Starling's interest in the vitality and politics of matter opens up this aspect of the aesthetic Anthropocene to be read through his work.

The final section of this chapter looks at two photographic series by New Zealand artist, Conor Clarke (1982-), whose practice interrogates the encultured norms of seeing Romantic nature through an established vocabulary of aesthetic typologies. With In Pursuit of the Object, at a Proper Distance (2012-2014) and Scenic Potential (2014-2015), Clarke complicates the boundaries between human and nonhuman forms, revealing the arbitrary ways in which the binary of nature and culture is established and maintained.

Clarke's series-essentially photographic typologies-are informed by the work of the German photographic duo, Bernd and Hilla Becher. The Bechers popularised the deadpan form and taxonomic style inherited by Clarke, but the New Zealand photographer updates this practice for contemporary concerns provoked by a changing climate. Looking at both artists side-by-side demonstrates the authority of typological aesthetics that inform ways of seeing our world. As Geoffrey Batchen

\footnotetext{
${ }^{25}$ Diana Coole, 'From Within the Midst of Things: New Sensibility, New Alchemy, and the Renewal of Critical Theory.' In Cox, Jaskey, and Malik, Realism, Materialism, Art, 41-46.
} 
states of the Bechers, 'we learn little from looking at their work other than about our own act of looking' ${ }^{26}$

This act of looking is what brings Clarke's photography into a new realist, posthumanist framework. The art historian and theorist Amanda Boetzkes has analysed historical models of ecological perception to demonstrate an encultured practice of constantly seeking the best of Romantic nature out of our views of the nonhuman world. ${ }^{27}$ Crucially, she identifies a difference between the individual act of receiving the optical information of nonhuman objects, and a cultural practice of affording privilege to certain shapes and patterns. Clarke's photographs can be read as demonstrations of this difference through art, revealing a set of Romantic priorities in vision that impede our ability to truly see the nonhuman.

Although the concepts that appear in this thesis are novel, and often convoluted, its purpose is ultimately simple: to establish what a theory of the aesthetic Anthropocene comprises, and to test that theory against contemporary artworks that engage with its central premises. The promise of the aesthetic Anthropocene is ambitious. It is presented as a solution, as a model-expressed in art-through which we may take our first steps toward a more productive, and eventually sustainable, relationship with our changing planet. The promise is great but, so far, remains unfulfilled. This is an opportunity to test that promise, and to scrutinise its viability.

\footnotetext{
${ }^{26}$ Geoffrey Batchen, 'Ordering Things,' in Brian Wallis (ed.), The Order of Things: Photography from the Walther Collection (Göttingen: Steidl Publishers, 2015), 333.

${ }^{27}$ Amanda Boetzkes, 'Ecologicity, Vision, and the Neurological System,' in Davis and Turpin, Art in the Anthropocene, 271-282.
} 


\section{Chapter One.}

\section{The Aesthetic Anthropocene}

The world is going to pieces and people like

Adams and Weston are photographing rocks!

Henri Cartier-Bresson 
The aesthetic Anthropocene appears to us with three faces. The first is the idea of a new geological epoch, bringing with it the promise of new ideas for humanity, nature, and the relationship between the two. The second is a solution, a means to bring that possibility into being through artistic expression. The third is a philosophy that supports the prior two, connecting them within a theoretical framework that smooths over their contradictions and shortcomings.

Taking the aesthetic Anthropocene seriously requires an investigation of each of these three faces. It means presenting the arguments for the concept, as its proponents express them-before measuring it against contemporary artistic expressions of climate change and the concept of increased human influence over the Earth. Due to the limited space of this text, it also requires narrowing the aesthetic Anthropocene to a single conception. Consequently, I have chosen to explore the theories and concepts expressed by the ecological philosopher Timothy Morton. Morton makes an appropriate choice for the following reasons: having entered into popular as well as philosophical discourses, he is as close as the Anthropocene concept has to a public face. On top of publishing numerous books on the topic, Morton has crossed over to become something of a cultural figure. He has been profiled by the Guardian, appeared at Glastonbury, and given high-profile public lectures alongside major art-world figures like Olafur Elliason and Hans-Ulrich Obrist. ${ }^{28}$ Secondly, Morton has created a fully formed aesthetic theory for the Anthropocene. Where others have made overtures towards a connection between art and the Anthropocene epoch, Morton has fully expressed these in his twin concepts of ecomimesis and dark ecology. Finally, he comes from the posthumanist intellectual milieu that informs the popular Anthropocene concept.

An idea, a solution, a philosophy.

\footnotetext{
${ }^{28}$ Alex Blasdel, “'A Reckoning for Our Species”: The Philosopher Prophet of the Anthropocene,' accessed 19 July 2017, the Guardian, https://www.theguardian.com/world/2017/jun/15/timothymorton-anthropocene-philosopher.
} 


\section{A Power of a Higher Order}

An idea has taken hold. It did not come from the visual arts, but we have adopted it as one of our own. We have celebrated its potential as a discursive tool, claimed it as a new methodology - a new way of seeing for a new world. This idea had been gestating for many years before its current ascendency. It shifted, changing name and appearance. We know it now as the Anthropocene. Perhaps, it is already broken. The idea itself is still young, having only entered critical discourse at the turn of the millennium, and came to its popularity in the last decade. Like all young terms, the Anthropocene is vulnerable, easily malleable, adapting to new meaning. It has taken on an ever-expanding multitude of contradictory intentions, first within the earth sciences, then the humanities, and now in the global art economy.

This idea is now over-burdened. Like postmodernism before it, Anthropocene has become a term that is asked to mean everything to everyone, and in doing so ends up meaning nothing in particular. Before it was tortured entirely out of shape the Anthropocene tried to say something about a changing world. Now, liberally applied to any showing of remotely environment-adjacent art, it has taken on the appearance of an immense, vague metaphor for a revised relationship between humanity and nature. Nevertheless, it achieves little simply to dismiss the Anthropocene because it attained buzzword fashionability and lost much of its coherency and critical potential in the process. It is necessary to go back and ask what the Anthropocene initially had to offer, what happened to the term when it left the sciences, and what (if any) relevance it may still hold for contemporary art.

The Anthropocene began as a proposed epoch: a subdivision of geological time, discernible as a distinct layer in the Earth's stratigraphic record.$^{29}$ Epochs are one of the divisions used by stratigraphers-our geological timekeepers-to organise the material history of the planet. Epochs make up a period, which in turn constitute eras, and eons beyond that. This is a lexicon we are vaguely familiar with, connoting

${ }^{29}$ Elizabeth Kolbert, 'Enter the Anthropocene: Age of Man', in Jamie Kruse and Elizabeth Ellsworth (eds), Making the Geologic Now: Responses to Material Conditions of Contemporary Life, ed. (New York: Punctum Books, 2012), 28. 
unspecified, immense spans of time, but which constitute the very specific vocabulary of the stratigrapher. A number of writers will tell you that the Anthropocene could be the first truly human epoch. ${ }^{30}$ With a lack of deference to the specificities of stratigraphy, they might tell you that it is the first human age or era. But the Holocene, the epoch which began around 11,700 years ago at the conclusion of the last in a series of ice ages, has always been the human epoch. It is the only time in which there have been 'symphony orchestras and hypodermic needles, moon landings and gender equality laws, patisseries, microbreweries, and universal suffrage'.${ }^{31}$ In other words, this twelve-millennia period of relative climate stability is the only time in which humanity, and human culture, have thrived. To subscribe to the Anthropocene theory is, therefore, to pronounce that the human age is over and that we are living in something else entirely.

The conception of a new epoch has its genesis in the nineteenth century. One of the first texts to recognise that human action had the potential to fundamentally alter the geological character of the planet was George Perkins Marsh's Man and Nature: Or, Physical Geography as Modified by Human Actions (1864). ${ }^{32}$ Written in Italy, while his native America was in the midst of an existential conflict, Marsh outlined in his preface the wish:

To indicate the character and, approximately, the extent of the changes produced by human action in the physical conditions of the globe we inhabit; to point out the dangers of imprudence and the necessity of caution in all operations which, on a large scale, interfere with the spontaneous arrangements of the organic or the inorganic world; to suggest the possibility and the importance of the restoration of disturbed harmonies and the material improvement of waste and exhausted regions; and, incidentally, to illustrate the doctrine, that man is, in both kind and degree, a power of a higher order than any of the other forms of animated life, which, like him, are nourished at the table of bounteous nature..$^{33}$

\footnotetext{
${ }^{30}$ Jeremy Davies, The Birth of the Anthropocene (Berkeley: University of California Press, 2016), 7.

${ }^{31}$ Davies, The Birth of the Anthropocene, 5.

${ }^{32}$ Paul Crutzen, 'Geology of Mankind,' Nature 415 (2002): 23, accessed 23 April 2017, http://www.nature.com/nature/journal/v415/n6867/full/415023a.html?foxtrotcallback=true. ${ }^{33}$ George Perkins Marsh, Man and Nature: Or, Physical Geography as Modified by Human Actions, 1864. Facsimile of first edition, ed. David Lowenthal (Cambridge: Harvard University Press, 1965), iii.
} 
This initial offering in the discourse of the Anthropocene touched on the dominant themes that define the concept today: the extent of human influence and its attached dangers, the presumption of human primacy among species, and the relationship of humanity to nature as a network of 'spontaneous arrangements' in harmonious interface.

Marsh's ideas were built on by Antonio Stoppani, an Italian geologist familiar with Man and Nature through its translation in $1872 .{ }^{34}$ The year following, Stoppani published his three-volume Corso di Geologia, in which he spoke of humanity as a 'telluric force that for its strength and universality does not pale in the face of the greatest forces of the globe'.$^{35}$ It was with confidence in the transformative abilities of this 'new element' of Homo sapiens sapiens that he inaugurated the 'Anthropozoic era', a time defined by humanity's new-found dominance over the inorganic forces which had governed the species for millennia, and the planet for billions of years. ${ }^{36}$ While Stoppani's Anthropozoic era remained framed within the 'absolute dominion that man received from God', in the 1920s V. I. Vernadsky and Teilhard de Chardin separately endorsed a more strictly humanist 'Noösphere'. ${ }^{37}$ This 'world of thought' represented the increasingly prevalent power of the human brain to shape the physical world, particularly through efforts in atomic science. ${ }^{38}$ To this list of antecedents we can add the scientific journalist Andrew Revkin, who 'offhandedly proposed an "Anthrocene" age in the early 1990s' ${ }^{39}$ While these predecessors of the Anthropocene inform our conceptions of the proposed epoch, it would be misguided to treat them as a path of linear teleology towards an ultimate definition. Instead, they are better seen as a set of analogues for the theories of the Anthropocene that would emerge as such in the twenty-first century.

The first of these theories, the one that gave us the epoch's popular title and brought the Anthropocene into critical consciousness, was developed by the Dutch

\footnotetext{
${ }^{34}$ Crutzen, 'Geology of Mankind,' 23.

${ }^{35}$ Antonio Stoppani, quoted in Etienne Turpin and Valeria Federighi, 'A New Element, A New Force, A New Input: Antonio Stoppani's Anthropozoic,' in Kruse and Ellsworth, Making the Geologic Now, 36. ${ }^{36}$ Ibid.

${ }^{37}$ Turpin and Federighi, 'Antonio Stoppani's Anthropozoic,' 37; Crutzen, 'Geology of Mankind,' 23.

${ }^{38}$ Crutzen, 'Geology of Mankind,' 23.

${ }^{39}$ Davies, The Birth of the Anthropocene, 43.
} 
atmospheric chemist Paul Crutzen at the turn of the millennium. Awarded the Nobel prize for chemistry in 1995 for his work related to the discovery of the ozone hole, Crutzen was attending an earth system sciences conference in Mexico City in 1999. ${ }^{40}$ During a discussion on the Holocene, he abruptly told the conference delegates that they should stop using that word to describe the contemporary epoch. Like a Dorothy of the earth sciences, Crutzen told his attendant Totos that 'we're not in the Holocene anymore ${ }^{41}$ And in that moment he christened the new epoch, stammering to the delegates, 'we're in the ... the ... the Anthropocene!' ${ }^{22}$ While seductive, this story smacks of apocryphal retellings and mythologisings. Crutzen himself has downplayed the spontaneity of the event, stressing that the 'emergence of the concept was more drawn-out and more complicated than the story about the conference might suggest' ${ }^{\prime 3}$ Yet this story is inevitably repeated because it offers a neat narrative beginning, a birth of the Anthropocene at the birth of a new millennium.

In collaboration with the ecologist Eugene Stoermer, Crutzen published the first theory of the Anthropocene in the newsletter of the International GeosphereBiosphere Programme in 2000. They argued that the designation of a new epoch would reflect the 'central role of mankind in geology and ecology': humanity as a dominant force in the make-up of the whole earth system. ${ }^{44}$ The root, Anthropo-, from the Greek for human, would reflect this particular centrality, making it the unique and defining feature of the epoch. ${ }^{45}$ Crutzen and Stoermer hypothesized an unknown date in the late eighteenth century as the beginning of the new epoch, representing a time when an increase in atmospheric methane and carbon dioxide had made the 'global effects of human activities ... clearly noticeable'. ${ }^{46}$ Crutzen restated his and Stoermer's conception of the Anthropocene in Nature in 2002. He added to the

\footnotetext{
${ }^{40}$ Davies, The Birth of the Anthropocene, 42.

${ }^{41}$ Ibid.

${ }^{42}$ Ibid.

43 Ibid.

${ }^{44}$ Paul Crutzen and Eugene Stoermer, 'The “Anthropocene”,' Global Change Newsletter 41 (May 2000): 17.

${ }^{45}$ Ibid.

${ }^{46}$ Ibid.
} 
original statement about the Anthropocene that responsibility for this epochal change could only be attributed to a quarter of the world's population: those living in Europe, North America, and to an increasing extent, Asia ${ }^{47} \mathrm{He}$ also suggested that humanity's path to navigating the Anthropocene may lie in large-scale technocratic interventions such as geoengineering and technological climate optimisation. ${ }^{48}$

Crutzen's additions point towards a necessary distinction that is absent from many discussions of the Anthropocene. Geoengineering and climate optimisation are proposed solutions to the negative effects of climate change/global warmingbrought about by increases in atmospheric carbon dioxide and methane-such as retreating glaciers, melting ice caps, rising sea levels, extreme weather systems, massextinctions, and disrupted ecosystems. While climate change is a central pillar of the Anthropocene, and the most noticeable, urgent, and existential manifestation of the proposed epoch, it is not its totality. The Anthropocene, conceived as a geological epoch, is the period in which 'contemporary anthropogenic change [has become] comparable in scale to various geologic events of the past' ${ }^{49}$ Climate change is an example of geological and chemical alterations born of anthropogenic forces but it is not itself a geological epoch. Many post-Crutzen writers have manufactured an equivalency between the two concepts, rendering them as synonyms in cultural discourse. While the two ideas are indelibly connected, deploying the Anthropocene as a shorthand for climate change reduces a geological designation to a signifier of global warming and nothing more.

Crutzen's Nature article represents an axial moment in the Anthropocene's evolution. It marks the point at which a geological concept left the bounds of the scientific community and was taken up by the humanities. The term has accrued a peculiarly intense fashionability for what was ostensibly a piece of earth-science jargon. In his book on the evolution and meaning of the term, The Birth of the

\footnotetext{
${ }^{47}$ Crutzen, 'Geology of Mankind,' 23.

${ }^{48}$ Ibid.

${ }^{49}$ Jamie Kruse and Elizabeth Ellsworth, 'Design Specs in the Anthropocene: Imagining the Force of 30,000 Years of Geologic Change,' in Heather Davis and Etienne Turpin (eds), Art in the Anthropocene: Encounters Among Aesthetics, Politics, Environments and Epistemologies, (London: Open Humanities Press, 2015), 163.
} 
Anthropocene (2016), Jeremy Davies quite rightly argues that the Anthropocene has 'passed further into popular awareness than any geological concept since plate tectonics' ${ }^{50}$ After the Nature article, the idea was no longer restricted to geological conferences and journals, instead populating all of the sciences, the humanities, news institutions, and popular fiction. This surge in interest reached a crescendo at the turn of the last decade when, in 2011 alone, the Anthropocene was featured in The Economist, National Geographic, Science, and the BBC. ${ }^{51}$ In that same year, three journals were established that devote themselves solely to developments in Anthropocene science and thought. ${ }^{52}$

This flurry of activity has only increased in the succeeding years, gradually diluting the term's critical use. As Jeremy Davies puts it, the Anthropocene has picked up 'a variety of incompatible meanings, each implying different concepts and commitments' ${ }^{53}$ Bruno Latour has argued that the Anthropocene's contemporary ubiquity is partly due to a seductive universal applicability. ${ }^{54}$ But, when a complex new term with no official meaning or established conventions is liberally applied with an array of contradictory definitions, how does it retain any real meaning at all? Each new usage has been met by a matching criticism. And where the early debates were built around questions of science (is there enough evidence of change in the rock strata? Do we date the new epoch to the industrial revolution or the nuclear age?), the Anthropocene was now forced to reckon with its uncomfortable ethical implications. The concept has been ridiculed for being naïvely technocratic and utopian, nihilistically misanthropic and apocalyptic, and dangerously, ignorantly universalist.

The temptation to employ the Anthropocene as a tool of the high modernist, planetary utopia is understandable, and it is a temptation to which Crutzen himself has succumbed. In this view, the acceptance of the Anthropocene thesis acts as the spark which unites humanity through the shared cause of combating climate change,

\footnotetext{
${ }^{50}$ Davies, The Birth of the Anthropocene, 56.

${ }^{51}$ Blasdel, '“A Reckoning for Our Species”: The Philosopher Prophet of the Anthropocene.'

52 Ibid.

${ }^{53}$ Davies, The Birth of the Anthropocene, 41.

${ }^{54}$ Bruno Latour, in conversation with Heather Davis, 'Diplomacy in the Face of Gaia,' in Davis and Turpin, Art in the Anthropocene, 48.
} 
and the recognition of our geological influence as a species. But these visions, especially as espoused by Crutzen and his contemporaries, all too easily revert to technocratic fantasies. Geoengineering and climate optimization have been routinely criticised for the questionable feasibility and ethics involved in large-scale, purposeful climate manipulation designed to reverse the effects of inadvertent climate manipulation. ${ }^{55}$

This technocratic Anthropocene projects a vision of the Earth wherein a 'scientific elite [administers] global affairs from the top down, so that natural resources may be exploited in the most efficient way and affluent consumer lifestyles may be kept afloat for as long as possible'. ${ }^{56}$ While Davies' statement is undoubtedly a cynical outlook, it speaks to issues inherent in a technocratic, utopian Anthropocene. Firstly, geoengineering solutions such as reflecting sunlight or off-planet transportation of greenhouse gasses are based on a model of sustainability. While sustainable thinking has long held a central position in environmental politics, it has recently faced increasing criticism for a lack of long-term vision, emphasis on elitist managerialism, and impracticality for much of the global population. ${ }^{57}$

Geoengineering solutions tackle the questions raised by the Anthropocene by refusing to address them at all, instead manipulating technology to retain the status quo. Secondly, this vision for the Anthropocene has its critical potential sapped by appealing to the mass lethargy inherent-though rarely discussed-in utopian thought. Technocratic solutions inevitably make the global questions of a new epoch somebody else's problem. The Anthropocene becomes a reflection of the neoliberal obsession with specialization where, as French cultural theorist Sylvère Lotringer argues, we can eschew individual responsibility, shrug our shoulders at climate change and say 'well, there is a specialist for that'. ${ }^{58}$

\footnotetext{
${ }^{55}$ Asayama Shinichiro, 'Ambivalent Climate of Opinions: Tensions and Dilemmas in Understanding Geoengineering Experimentation,' Geoforum 80 (2017): 82, accessed 17 July 2017, https://doi.org/10.1016/j.geoforum.2017.01.012.

${ }^{56}$ Davies, The Birth of the Anthropocene, 8.

${ }^{57}$ Davies, The Birth of the Anthropocene, 194.

${ }^{58}$ Sylvère Lotringer, in conversation with Heather Davis and Etienne Turpin, 'The Last Political Scene,' in Davis and Turpin, Art in the Anthropocene, 377.
} 
This utopian Anthropocene is matched by its apocalyptic opposite. A story is woven wherein our species has finally shaped the Earth in our image, and in doing so has ensured our own destruction and that of the organic and inorganic entities with which we share the planet. The narrative leaves no space for action or reflection, only for passive observation of the rapid march towards an unknown but inevitable expiration date. Lotringer calls the Anthropocene 'the last scene', in which humanity announces its 'exit as a species' ${ }^{59} \mathrm{He}$ argues that we need to place death at the centre of all expressions of the Anthropocene experience, especially in the arts, as 'to think of an art of the Anthropocene without raising the question of collective extinction and death doesn't make sense'.$^{60}$ In his 2015 book, Learning How to Die in the Anthropocene: Reflections on the End of a Civilization, Roy Scranton echoes Lotringer's position, arguing that 'the current geological, technological, and climatic global situation has shifted the classic philosophical problem from how to die as individuals to how to die as a civilization' ${ }^{61}$ Peter Sloterdijk, referencing a remark of Schopenhauer's, suggests that the Anthropocene conjures an image of 'the human race as a fleeting cover of mould on the surface of Planet Earth' ${ }^{62}$ In his conception, the Anthropocene is an 'apocalyptic logical framework', the very use of which summons the self-destruction of the human mould. ${ }^{63}$ To Sloterdijk, the term Anthropocene itself 'inevitably obeys an apocalyptic logic: it indicates the end of any peace of mind in the cosmos, on which historical forms of human being-in-the-world rested' ${ }^{64}$

This conception renders the Anthropocene as a self-fulfilling prophecy, and its use only reinforces a feedback loop of destruction. Reducing the environment and environmental catastrophe to a universal sign marked Anthropocene is not only discursively useless, but possibly the height of humanity's hubris. The anonymous

\footnotetext{
${ }^{59}$ Lotringer, 'The Last Political Scene,' 372.

${ }^{60}$ Lotringer, 'The Last Political Scene,' 373.

${ }^{61}$ Roy Scranton, Learning How to Die in the Anthropocene: Reflections on the End of a Civilization (San Francisco: City Light Books, 2015), 21.

${ }^{62}$ Peter Sloterdijk, 'The Anthropocene: A Process-State at the Edge of Geohistory?' trans. Anna-Sophie Springer in Davis and Turpin, Art in the Anthropocene, 328.

${ }^{63}$ Sloterdijk, 'The Anthropocene,' 330.

${ }^{64}$ Ibid.
} 
anarchist collective, the Invisible Committee, put this best when they state:

At the apex of his insanity, Man has even proclaimed himself a 'geological force,' going so far as to give the name of his species to a phase of the life of the planet: he's taken to speaking of an 'anthropocene.' For the last time, he assigns himself the main role, even if it's to accuse himself of having trashed everything-the seas and the skies, the ground and what's underground- even if it's to confess his guilt for the unprecedented extinction of plant and animal species. ${ }^{65}$

Yet even the reflexive position of the Invisible Committee does not edit the fatalism from the Anthropocene, choosing instead to engage in a kind of misanthropic multiplication wherein they denigrate humanity for denigrating humanity.

Finally, the accusation that the Anthropocene is a tool of ignorant universalism is the most frequently and fiercely levelled criticism of the concept. This particular backlash to the Anthropocene thesis has grown in accordance with the concept's own popularity ${ }^{66}$ These critics argue that the Anthropocene is a disingenuous and inequitable tool for thinking through contemporary ecological crises. The general argument follows that, in its condemnation of all humanity for the destruction of the environment, the Anthropocene distributes blame among an entire species, neglecting our division into social groups with unequal power and responsibility ${ }^{67}$ It washes over differences of nationality, history, gender, ethnicity, class, and any number of factors that should be accounted for when addressing the threats of climate change. Technically, a geological epoch is not a designation of blame, and its existence does not depend on an accurate breakdown of responsibility for ecological changes among a single species. However, the two are still connected, and the frequency with which this argument is levelled against the Anthropocene merits investigation.

Much of this argument rests on concerns with the nomenclature of the Anthropocene, and the insufficiency of Anthropo- to adequately articulate the

${ }^{65}$ The Invisible Committee, To Our Friends (Los Angeles: Semiotext(e), 2015), 32.

${ }^{66}$ Davies, The Birth of the Anthropocene, 51.

${ }^{67}$ Davies, The Birth of the Anthropocene, 51-52. 
political causes, consequences, and potential blame for the concept it describes. In their 2014 essay, 'The Geology of Mankind? A Critique of the Anthropocene Narrative,' the Swedish human ecologists Andreas Malm and Alf Hornborg question the suitability of naming the epoch after the whole human species, the Anthropos. ${ }^{68}$ They argue that such a designation suggests equal culpability among all humanity for a new geological reality, when the global rich, wielding the institutions of capitalism, are truly causally responsible.$^{69}$ Donna Harraway has mounted a similar critique, asking:

The anthropos-what is that? All of Homo sapiens sapiens? All of mankind? Well, who exactly? Fossil-fuel-burning humanity is the first short answer to that. Industrial humanity, however, is still a kind of species-being; it doesn't even speak to all of industrial humanity, but specifically the formations of global capital and global state socialism..$^{70}$

This should be a particularly salient point to those making connections between the Anthropocene thesis and contemporary art. The audience and consumers of the global art economy are not the global poor but their enriched opposites.

The universalist Anthropocene charges the Anthropos with irresponsibly comforting the prosperous through attaching collective blame. But, as Malm and Hornborg argue, it also implies a collective vulnerability—that we will all suffer the environmental consequences of the human epoch. ${ }^{71}$ This statement is ultimately true, as a world of total environmental collapse-one without oxygen or photosynthesiswill result in equal devastation, regardless of individual or societal capital. But in the short term, the regions worst hit by the effects of climate change will be those which have contributed least to the problem, particularly sub-Saharan Africa and the island

\footnotetext{
${ }^{68}$ Andreas Malm and Alf Hornborg, 'The Geology of Mankind? A Critique of the Anthropocene Narrative', The Anthropocene Review 1, no. 1 (2014): 62-69 , accessed 15 July 2017, http://journals.sagepub.com/doi/abs/10.1177/2053019613516291.

${ }^{69}$ Malm and Hornborg, 'The Geology of Mankind?' 66.

${ }^{70}$ Donna Harraway, in conversation with Martha Kenney, 'Anthropocene, Capitalocene, Chthulucene,' in Davis and Turpin, Art in the Anthropocene, 259.

${ }^{71}$ Malm and Hornborg, 'The Geology of Mankind?' 66.
} 
nations of the Pacific. ${ }^{72}$ Until the earth tips over an axial point where the basic conditions to sustain life are universally scarce, the rich will have their life boats. ${ }^{73}$

In light of the infelicity of Anthropo-, a number of alternative names have been suggested that might better capture the nuances and socio-political complexities of this potential epoch. These include the Capitalocene, suggested by both Malm and Jason Moore, which points explicitly at the economic structure that gave rise to the epoch and perpetuates the conditions that fuel its attendant environmental crises. ${ }^{74}$ French philosopher Jean-Luc Nancy, along with Sloterdijk, have endorsed both the Eurocene or Technocene as superior alternatives. ${ }^{75}$ These titles have a strong emphasis on historical causality, stressing the importance of the technological developments of the Enlightenment and Industrial Europe in the foundation of the potential epoch. A panel discussion at the University of Aarhus in 2014 put forward the Plantationocene as an alternative, highlighting the explicit colonial roots of the epoch and the role of slave economics and other forms of oppressive labour in environmental change. ${ }^{76}$ Harraway's offering is the Chthulucene, from the Greek khthon, of the earth, and kainos, completely new. ${ }^{77}$ Her choice connects her to a similarly named monster of neo-gothic fiction. ${ }^{78}$ In the Chthulucene, the forces of culture, politics, and economics wrap their tentacles about the Earth, like H. P. Lovecraft's malevolent cosmic entity, Cthulhu.

The purpose of exploring these competing conceptions-the utopian, dystopian, and universalist Anthropocene-and their critics in some detail is to demonstrate the great tension within this fledging idea. It has been hung, drawn, and quartered by a battery of competing conceptions, each dragging a limb further down its own axis. Consequently, the idea that was eventually inherited by the visual arts was not a straightforward geological proposition, but a conflux of incongruous

\footnotetext{
${ }^{72}$ Nicholas Mirzoeff, How to See the World (London: Pelican Books, 2015), 215.

${ }^{73}$ Dipesh Chakrabarty, 'The Climate of History: Four Theses', Critical Inquiry 35, no. 2 (2009): 221, accessed 15 July 2017, http://www.jstor.org/stable/10.1086/596640.

${ }^{74}$ Heather Davis and Etienne Turpin, 'Art \& Death: Lives Between the Fifth Assessment \& the Sixth Extinction', in Davis and Turpin, Art in the Anthropocene, 7.

${ }^{75}$ Davis and Turpin, 'Art \& Death,' 8.

${ }^{76}$ Ibid.

${ }^{77}$ Donna Harraway, Staying with the Trouble: Making Kin in the Chthulucene (Durham: Duke University Press, 2016), 2.

${ }^{78}$ Ibid.
} 
statements about humanity's future. There is no single, dominant narrative of Anthropocene thought, and there is no authoritative body of texts from which to derive a homogenous idea of the approaching epoch. Herein lies an important, even crucial, question for this thesis or any other text that seeks to address the intersections of art and the concept of the Anthropocene. How can we talk about art and the Anthropocene-or even art in the Anthropocene-without falling into a trap set by fashionable language, appealing to pop geology without contributing anything constructive to the discourse? The above critiques of the term's usages should act as a warning against trying to do just that. Nevertheless, a genre of art/Anthropocene books, essays, exhibitions, and seminars has established itself, and, I would argue, has fallen into this very trap.

Welcome to the Anthropocene: The Earth in Our Hands (2014-16, Berlin: Deutsches Museum), the first entry in the genre, offered 'artistic interpretations [that] provide visions for the future and ask us to look at the world in new ways' ${ }^{79}$ At the Victoria and Albert Museum's Disobedient Objects (London, 2014) we were told that 'the ancient distinction between natural history and human history, between culture and nature [is collapsing] ${ }^{\prime}{ }^{80}$ The Anthropocene also appeared in the titles of exhibitions at Trish Clark Gallery (Auckland, 2017), Bartley and Company (Wellington, 2017), AIRspace (Sydney, 2017), Norton Museum of Art (Florida, 2017), and Cleveland Print Room (Ohio, 2018). Articles about it have appeared in Artforum, Art in America, and e-flux. It makes frequent appearances in the Instagram feeds of art superstars Olafur Eliasson and Hans-Ulrich Obrist. All this is to say that the Anthropocene has made a very real impression on art makers and thinkers worldwide. And yet it means vastly different things to different people. At the Deutsches Museum it was a warning, at the V\&A a call to arms, and to Eliasson a way to promote his particular brand of techno-environmental art-making.

\footnotetext{
${ }^{79}$ Deutches Museum, 'Welcome to the Anthropocene: The Earth in Our Hands,' accessed 27 April 2017, http://www.deutsches-museum.de/en/exhibitions/specialexhibitions/archive/2015/anthropocene. ${ }^{80}$ Gavin Grindon, Victoria and Albert Museum, 'Art and Activism in the Age of the Anthropocene,' accessed 27 April 2017, https://www.vam.ac.uk/blog/disobedient-objects/art-and-activism-in-theage-of-the-anthropocene.
} 
Whether one believes that the Anthropocene is utopian, apocalyptic, universalist, or some mix of the three, the variants of the idea always rest on a shared conception. Proponents of the concept (designated here as Anthropocenists for simplicity and clarity) consistently frame the proposed epoch in terms of a statement regarding humanity's relationship to nature. The Anthropocene, 'undoes aesthetic sensibilities and ungrounds political commitments', it 'disorganizes ... the dichotomy between nature and culture that characterizes Western modernity's cosmography', and it 'describe[s] human beings merging into nature as a geological force' ${ }^{81}$ Every one of these statements, every art and the Anthropocene exhibition and essay, is predicated on a belief that there is some set of material things or qualities that can be called nature, and something called humanity it can be measured against. The classical epistemological separation of humanity from nature is posited as something that-with the help of the Anthropocene-we will suddenly overcome, dissolve, or even merge into. Art, in this argument, becomes the space in which we express this resolution, demonstrating the coming together of nature and human culture in a kind of geological, ecological unity. Attending to this relationship between humanity and nature, is an important, even noble goal. If we are truly to address the crises of climate change, then the interactions between human societies and the spaces we occupy must fundamentally alter. But the supporters of an aesthetic for the Anthropocene employ a worrisome, contradictory logic to achieve this.

They suggest that nature is itself the problem, that it is a fantasy dreamed up by the Anthropos as a stage on which we act out our play of evolution and civilisation..$^{22}$ If only we could destroy this binary, revealing the innate natural geology of all humanity, then we could see the world in a new light. But art does not sit apart from the rest of the world, delivering edicts free from corruption and influence. It exists within and of the world, governed by its same vices, preoccupations, and rigid epistemological binaries. ${ }^{83}$ To the Anthropocenists, this is especially true of a particular fantasy of nature, a structure built mostly from Romantic signs of fear and

\footnotetext{
${ }^{81}$ Davis and Turpin, 'Art \& Death,' 3, 12; Davies, The Birth of the Anthropocene, 53.

${ }^{82}$ Sloterdijk, 'The Anthropocene,' 334.

${ }^{83}$ Fabien Giraud and Ida Soulard, 'The Marfa Stratum: Contribution to a Theory of Sites,' in Davis and Turpin, Art in the Anthropocene, 168.
} 
desire. It is a structure that art and artists have been deeply complicit in constructing and maintaining. And it is a structure that has, in no small way, contributed to the existential environmental crises of climate change that we now face as a planet. Nature, an object laden with Romantic illusions, becomes the crux of an aesthetic Anthropocene. The concept seeks to engage with humanity's relationship with what might be called the nonhuman-the physical environmental facts that supposedly lie beneath the mediative lens of nature. But until nature itself is addressed in art, until it is confronted and interrogated, it will always be an impediment to thinking through such a relationship. Before we can have an art and the Anthropocene, we need an art without nature. 


\section{The Table of Bounteous Nature}

Nature is a particularly slippery word. It resists easy definition, meaning different things at different times to different communities and social groups. The Anthropocenists do not talk about the dilemma that is the nature of being, nor the vortex of morality, causal determinations, and free-thinking opposites that is human nature. Rather, their target is the complex network of interlocking projections and ideologies-maturing in the Romantic period-which have ossified into a set of insidious and inveterate mythologies of the natural world. These ideas have operated as a source of fear and desire, religious authority and secular reverence, a mark of both civilised progress and redolent primitivism. Timothy Morton, one of the chief exponents of art and Anthropocene thinking, takes particular umbrage with nature, demanding its total erasure from our thinking. Consequently, my focus is on a tension he identifies at the centre of a particular nature: Romantic nature. It is Romantic nature that speaks closest to this interrogated relationship between our species and the material world. It is the relationship that the Anthropocene concept aspires to represent. This is a struggle between dominion and preservation, a kind of semiotic doublethink wherein the physical environment can be simultaneously revered and defiled. Beyond the obvious connections to issues of climate change, the continuing authority of this Romantic construction in contemporary conceptions of nature-whether artistic and otherwise-necessitates such a focus.

Morton fixes nature to the point at which metonymy transforms into metaphor. ${ }^{84}$ The metonymic list of natural world phenomena encompasses everything from lightning strikes and sea breezes to Everest and Tāne Mahuta. This list of objects seems to be what the Anthropocenists suggest nature to be. But more than this, it is when this potentially infinite taxonomy collapses into itself and emerges as a thing, as a concretisation of thought into a metaphor that exists 'out there' in the 'real world', that it becomes nature..$^{85} \mathrm{~A}$ fundamental consequence of this

${ }^{84}$ Timothy Morton, Ecology Without Nature: Rethinking Environmental Aesthetics (Cambridge: Harvard University Press, 2007), 14.

${ }^{85}$ Ibid. 
transition-this transformation of metonymy into metaphor-is that the idea of nature has no independent, non-textual existence. ${ }^{86}$ Instead, it functions as a semiotic other to human culture, a device through which human societies have expanded and contracted conceptual distance from the nonhuman world. Textuality, however, is not synonymous with ontological isolation. These natural illusions exert a power over the material world as ideological fixations exude from contradictory foundations, effecting physical and biological change ${ }^{87}$ As a cultural construction, nature becomes a receptive vessel by which human societies assert their fantasies, fears and desires on to the physical environment. It is a series of mediations between the Anthropos and our physical environments. To the Anthropocenists, we do not ever really experience the nonhuman, but rather feel, think, and see 'nature'.

This is not the nature of Māori, nor First Nations, nor Maasai. The nature described by Morton-a 'transcendental term in a materialist mask' —is the construction of culturally dominant classes in Western, particularly Euro-American societies, assumed in their national, imperial, and neoliberal forms. ${ }^{88}$ This particular model of thinking about the nonhuman is the poltergeist that animates an illusory and increasingly unworkable perception about a materially transforming planet.

One aspect of this construction, dominion, visualises the planet as a tool or resource to be exploited. It stems from a desire to control the primal, to temper a fear of the primitive, and to impose order and purpose on our universe ${ }^{89}$ Preservation, a theoretical child of the Romantic age, values all that is wild, pristine, and untouched in the 'natural' world. And held together, as the orthodox view of nature, preservation functions as the antidote to dominion's bane, allowing for simultaneous destruction and adoration. Morton likens this to misogynistic oppression, wherein placing 'something called nature on a pedestal and admiring it from afar does for the environment what patriarchy does for the figure of Woman. It is a paradoxical act of sadistic admiration'.$^{90}$ Dominion and preservation are both ideologies of control, and

\footnotetext{
${ }^{86}$ Morton, Ecology Without Nature, 21-22.

${ }^{87}$ Ibid.

${ }^{88}$ Morton, Ecology Without Nature, 14.

${ }^{89}$ Clarence J. Glacken, Traces on the Rhodian Shore: Nature and Culture in Western Thought from Ancient Times to the End of the Eighteenth Century (Berkeley, Los Angeles, London: University of California Press, 1967), 36.

${ }^{90}$ Morton, Ecology Without Nature, 5.
} 
their symbiotic relationship in the Western imaginary has fostered the conditions for an environmental crisis.

Exploiting nonhuman materials as a resource is a fundamental aspect of the human experience. It is how the Anthropos matured as a species, how we rid our fears of the primeval woods and built towering cities in their stead. The impulse was there when Francis Bacon declared that the natural world was provided to humanity by God 'for the relief of man's estate' ${ }^{91}$ It was there when the European eye of empire oversaw the large-scale destruction of natural environments, readily surveyed into grids - that perfect form of order and control—and occupied by settling foreigners. ${ }^{92}$ And it exists now, as exploitation of the planet's resources in service of the inexorable march of global capital continues unabated. Donna Harraway has suggested that the dominant visual mode of the twentieth century was 'the eye that fucks the world to make techno-monsters'.$^{93}$ This ideology of dominion is arguably one of the root causes of anthropogenic climate change; eutrophic streams and acid rain as the inevitable consequences of a belief-system built around ownership and exploitation of material resources.

This notion of dominion and control stretches the metonymy of Nature beyond a strict environmental taxonomy. A. E. Pilkington argues that, in the Enlightenment, Nature became a rhetorical device used to establish racial and sexual identities'proven' through science and reason. ${ }^{94}$ Normative categories of a dominant culture were first seen and described as natural, while their supposedly pathological opposites became unnatural. $^{95}$ And, in line with the Cartesian split, culture became the domain of reason, and the rational mind, while nature was of cumbersome and

\footnotetext{
${ }^{91}$ Francis Bacon, quoted in Mirzoeff, How to See the World, 220.

${ }^{92}$ Geoff Park, 'Edward Gibbon Wakefield's Dream, Thomas Shepherd's Eye and New Zealand's Spatial Constitution,' in Park (ed.), Theatre Country: Essays on Landscape \& Whenua (Wellington: Victoria University Press, 2006), 37.

${ }^{93}$ Donna Harraway, quoted in Fabien Giraud and Ida Soulard, 'The Marfa Stratum: Contribution to a Theory of Sites,' in Davis and Turpin, Art in the Anthropocene, 171.

${ }^{94}$ A.E. Pilkington, '“Nature” as Ethical Norm in the Enlightenment,' in Ludmilla Jordanova (ed.), Languages of Nature: Critical Essays on Science and Literature (London: Free Association Books, 1986), 55.

${ }^{95}$ Ibid.
} 
dysfunctional corporeality. ${ }^{96}$ This dualism also followed a gendered logic, wherein 'nature/ the body [was] routinely conflated with woman, the feminine' ${ }^{97}$ This concept of nature as a somehow essentially feminine, vulnerable, and corporeal space has not left us since.

These beliefs have, since the eighteenth and nineteenth centuries, been tempered by a distinctly Romantic impulse to preserve and revere all things 'natural'. Through avatars such as Jean-Jacques Rousseau, and later Henry David Thoreau and John Muir, pristine nature-and all things natural—underwent an ideational metamorphosis, transforming into balms for the ills of civilisation..$^{98}$ The illusions of nature, particularly ideas of natural place, became 'retroactive fantasy constructs determined precisely by the corrosive effects of modernity'. ${ }^{99}$ The classical fear of the primal in nature, its function as a sign of cultural anxieties attached to referents of our antediluvian origins, began to be replaced by adoration and longing. ${ }^{100}$ Simon Schama argues that 'once a certain idea of landscape, a myth, a vision, establishes itself in an actual place, it has a peculiar way of muddling categories or making metaphors more real than their referents; of becoming, in fact, part of the scenery'.$^{101}$ So many of these myths and visions, the ideas of nature which have made 'metaphors more real than their referents', are Romantic in origin.

In Ecology Without Nature: Rethinking Environmental Aesthetics (2007), Morton points directly to the Romantic age as the source of our most ardent natural fantasies, as, 'in the Romantic period and afterward, [nature became] a way of healing what modern society has damaged' ${ }^{102}$ This is not a new idea. Its genesis can be seen in the opening sentences of the archetypal art and nature text, Kenneth Clark's Landscape into Art (1949):

\footnotetext{
${ }^{96}$ Vicki Kirby, Quantum Anthropologies: Life at Large (Durham and London: Duke University Press, 2011), 69 .

${ }^{97}$ Ibid.

${ }^{98}$ Alasdair Clayre (ed), Nature \& Industrialization (Oxford: Oxford University Press, 1977), xx.

${ }^{99}$ Morton, Ecology Without Nature, 11.

${ }^{100}$ Glacken, Traces on the Rhodian Shore, 172.

${ }^{101}$ Simon Schama, Landscape and Memory (London: Harper Collins, 1995), 61.

${ }^{102}$ Morton, Ecology Without Nature, 22.
} 
We are surrounded with things which we have not made and which have a life and structure different from our own: trees, flowers, grasses, rivers, hills, clouds. For centuries they have inspired us with curiosity and awe. They have been objects of delight. We have recreated them in our imaginations to reflect our moods. And we have come to think of them as contributing to an idea which we have called nature. Landscape painting marks the stages in our conception of nature. Its rise and development since the middle ages is part of a cycle in which the human spirit attempted once more to create a harmony with its environment. ${ }^{103}$

There is a genealogy of art and nature writing, however, running from Clark through art historians such as John Barrell, Barbara Novak, and W. J. T. Mitchell, that provides Morton with an evolved view of the imposition of Romantic landscape ideals on nature.

In The Dark Side of the Landscape: The Rural Poor in English Painting 17301840 (1980), Barrell demonstrated how the Romantic English landscape movement was directly tied to 'the enclosure of common fields and the dispossession of the English peasantry'. ${ }^{104}$ Refusing to see landscape as an artistic category, but as an active cultural practice, Mitchell describes the process of artistic representation of the nonhuman world in terms of power and exchange:

Landscape is a medium of exchange between the human and the natural, the self and the other. As such, it is like money: good for nothing in itself, but expressive of a potentially limitless reserve of value ... Landscape is a natural scene mediated by culture. It is both a presented space, both a signifier and a signified, both a frame and what a frame contains, both a real place and its simulacrum, both a package and the commodity inside the package. ${ }^{105}$

With Morton's Anthropocene at the end, this genealogy can be read as a progressive realisation of the power of Romantic nature fantasies—created and maintained in art-to affect the physical world.

These concepts were, of course, not restricted to the imaginations of a handful of Romantic gentlemen struck by wanderlust. Like all ideas of nature, they had

\footnotetext{
${ }^{103}$ Kenneth Clark, Landscape into Art, 1949, rev. ed. (London: John Murray, 1976), 1.

${ }^{104}$ John Barrell, The Dark Side of the Landscape: The Rural Poor in English Painting 1730-1840 (Cambridge: Cambridge University Press, 1980), 12-13.

${ }^{105}$ W. J. T. Mitchell, 'Imperial Landscape,' in Mitchell (ed.), Landscape and Power (Chicago and London: Chicago University Press, 1994), 5.
} 
tangible manifestations in the physical world. Following from his art and nature predecessors, Morton suggests that, 'Nature' is a focal point that compels us to assume certain attitudes' towards the physical environment. ${ }^{106}$ Romantic thinkers began to advocate for the preservation of all things wild, untamed, and pristine. 'In Wildness is the preservation of the World', insisted the transcendentalist Thoreau in 1862, a sentiment that was echoed by nascent conservation movements in the late Romantic period.$^{107}$ Increasing anxieties over the loss of areas of natural flora and fauna-tied directly both to Romantic ideologies and increasing European and North American nationalisms-led to Western governments enacting the first attempts at conservation legislation, protecting areas of the environment from cultural encroachment.

Areas of the natural world had been set aside by governments before the Romantic period. The English have a thousand-year history of alternately exploiting and protecting royal forests such as Sherwood or the New Forest. ${ }^{108}$ Jean-Baptiste Colbert, Louis XIV's Minister of Finances, undertook an immense campaign to protect and plant French woodlands in the seventeenth century. ${ }^{109}$ What marks Romantic conservation apart from these earlier efforts is the purpose for which the natural world was secluded, and the ways in which it was seen. In these early examples, woodlands were preserved out of a fear that domestic stocks of timber would be exhausted by rampant deforestation, crippling national navies. ${ }^{110}$

By contrast, the imposition of Romantic conservation was born, not of concerns over economic utility, but out of a determined regard for aesthetics. Wordsworth described the Lakes District as 'a sort of national property in which every man has a right and interest who has an eye to perceive and a heart to enjoy'. ${ }^{111}$ The crucial phrase in that passage is 'an eye to perceive'. Romantic preservation was not only an evolution of Rousseauian adoration of the natural world, but a complete

\footnotetext{
${ }^{106}$ Morton, Ecology Without Nature, 20.

${ }^{107}$ Henry David Thoreau, 'Walking,' the Atlantic, accessed 12 September 2017, https://www.theatlantic.com/magazine/archive/1862/06/walking/304674.

${ }^{108}$ Schama, Landscape and Memory, 135-174.

${ }^{109}$ Schama, Landscape and Memory, 176.

110 Ibid.

${ }^{111}$ William Wordsworth, quoted in Saeko Yoshikawa, William Wordsworth and the Invention of Tourism, 1820-1900 (Burlington: Ashgate, 2014), 3.
} 
transformation of the methods by which the Western eye could visualise it. It was land to be protected, not for defence or commerce, but for a very human pleasure.

There is a connection between the early nineteenth-century-rise of landscape painting as a dominant genre and the ability for Western eyes to see the nonhuman world with Romantic vision. The Romantic origins of the sublime and picturesque are found in art as much as they are in philosophy or natural science. Through the veneration of Claude and Poussin, by the English in particular, a fantasy emerged of what the picturesque arcadia could and should look like. ${ }^{112}$ And, in admiring artists such as Salvator Rosa, they saw the untamed beauty of the sublime, the awesome power of the primitive. ${ }^{113}$ E. H. Gombrich argued that landscape painting provided the Western eye with the ability to finally see in pictorial terms, stating that 'nature could never have become "picturesque" for us unless we, too, had acquired the habit of seeing it in pictorial terms' ${ }^{114}$ Nowhere is this more evident than in the eighteenthcentury obsession with the Claude Glass: a tinted convex pocket mirror through which, in the words of Thomas West, observers could see the natural world 'suffused with the mellow glow of Claude's visions of Elysium'. ${ }^{115}$ Observers would literally turn their backs on the object of their fascination so as to view their environment, not as it was, but as passed through a pictorial lens.

Romantic preservation became a process of projecting the ideals of the landscape genre on to the natural world. It represents the point at which environments were finally cleansed of their terrible primal spirits to become true landscapes and scenery. ${ }^{116}$ Common usage defines 'landscape' as an image of the natural world, but when it entered the English vocabulary in the sixteenth century, the Dutch landschap was an area demarcated by human occupation. ${ }^{117}$ The Romanticising of the natural world - the landscaping of untouched environments

\footnotetext{
${ }^{112}$ Geoff Park, 'Theatre Country,' in Park, Theatre Country, 116.

${ }^{113}$ Ibid.

${ }^{114}$ E. H. Gombrich, Art and Illusion: A Study in the Psychology of Pictorial Representation, 4th ed. (London: Phaidon, 1972), 266.

115 Thomas West, quoted in Park, 'Theatre Country,' 116.

${ }^{116}$ Ibid.

${ }^{117}$ Schama, Landscape and Memory, 10.
} 
through preservation-follows closer to this original definition than its common variant.

It is worth asking what an impulse to conserve parcels of 'untouched' national property actually achieves, and what the consequences of these actions are on their local ecologies. Perhaps a perfect example is Papaitonga Lake in the Horowhenua district. Papaitonga, once a body of water in the midst of a large forest, now consists of the lake itself and a small pocket of vegetation which surrounds it. ${ }^{118}$ It is a conserved piece of land, legally protected for scenic purposes and the hoped-for survival of a rare ecosystem. Long before the New Zealand government legislated to protect the lake from development, Papaitonga, known also as Waiwiri, was populated by eeling villages along its shoreline. ${ }^{119}$ Now there is nothing but the land, the fulfilment of a Romantic perception of what scenery constitutes. In conserving environments, Western governments have often dehistoricised them, removing the context of a relationship between people and land. The intertwined relationship of human history and physical place, expressed in the Māori concept of whenua, is often lost in the process of conservation. ${ }^{120}$

Perhaps worse than dehistoricising is the fact that conservation often works against its own aims. Papaitonga is dying; agricultural runoff from farmland surrounding the scenic reserve has poisoned its waters. ${ }^{121}$ Setting aside a piece of land for conservation often arrives with an implication that the surrounding areas are open to limitless exploitation. In a large-scale aquatint from 1977, Who's Watching: Omelette Country Icon V (Nelson: Suter Art Gallery Te Aratoi o Whakatū) (fig. 2) the conservationist and sometime artist Geoff Park demonstrated the peculiarity of this attitude toward conservation. The focal point of the image is a miniature scene of native New Zealand forest held inside an elaborate birdcage. Watching on are a rooster and a grotesque caricature of a politician. Park's etching was a response to a statement made by sawmiller and Buller County Council Chairman Bill Mumms, who responded to the efforts of the nascent conservation movement with the suggestion

\footnotetext{
${ }^{118}$ Geoff Park, 'The Polynesian Forest,' in Park, Theatre Country, 24.

${ }^{119}$ Ibid.

${ }^{120}$ Ibid.

${ }^{121}$ Ibid.
} 
that you 'can't make an omelette without breaking eggs' ${ }^{122}$ The prevailing national sentiment, implicit in Mumms' culinary metaphor, was that the economic success of New Zealand rested on the continued exploitation of its natural resources.

Park's etching shows the results of a national conservation estate which acquiesced to the beliefs of industrialists like Mumms. The birdcage represents the parcels of land across New Zealand that have been set aside for conservation. They are pretty to look at, self-contained, but disconnected from the far greater lands which surround them and the people that inhabit them, both of which remain vulnerable to continued exploitation. The delicate ecosystems at Papaitonga that an act of conservation was designed to protect have been corrupted, partly as a result of that very act of conservation. Once again, the values attached to nature by the Romantic imagination are underpinned by a destructive irony. Conservation, the act of setting aside individual sites for protection, is forever sabotaged by the broader project of exploiting the nonhuman for the relief of our estate.

Today's nature, bound in its centuries-old ideological paradox, can best be demonstrated by way of two proposed solutions to the effects of anthropogenic climate change. Both geoengineering and Rewilding have been championed in the last decade as means to correct humanity's impact on the environment. Yet both are caught in the same ideological traps that contributed towards the climate crises to which they supposedly respond. I have already mentioned some of the common critiques of proposed geoengineering programs; primarily that they function around a model of sustainability that does not engage with the long-term consequences of climate change. They may also be seen as tools of our complicated relationship to nature. Geoengineering solutions are what Giraud and Soulard, following from Bruno Latour and using the Dust Bowl as a metaphor for contemporary climate change, have described as an extension of the 'blade of reason'. ${ }^{123}$ Geoengineering asks that we simply repurpose the same tools of dominion and preservation, employing the

\footnotetext{
${ }^{122}$ Suter Art Gallery Te Aratoi o Whakatū, 'Who's Watching: Omelette Country Icon V; Geoff PARK; 1977; 655,' accessed 4 September 2017, http://www.nzmuseums.co.nz/account/3001/object/586205. ${ }^{123}$ Giraud and Soulard, 'The Marfa Stratum,' 172.
} 
same engagements with the irrational adoration of an idea and the strictly rational expansion of capital, but to more noble ends:

According to the position we will call 'extensionism,' the plough should not be abandoned, but instead prolonged and repurposed. The only way out of the storm is a deepened engagement with the blade, not a retreat from its implications... To escape the dust bowl, the extensionists strive for the production of literal escape routes and the enhancements of all technologies as the only path to salvation. ${ }^{124}$

Ultimately, this is not a reconfiguration of humanity's relationship to the physical environment, but yet another extension of Bacon's original call for dominion. Geoengineering asks that we dig ourselves out of a hole with the shovel that took us there.

Rewilding, pioneered by conservation biologists Michael Soulé and Reed Noss, and popularised by environmental columnist George Monbiot, has found everincreasing support over the last decade. ${ }^{125}$ Rewilding operates on a theory of 'cores, corridors, and carnivores', wherein the reintroduction of traditional fauna-including a strong population of apex predators - to protected areas of the natural environment will restore imbalanced ecological circuits and reinvigorate biological diversity. ${ }^{126}$ Projects such as the Yellowstone to Yukon Conservation Initiative in the United States, and Rewilding Europe, are advertised as initiatives designed to stem the tide of extinctions and bring back harmony to nature. ${ }^{127}$ Rewilding Europe has even introduced domesticated breeds of cattle to simulate the extinct aurochs which once dominated central European forestland. ${ }^{128}$ Like most conservationism, rewilding is informed by naïvely Romantic, primitivist visions of nature. It is a paean to an imagined state of ecological harmony demonstrating a willing blindness to

${ }^{124}$ Ibid.

${ }^{125}$ The popular expression of this movement is displayed in Mobiot, Feral: Searching for Enchantment on the Frontiers of Rewilding (London: Allen Lane, 2013).

${ }^{126}$ Dave Foreman, Rewilding North America: A Bold, Hopeful Vision for Conservation in the $21^{\text {st }}$ Century (Washington: Island Press, 2004), 135.

${ }^{127}$ Henrique M. Pereira and Laetitia M. Navarro, Rewilding European Landscapes (Cham: Springer International Publishing, 2015), 171.

${ }^{128}$ Pereira and Navarro, Rewilding European Landscapes, 179. 
contemporary material realities. Rewilding rejects a recognition of material change in favour of a continuation of our Romantic nature fantasies.

This Rewilding movement is an evolution of the thinking that produced the Gaia theory in the 1970s. That theory, developed by the chemist James Lovelock and the microbiologist Lynn Margulis, proposes that life and nonlife have constantly participated in a complex, synergistic, and self-regulating relationship to maintain the continued conditions for life to thrive on Earth. ${ }^{129}$ As summarised by Toby Tyrrell, it is 'the idea that life moderates the global environment to make it more favorable for life'. ${ }^{130}$ Named for the primordial Greek goddess, the Gaia theory envisions the Earth as a total organism, maintained in perfect balance. Climate change, with its attendant ecological crises, represent the interruption of this balance by a single species that is ignorant of the fragility of the total system. Rewilding is the fulfilment of the Gaia theory's central implication, that if we could only return the Earth to the ecological harmony that fostered us through the Holocene, we would continue to thrive as a species. Scientific consensus disapproves of the Gaia theory as its proclamations are out of step with geological truths about the way the Earth has developed over millennia. ${ }^{131}$ However, it has retained a popular following, arguably as a consequence of its enactment of Romantic nature myths. Gaia is an eternal and authoritative nature-yet another retroactive fantasy construct which claims the power to heal our wounded planet were we only able to return to the perfect ecological harmony from which our species emerged. It is fitting that Margulis and Lovelock's theory is named after a mythical entity, for how better to personify a mythical nature?

Morton makes a crucial departure from his art and nature forebears with the assertion that the sempiternal authority of Romantic nature fantasies has not faded, but remains deeply engrained in contemporary environmental art and thought. The environmental movements and organisations of the 1960s and '70s (of which Gaia and Rewilding are products) adapted Romantic preservation for a new age. Morton supports the argument that this was an evolution of prior thought rather than an

\footnotetext{
${ }^{129}$ Toby Tyrrell, On Gaia: A Critical Investigation of the Relationship Between Life and Earth (Princeton: Princeton University Press, 2013), 1.

${ }^{130}$ Ibid.

${ }^{131}$ Davies, The Birth of the Anthropocene, 125.
} 
entirely new environmental discourse. He points to the parallel developments of global environmentalisms with a school of Romantic revisionism which looked to the likes of Wordsworth and Thoreau as the progenitors of contemporary ideas of conservation and preservation. ${ }^{132}$ As such, 'Romantic artistic and philosophical practices and theories are preserved within contemporary ecological languages and beliefs' ${ }^{133}$ We still live in and with these conceptions of nature, and they are strange bedfellows for a changing planet.

For the artists, curators, and gallerists who have so eagerly adopted the Anthropocene thesis, there is another, crucial recognition that remains. Romantic nature has historically been supported by an artistic feedback loop. Aesthetic movements have both buttressed the ideologies that maintain an idea of nature, and directly contributed to their construction as conceptual apparatus through which 'the fantasies we have about nature take shape and dissolve'. ${ }^{134}$ Almost any artist of the Romantic period could demonstrate this function. And, as Morton argues, any contemporary artist who has inherited these ideas could do so too. Thomas Cole, founder of the Hudson River School, demonstrates Morton's view of nature, as his landscapes captured the precise tension between dominion and preservation that underscores Romantic nature. This is a tension that Cole himself understood, yet inevitably repeated through his work.

The Course of Empire (1833-36, New York: New York Historical Society), a fivepart narrative landscape series, charts the ascent and decline of a fictive civilisation from pastoral innocence though gluttonous self-indulgence and eventual destruction. The parabolic series warns against the hubris of empire, championing instead the Rousseauian virtues of the pastoral idyll. ${ }^{135}$ With The Course of Empire, Cole warily questioned the merits of America's 'manifest destiny', specifically the vigorous expansionist policies of the Jackson administration. ${ }^{136}$ The series' central moral arrives with the fourth image, Destruction (1836) (fig. 3), wherein the marble

\footnotetext{
${ }^{132}$ Morton, Ecology Without Nature, 83.

${ }^{133}$ Morton, Ecology Without Nature, 92.

${ }^{134}$ Morton, Ecology Without Nature, 1.

${ }^{135}$ Angela Miller, The Empire of the Eye: Landscape Representation and American Cultural Politics, 1825-1875 (Ithaca and London: Cornell University Press, 1993), 24.

${ }^{136}$ Miller, The Empire of the Eye, 36.
} 
arches and colonnades of Cole's once-prosperous civilisation glow red with the flames of invasion. Yet Desolation (1836) (fig. 4), the final image, reveals the series to be more than just a warning against national expansion. It is an offering at the altar of Romantic nature. In the first four paintings, the nonhuman environment is progressively lived with, cultivated, and then effaced altogether. In Desolation, nature returns with patient retribution. Saplings have burst through crumbled entablature, vines and mosses ascend yellowing columns, and at the top of a decaying capital, a small black bird has made its nest. The statement is clear. We may push against nature, for a time we may even subdue it, but it will always return. Nature is eternal, divine, inviolable. In The Course of Empire, Cole presented the American public with a 'fully autonomous, cyclically self-renewing nature', the alpha and omega of a natural Hegelian loop. ${ }^{137}$

View from Mount Holyoke, Northampton, Massachusetts, after a Thunderstorm -The Oxbow (1836, New York: Metropolitan Museum of Art) (fig. 5), painted as a means to refresh and renew Cole's creative energies during the labourintensive project of completing The Course of Empire, condensed the themes of the grand series into a single image. The painting is traditionally interpreted as an image of contrast and conflict between the forces of human culture and nature. On the right of the painting, the Connecticut River meanders past neatly gridded agricultural parcels along the work's titular oxbow. To the left of the Connecticut, a verdant, primeval woodland is lashed by the blue-grey downpour of an ominous storm front. The picturesque is perfectly tempered by the sublime. Schama suggests that 'the balance between settlement and pastoral innocence, between cultivation and wilderness, has been magically frozen at a moment of perfect equilibrium' ${ }^{138}$ Nature is frozen, but a cultural motion unfolds. As Angela Miller argues, the viewer knows that they are witnessing the 'landscape progressively transformed by the natural and inevitable process of cultural colonization' ${ }^{139}$ Soon, the chaos of sylvan sublimity will be erased by the march of human progress, by the exploitation of America's land at the hand of her newest residents.

\footnotetext{
${ }^{137}$ Miller, The Empire of the Eye, 42.

${ }^{138}$ Schama, Landscape and Memory, 367.

${ }^{139}$ Miller, The Empire of the Eye, 41.
} 
We know from Cole's anti-Jacksonian sentiments that he was not advancing a utopian vision of this interior colonisation, as his Hudson School compatriots Albert Bierstadt or Frederich Edwin Church might have been. This is evident in the directional ambiguity of The Oxbow's reading:

... it remains for the viewer to decide whether the storm front is moving from right to left, emphasizing nature's more benign face and promising that the wilderness, now cast in the shadow of the storm, will shortly be bathed in the light of human dominion, or from left to right, in which case the sunny agricultural landscape will soon be engulfed in storm clouds. ${ }^{140}$

In keeping with Cole's broader project, this uncertainty can be read as both purposeful and irrelevant. Purposeful, as Cole, suspicious toward unchecked expansionism, did not wish to wholeheartedly endorse the westward mission. And irrelevant, because regardless of whether the front moves to the left or right, the storm will eventually return. Just as in Desolation, nature, that undying other, will one day reclaim the lands conquered by civilisation.

Cole demonstrated an awareness of the irony inherent in Americans' reverence for their environment-passionate idolatry for an object they sought ultimately to destroy. Yet, in the Romantic mode, his answer was an appeal to a fantasy of primeval nature as a panacea to the ills of Jackson's America. But there is one final element of The Oxbow that turns the painting from just an illustrative example of Romantic contributions to our fantasies of nature, into object of central importance to artistic participation in said fantasy. This is the inclusion of Cole himself. There is only one human figure in The Oxbow:

... that of the partially concealed artist nestled in a slight concavity in the center foreground and signalled by a camp stool and folded umbrella on a nearby rocky outcropping. Cole's artist is a passive observer witnessing the grand natural spectacle that unfolds before him, a miniature version of which is presumably on his easel in a form of mise-en-abîme. Far from assuming the posture of mute witness, however, he turns his head to gaze back toward the audience of his painting. The gesture suggests

${ }^{140}$ Miller, The Empire of the Eye, 46. 
a type of artistic double consciousness in which the painter is both a witness and spectator of the natural landscape and a participant or actor in our world..$^{141}$

Perhaps Miller ascribes an overly modern reflexivity to Cole, an awareness of the construction and shaping of meaning that the nineteenth-century American would not likely possess. I would argue, however, that the painter of such public and unashamedly moralising images was cognisant of the conveyance of meaning and interpretation which passes from artist to audience. Enough so, at least, to justify Miller's claims. She continues:

The curious transaction between artist and viewer prompts us not only to consider the natural drama that is the subject of the painting but the aesthetic formulas that shape our encounter with nature. ${ }^{142}$

Miller is gesturing towards an argument for the relationship between artistic production and natural fantasies: constructing an aesthetic image of nature is far more than an act of interpreting the physical through an ideological lens. It is the direct imposition of a worldview on to the material environment. This history of aesthetic imposition is what the proponents of an art for the Anthropocene lack from their analysis. Even in demonstrating a wariness towards his adoptive nation's perceptions of its physical environment, Cole asserted and imposed his own worldview, his distinctly Romantic weltanschauung. In the process, he produced images of a concept of nature which succinctly captured the tension between dominion and preservation - the crux of the Romantic fantasy. To Morton, this ability to conceive of the natural world in contradictory terms-antithetical conceptions that in reality act in destructive opposition-is the nature we inherit today.

${ }^{141}$ Miller, The Empire of the Eye, 41. Emphasis my own.

${ }^{142}$ Ibid. 


\section{Restoration of Disturbed Harmonies}

The paintings of Thomas Cole can demonstrate a reciprocal relationship that has existed between art and Romantic ideas of nature. They show how conceptions of nature-a tension between dominion and preservation-are made manifest in art, and how nature, in turn, comes to embody these ideas. But they do this so well because the images themselves make this tension their central motif. Timothy Morton has formulated this artistic relationship to nature into an aesthetic theory. Titled ecomimesis, Morton attempts to show how artistic depictions of nature, even those that seemingly promote a sustainable relationship with humanity, inevitably collapse into Romantic ideas of nature. This ultimately leads Morton to reject nature as a useful idea all together. Ecomimesis acts as an aid to thinking what an art without nature might look like. However, this theory, and Morton's wider ecological philosophy of dark ecology, contain serious flaws that problematise its wholehearted adoption. Investigating the theory, its flaws, and the wider philosophical context of posthumanist thinking from which it arises, can produce a reading of Morton's theory that is useful to the aims of this thesis: assessing the viability of an aesthetic Anthropocene.

Ecomimesis requires a reading of artistic depictions of nature as a form of ecological and environmental criticism. They are not only aesthetic gestures, but active statements regarding the human and nonhuman, and the relationship between the two. ${ }^{143}$ Ecocriticism is, in a broad sense, the subject of Morton's critique of nature, specifically as it pertains to Romantic literature. It is the act of mediation within ecocritical works, the product of statements about nature which-through their reliance on Romantic ideology—have manufactured and sustained a noxious orthodoxy for the environment.

In Ecology Without Nature, the central text for this theory, Morton's flair for neologising, particularly his overuse of $e c o$ - as a prefix, obfuscates his argument. Beyond ecomimesis' bifurcation into 'weak' and 'strong' variants, ecorhapsody,

\footnotetext{
${ }^{143}$ Morton, Ecology Without Nature, 9.
} 
ecodidacticism, ecologistics, and ecologocentrism enter a pantheon of Mortonisms, rendering the central argument opaque at best. ${ }^{144}$ In order to navigate this esoteric vocabulary and the closed logic it often produces, I will present a reading of ecomimesis which captures the argument as it applies to art and nature.

Ecomimesis is comprised of an objective and a subjective face: the object of nature we are brought to perceive, and the body and mind we are encouraged to perceive it with. The interaction of these two faces is what constitutes the ecomimetic artwork and the active process of ecomimesis. The first, the objective face, is the construction of an idea of nature through an artwork. This is the ideal of Romantic nature, carried through to the present, that preserves the notion of the natural world as a balm to the ills of industrialisation, modernity, and corruptive civilisation. ${ }^{145}$ It is a form of magical thinking - the creation of a place with no real external referent. It is eternal, divine, and unmoving.

Objective ecomimesis evokes an atmosphere of place and environment to which we, the viewer, are granted immediate access. ${ }^{146}$ Of course, this is not access in any real or tangible sense. The nature depicted, whether be it Cole's Mount Holyoke, Hodges' Dusky Bay, or Cézanne's Mont Saint-Victoire, is the idea of nature as a semiotic other to humanity. Yet ecomimesis does provide an appearance of the direct atmosphere of a physical environment. Morton labels a number of techniques for creating this sense of real place as 'ambient poetics' ${ }^{147}$ As an example, he offers Wordsworth's statement, 'Oh there is a blessing in this gentle breeze', in The Prelude ${ }^{148}$ It is this breeze that blesses us, a unique feature of a place to which Wordsworth has granted the reader temporary access. ${ }^{149}$ The sum of these ambient techniques is the effacement of the aesthetic frame in service of the illusion of immediate access:

\footnotetext{
${ }^{144}$ Morton, Ecology Without Nature, 33.

${ }^{145}$ Morton, Ecology Without Nature, 11.

${ }^{146}$ Morton, Ecology Without Nature, 35.

${ }^{147}$ Morton, Ecology Without Nature, 32-54.

${ }^{148}$ William Wordsworth, quoted in Morton, Ecology Without Nature, 56.

${ }^{149}$ Ibid.
} 
Rendering attempts to simulate reality itself: to tear to pieces the aesthetic screen that separates the perceiving subject from the object. The idea is that we obtain an immediate world, a directly perceived reality beyond our understanding. When ecomimesis renders an environment, it is implicitly saying: "This environment is real; do not think that there is an aesthetic framework here." All signals that we are in a constructed realm have been minimized. ${ }^{150}$

Removing the presence of the aesthetic frame pretends to allow the viewer to experience, as the artist has, a particular natural place. This process of atmospheric evocation holds deceptive consequences.

Denying the presence of an artwork's frame pulls the viewer into a middleground between the inside and outside of a work. We stand in observation of an artifice of nature, yet we are encouraged to believe that we are a part of the same world as the artist who created it. ${ }^{151}$ When Cole's figure of the artist turns back to look at us in The Oxbow, we see objective ecomimesis in action. We know that-materially speaking-we are standing in front of an artefact of oil on canvas, yet the artist has implicitly invited us into a fictive environment, where we are both spectator and participant in his nature. Ecomimesis situates the viewer somewhere between subject and object, and that is always a slippery place to occupy. When we find our relationship with the nonhuman in this in-between space-in this ambience evoked by ecomimetic art-nature becomes real. It reaches out of the frame and affects the ways in which humanity shapes the physical environment. In blurring the boundaries between inside and outside, ecomimetic art promotes the belief that Romantic nature is a tangible reality, encouraging everything from wilderness hikes, to conservation movements, to Rewilding.

No artist better demonstrates the deceptive workings of ecomimesis than the original hero of nature photography, Ansel Adams. Adams' black-and-white, modernist landscapes have been rightly criticised for their extreme emphasis on personal and technical skill, their deceptive presentation of untouched wilderness, their hyper-masculinity, and chauvinist nationalism. But, in line with Morton's thinking, it is arguably a powerful ecomimetic form that underlies their continuing

${ }^{150}$ Morton, Ecology Without Nature, 35.

${ }^{151}$ Morton, Ecology Without Nature, 54. 
popularity and influence, and which deserves further scrutiny. Adams' oeuvre represents the height of Romantic nature fantasies, and manages to embody every facet of that fantasy, from the healing power of the wild to the divine inspiration found in the natural world.

Clearing Winter Storm, Yosemite National Park (1944, New York: Museum of Modern Art) (fig. 6) is one of the most enduring images of Adams' career. The top half of the photograph is dominated by the eddying, impetuous clouds of the titular storm, as they envelop and frame the Sierra Nevada mountain range. On a clear day at Tunnel View - the site from which Adams took the photograph-it is possible to see three of the most potent signifiers of Yosemite: El Capitan, Half Dome, and Bridalveil Fall. In Adams' image, Half Dome is obscured by the heavy clouds and the southwest face of El Capitan emerges from the mist as a towering granite monolith. But, in a scene dominated by cloud cover, Bridalveil Fall is illuminated by a single patch of sunshine, framing the thin, misted stream of water with piercing clarity. Below the stubborn ranges, snow-tipped conifers sweep across the valley floor, rearing up toward Adams' lens. The masterful tonal quality and carefully balanced interplay of light and shadow are hallmarks of Adams' technique of shifting gradations of light-his Zone System-that, in Clearing Winter Storm, connects the earth to the clouds above. ${ }^{152}$ The rational mind knows that this scene is full of sound and motion: the storm wind that cuts through the snowy pines and shifts the clouds above, the rush of the waterfall, plunging into Bridalveil Creek. Yet, as in all of Adams' Yosemite works, this photograph is perfectly, completely still. He has forever frozen the Yosemite Valley in time and space as eternal, silent nature.

Clearing Winter Storm is the quintessential objective face of ecomimesis. The intense, realer-than-real quality of Adams' photography is an embodiment of the effaced aesthetic frame. In part, this is a by-product of the medium's inherent suggestion of fidelity. The manufactured verisimilitude of the photographic image has always been an implicit deception, presenting the viewer with the myth of an unmediated image of the real. As the Barthian maxim holds, 'the photograph is

${ }^{152}$ James Alinder and John Szarkowski, Ansel Adams: Classic Images (Boston: Little, Brown and Company, 1984), 17. 
literally an emanation of the referent' ${ }^{153}$ Of course, the very act of framing constitutes the imposition of an aesthetic boundary, to say nothing of post-production editing, or the choice of content itself. But Adams' search for perfection, the confidence with which he conveyed the 'translation of light into precise tonal relationship' as a document of a specific location, heightens this quality. ${ }^{154}$ To stand in front of an Adams print, something John Szarkowski has described as the 'ultimate reality and central discipline of his art', is to be struck by a deeply tangible sense of the environment the photographer suggests to us. ${ }^{155}$ It is the sense of standing in the place of Ansel Adams, seeing the same landscape, taking the same photograph.

Late in his career, Adams stated of his practice: 'When I'm ready to make a photograph, I think I quite obviously see in my mind's eye something that is not literally there, in the true meaning of the word'. ${ }^{156}$ That 'something that is not literally there' is, of course, nature. Yosemite is a real place, El Capitan is a real mountain, but the majestic scope and epic grandeur with which Clearing Winter Storm is imbued are constructions of the photographer and reflections of a natural ideal. The notion that Adams' photographs are deceptive renderings of a real location is heavily trodden ground. The artist himself acknowledged as such when he stated in the introduction to The Negative (1955) that it is 'important to realize that the expressive photograph (the "creative" photograph) or the informational photograph does not have directly proportional relationship to what we call reality'. ${ }^{157}$ But the mythologising of Adams as a purveyor of verity may attest to the power of ecomimesis in his photographs. Adams' deceptive hyper-realism, his effacement of the aesthetic framework, is what draws us in to the blurred grounds of fantasy and allows us to indulge in the illusion of a true, natural environment.

The second face of ecomimesis is the subjectivity the viewer is encouraged to inhabit when engaging with artistic depictions of nature. While the objective face of

\footnotetext{
${ }^{153}$ Roland Barthes, Camera Lucida: Reflections on Photography, trans. Richard Howard (London: Jonathan Cape, 1982), 80.

${ }^{154}$ John Szarkowski, The Portfolios of Ansel Adams (Boston:Little, Brown and Company), ix.

155 Ibid.

${ }^{156}$ Burns, Ric (dir.), Ansel Adams: A Documentary Film (Boston: PBS, 2002).

${ }^{157}$ Ansel Adams, The Negative (1955; repr., Boston: Bullfinch Press, 1995), ix.
} 
ecomimesis pulls us in as participants, the subjective face ensures that we retain a simultaneous, moralised distance. Morton appropriates Hegel's concept of the 'beautiful soul' to explain this tension and difference. ${ }^{158}$ It is the residue of an impulse which has its origins in ancient Greece, but which was reaffirmed in the Romantic period, that equates beauty with morality. ${ }^{159}$ The beautiful soul is a moral position and a moral body, untouched by the ugliness of the world and separated from the ills of iniquity. It is a formation of moral righteousness, and as such it is a moral illusion as it promotes a fantasised image of pure virtue.

Morton argues that the beautiful soul is the reflection, or inverse, of beautiful nature. When we see the picturesque fantasy of nature in all its perfection, or sublime nature in its wild and untamed otherness, we elevate ourselves to the position of the beautiful soul. ${ }^{160}$ As spectators, we align ourselves with beautiful nature in opposition to the abject ugliness of contemporary ecological dysfunction, and as participants, we affirm ourselves as a reflection of that beautiful fantasy. The beautiful soul 'washes his or her hands of the corrupt world, refusing to admit how in this very abstemiousness and distaste he or she participates in the creation of that world'. ${ }^{161}$ The consequence of all ecomimesis is denial: not only of our participation in a dark and corrupted world, but of our own culpability in that corruption. ${ }^{162}$ Ecomimesis separates us from our own bodies, our own histories, beliefs, and actions.

This is not Morton's strongest argument. His adoption of Hegel is questionable, and the extent to which any viewer truly adopts the stature or mind-set of the beautiful soul is impossible to prove in any meaningful sense. It is, however, a powerful demonstration of the relationship between subject and object in artistic depictions of nature. Through engaging with these Romantic ideas, not only do we reaffirm a redolent construction of nature, pushing ourselves further away from our material environments, but we create distance between the consequences of nature thinking and our own actions. The beautiful soul works best when imagined as an

\footnotetext{
${ }^{158}$ Morton, Ecology Without Nature, 119..

${ }^{159}$ Vince Carducci, 'Ecocriticism, Ecomimesis, and the Romantic Roots of Modern Ethical

Consumption,' Literature Compass 6, no. 3 (2009): 640.

${ }^{160}$ Morton, Ecology Without Nature, 119.

${ }^{161}$ Morton, Ecology Without Nature, 13.

${ }^{162}$ Ibid.
} 
analogy for the popular conception of individual action in the face of climate change. The logic that 'I didn't personally burn fossil fuels, frack for natural gas, or invent the steam engine and therefore I am not responsible for their consequences' is an insidious deception that perpetuates inaction and resists responsibility.

Returning to Adam's Yosemite works, the photographs demonstrate the relationship between these objective and subjective faces. James Alinder has argued that Adams, desperate to contribute to the war effort, made 'his most important contribution ... in showing America something of what it was fighting for' ${ }^{163}$ He says of the Yosemite landscapes:

In these epic vistas, photographs that captured the glory of the country, Ansel made visual equivalents to American values: a great democratic country, with wide, sweeping landscapes of grandeur and majesty. The subjects of these photographs are enhanced by visualization to portray a landscape that is beyond the limits of human experience. Yet because they are photographs, one accepts the print as true. They are not true to fact, but faithful to Ansel's reverential idea of nature and of pure, unspoiled America. ${ }^{164}$

Here, the objective and subjective faces of ecomimesis collide. As the viewer occupies the space between the inside and outside of an image of perfect nature-straddling the roles of spectator and participant-the concept of the divine Yosemite, a force in the foundation of American national identity, acquires the status of reality. And if this perfect, God-ordained nature exists somewhere, then so too does the image of America it is supposed to signify. A photograph such as Clearing Winter Storm allows the American viewer to reach for, and momentarily attain, the posture of the beautiful soul. Perfect nature becomes a reflection of the perfect nation. The metaphor of Adams' Yosemite Valley expands out from the boundaries of the photographic object, to an entire continent. The beautiful soul is encouraged and enlarged by ecomimetic depictions of nature. Consequently, the thinking is not only an unachievable dream of nature, but of ourselves.

As a theory, ecomimesis has both large and small shortcomings. An issue of content arises from Morton's background in Romantic literature. He draws

\footnotetext{
${ }^{163}$ Alinder, Ansel Adams, 17.

${ }^{164}$ Ibid.
} 
consistently from a framework of poetics rather than the visual arts and, while he often grasps at a wide array of cultural products, they are predominantly employed in contrast with this poetic base. A more fundamental issues arises in that, despite the novelty and critical potential of his ideas, Morton's scholarship struggles under scrutiny. In a review of his 2016 book, Dark Ecology: For a Logic of Future Coexistence, Jennifer Peterson acknowledges that the power of Morton's ideas is frequently betrayed by a pervading atmosphere of 'woozy unsupported hypothesis'. ${ }^{165} \mathrm{His}$ writing consists of 'flashes of glittering assertions grazing across references from philosophy, literature, movies, and goth music' ${ }^{166}$ As these often-unsubstantiated sources unfold, linked by little but the force of Morton's own argument, the authority and substance of his work falters under the weight of endless, uncorroborated speculation.

Morton's penchant for term-coining is equally problematic. The dizzying array of neologisms and portmanteaus that confront his reader turns the act of deciphering his arguments into an exercise in lexicographic endurance. These linguistic idiosyncrasies and stylistic complexities constitute a far more fatal flaw than simply producing a challenging read. Morton creates for himself a kind of literary closedcircuitry wherein his ideas retain their force only within the network of his own writing, rather than engaging with a wider critical discourse. ${ }^{167}$ In deference to Morton, his writing is intended as a kind of Derridean double-play in which his opaque and peculiar style complements the themes of his argument-a marriage of content and form. While this strategy may function appropriately within the hermetic world of Morton's works, it would seem far too insular to contribute effectively to an analysis of visual art and nature. Nevertheless, the argument for ecomimesis in art can be made in the form stated above. And, in the pursuit of testing Morton and the Anthropocenists' logic seriously, I use this formulation going forwards.

\footnotetext{
${ }^{165}$ Peterson, Jennifer, 'A Mutable Cloud: On “Dark Ecology” and “Confessions of a Recovering Environmentalist and Other Essays”,' Los Angeles Review of Books, accessed 27 October 2017, https://lareviewofbooks.org/article/a-mutable-cloud-on-dark-ecology-and-confessions-of-arecovering-environmentalist-and-other-essays.

${ }^{166}$ Ibid.

${ }^{167}$ Ibid.
} 
Morton's book, Dark Ecology, a continuation of his ecological philosophy, provides a broader context for ecomimesis, while exhibiting many of the same flaws. He once again treads heavily into the territory of excessive word-coinage and unsupported hypothesis. In Ecology Without Nature, Morton demonstrated clear parallels between Romantic thought and aesthetics and contemporary ideas about nature. In the later book, however, he attempts to extend the sources of nature fantasies to a history-spanning logic of 'agrilogistics', which pits humanity against nature from the very beginnings of civilisation. The scope is too broad, and the argument lacks sufficient evidence to be a useful critical concept. But there is another set of arguments in Dark Ecology which, read as an inverse mirror of ecomimesis, offers some tools for thinking through contemporary art and nature.

To explain the concept of dark ecology, Morton relies on a frustratingly obtuse system of 'weird' loops. ${ }^{168}$ The loop form can be a helpful ally to ecological thinking, due to its analogous structure with the circuits of ecology. It also mirrors the effects of positive and negative feedback loops of human activity on the physical environment. The Dust Bowl is an example of a positive feedback loop, wherein the escalating attempts of farmers to tame the land increased strain on an ecological circuit which would ultimately collapse. ${ }^{169}$ Rewilding, or large-scale conservation, can be seen as negative feedback loops, which slow the pace of environmental change, or even reverse it for a time. ${ }^{170}$ This kind of looped thinking can be helpful, and is a central structure of dark ecology, but Morton pushes its logic beyond the parameters of constructive critical enquiry:

Ecological awareness is a loop because human interference has a loop form, because ecological and biological systems are loops. And ultimately this is because to exist at all is to assume the form of a loop. The loop form of being means we live in a universe of finitude and fragility, a world in which objects are suffused and surrounded by mysterious hermeneutical clouds of unknowing. ${ }^{171}$

\footnotetext{
${ }^{168}$ Morton, Dark Ecology For a Logic of Future Coexistence (New York: Columbia University Press, 2016), 5.

${ }^{169}$ Morton, Dark Ecology, 7.

170 Ibid.

${ }^{171}$ Morton, Dark Ecology, 6.
} 
Morton's expansion and over-reliance on the loop-equating it to the sum of existence and converting it into the central and only structural foundation of his argument-undermines the strength of dark ecology. But this may not mean we need to abandon the weird loop altogether.

If Morton's dark ecological project could be said to contain a central theme (and a central loop) it would be the effacement of the beautiful soul through an act of self-recognition and culpability. Morton continually returns to an analogy from films noir to describe this loop. It is discussed in Ecology Without Nature and Dark Ecology, but is best expressed in The Ecological Thought (2010):

Dark ecology puts hesitation, uncertainty, irony, and thoughtfulness back into ecological thinking. The form of dark ecology is that of noir film. The noir narrator begins investigating a supposedly external situation, from a supposedly neutral point of view, only to discover that she or he is implicated in it. The point of view of the narrator herself becomes stained with desire. There is no metaposition from which we can make ecological pronouncements. Ironically, this applies in particular to the sunny, affirmative rhetoric of environmental ideology. A more honest ecological art would linger in the shadowy world of irony and difference.... The ecological thought includes negativity and irony, ugliness and horror. ${ }^{172}$

This moment of self-recognition that Morton describes, the point at which the hero realises they are the criminal and the narrator becomes embedded in their own story, is the goal of dark ecology. The loop form for the Anthropos is symbolised here by the Ouroboros, the snake which devours its own tail. If ecomimesis allows the viewer of an artistic depiction of nature to become both spectator and participant in a fantasy, then the dark ecological artwork forces us to become spectator and participant in its inverse: the assumedly unmediated reality of the Anthropocene.

For Morton, the self-awareness implicit in dark ecology is a means through which to better understand the contemporary environmental moment. I have already alluded to the difficulty of envisioning climate catastrophe in its totality, or even coming to terms with its constituent parts. A fundamental aspect of dark ecological thought is that climate change is not still to happen, or even happening, but that it

${ }^{172}$ Timothy Morton, The Ecological Thought (Cambridge: Harvard University Press, 2010), 16-17. 
has in many ways already occurred. ${ }^{173}$ The consequences of anthropogenic alteration of the nonhuman world are present and immutable-at least from the perspective of the Anthropos. Dark ecology rebukes the fundamental optimism of contemporary green environmentalisms by asserting that global interconnectivity already exists. Yet it is not a connection to celebrate: it is something to be terrified of, and in which we are all embedded.

In terms of actual aesthetic strategies, through which a dark ecology could be inserted into artistic production to combat ecomimesis, Morton is, as usual, opaque. Yet he does gesture towards some areas of concern. As a starting point, Morton promotes the presence of irony, contradiction and the environmentally abject. These are imperatives of both form and content. Art can quite literally show us the depressing and dark realities of contemporary ecological life: the Gulf Sea oil spill, the collapsing Ross Sea ice shelf, the ubiquitous isolated polar bear stranded on a floating iceberg. Notwithstanding the emotional impact of such images, this strategy has been, as David Hilmer Rex argues, a predominantly unsuccessful one:

The way in which climate change has been dealt with in the arts is a good example of its inefficacy as an official narrative or discourse. Climate change has largely been experienced as external to us, and maybe for that reason has been dealt with on a representational, symbolic and thematic level within the arts, without substantially changing what an artistic practice could be when faced with such a complex, distributed phenomenon as climate change. ${ }^{174}$

As a formal question, however, there is the potential of reading these ideas into art through techniques of collage, photomontage, and general juxtaposition. A kind of Brechtian disconnect (verfremdungseffekt), wherein the contrast between conflicting images pulls the viewer away from the seamless continuity of mimetic form, could achieve this goal. ${ }^{175}$ These techniques are significant for their opposition to ecomimetic strategies. They could, according to Morton, constitute an awareness of the form and materiality of art that avoids both the objective illusion of Romantic

\footnotetext{
${ }^{173}$ Morton, Dark Ecology, 61-62.

${ }^{174}$ Aslak Aamot Kjærulff and David Hilmer Rex, 'Organizing in the Anthropocene,' The Distance Plan 2 (2014): 33.

${ }^{175}$ Morton, Ecology Without Nature, 143.
} 
nature in art and the possibility of occupying the subjective platform of the beautiful soul. ${ }^{176}$ Contradiction denies consistency and presence; it creates motion and action where ecomimetic strategies promote an immortal stillness.

Along with ecological writer Paul Kingsnorth, Morton has advocated for the presence of grief in ecological awareness. ${ }^{177}$ As Morton quotes William Blake in Dark Ecology, 'Under every grief \& pine, runs a joy with silken twine'. ${ }^{178}$ In dark ecology it is important to grieve for what is lost. This means both the literal losses of species, habitats, and ways of life, but also the comforting ideology of Romantic nature which has sustained our relationship to the planet for so long. In doing so, we make room for the newer concepts and strategies, necessary for the transition into the Anthropocene. As Morton states: 'If we get rid of the grief too fast, we eject the very nature we are trying to save'. ${ }^{179}$ To be honest in our undertaking of a revised ecological awareness, we have to avoid the techniques of shutting off or avoiding the grief and trauma of total environmental collapse which green environmentalisms often seek to assuage. It is a means of staying with the crises of climate change, to reflect on their causes and consequences, instead of rushing past the individual grief all of us surely feel at the destruction of our own planet. For artworks, this again means avoiding the pitfalls of naïve utopianism, and allowing a place for feelings of sadness, loss, and isolation. ${ }^{180}$

Dark ecology is a rejection of ecomimesis and, consequently, a rejection of nature itself. Morton's theories suggest that the very notion of nature is the root cause of the Anthropocene. Herein lies a sticky question for Morton and the Anthropocenists. The proposed epoch supposedly offers the resolution of nature and humanity, the disruption and collapse of an arbitrary binary. But by defining the histories and functions of nature, and then asking for its removal as a category of thought and classification, is it not conjured into being? And, if nature could truly be got rid of, what would be there in its place? To the supporters of the Anthropocene,

\footnotetext{
176 Ibid.

${ }^{177}$ Petersen, 'A Mutable Cloud,'.

${ }^{178}$ William Blake, quoted in Morton, Dark Ecology, 111.

${ }^{179}$ Morton, Ecology Without Nature, 185.

${ }^{180}$ Morton, Dark Ecology, 110.
} 
the answers to these questions come from a loose movement of posthumanist philosophies that inform Morton's work. 


\section{Spontaneous Arrangements of the Organic or Inorganic}

Morton's concepts, and their reading into a visual-arts framework, do not emerge from a theoretical vacuum. The foundations of ecomimesis and dark ecology are found in the recent posthumanist turn toward new realisms and materialisms. The assertion shared by these disparate movements is a restated essentialism; a search for something real, and permanent, beneath discourse. The development of a revised interest in questions of the real and material in the last decade has produced a shifting economy of philosophical and aesthetic pronouncements about an evolution in twenty-first century thought. If this amorphous, often contradictory movement (traits that can be applied to the discourse of the Anthropocene itself) could be said to have an origin story, it is one as coincidental and packed with apocryphal mythology as Paul Crutzen's notorious pronouncement of the end of the Holocene.

In 2007, the philosophers Ray Brassier, Graham Harman (a collaborator of Morton's), Quentin Meillassoux, and Ian Hamilton Grant convened a conference at Goldsmith's College, University of London. Entitled 'Speculative Realism', the panel was united by a shared critique of the perceived ills of Kantian correlationism, and the anthropocentrism of human thought that has accompanied its centuries-long philosophical dominance. ${ }^{181}$ Meillassoux, a professor of philosophy at the Sorbonne, defines correlationism in After Finitude: An Essay on the Necessity of Contingency (2006, translated into English 2008) as the 'idea according to which we only ever have access to the correlation between thinking and being, and never to either term considered apart from the other' ${ }^{\prime}{ }^{182}$ It is seen as an act of intellectual dishonesty which, since Kant, has allowed Western thinkers to manoeuvre around the issue of considering the world as it exists prior to, and apart from, human access to it. ${ }^{183}$

In their introduction to Realism, Materialism, Art (2015)—what might be considered the first new realist reader with an aesthetic focus-Christoph Cox, Jenny

\footnotetext{
181 Thomas Lemke, 'Materialism Without Matter: The Recurrence of Subjectivism in Object-Oriented Ontology,' Distinktion: Journal of Social Theory 18, no. 2 (2017): 135.

${ }^{182}$ Quentin Meillassoux, After Finitude: An Essay on the Necessity of Contingency, trans. Ray Brassier (London: Continuum, 2008), 5.

${ }^{183}$ Christoph Cox, Jenny Jaskey, and Suhail Malik (eds), Realism, Materialism, Art (New York: Sternberg Press, 2015), 18.
} 
Jaskey, and Suhail Malik define the absolutism of correlationist thinking as that which maintains:

...our apprehension of the natural and social worlds is either constituted or mediated by a discursive field or a cognitive subject, and that nothing — or nothing meaningful-exists outside of discourse or its socially-organized construction. In short, this orthodoxy has been staunchly anti-realist. ${ }^{184}$

To the new realist, this thinking has a clear lineage. Kant's binary realms of noumena and phenomena introduced (to Western thought) the concept of the inaccessibility of anything outside of human knowledge. ${ }^{185}$ Hegel solidified the correlationist concept by asserting that there is no division between 'the world-as-it-appears-to-us and the world-as-it-is-in-itself', but that instead the real was to be found in the very correlation between thinking and being. ${ }^{186}$ To Meillasoux and his fellow protagonists of new realism and materialism, the danger is not found in the mere existence of this kind of thinking. They take issue with its unquestioned dominance in twentieth and twenty-first century philosophies, even post-structuralism, which questioned the feasibility of any kind of essentialism. ${ }^{187}$ When Lacan states that 'there is no such thing as a pre-discursive reality'; Foucault that 'everything is already interpretation'; and Barthes that 'there is nothing beneath' discourse; the posthumanist sees an affirmation of the absolute primacy of correlationism in Western thinking. ${ }^{188}$

Speculative Realism, the title of that 2007 conference, became a catch-all term for a loose movement of thinkers who wished to move away from the dominance of correlationism. These writers suggested that the assertion of a realm beyond discourse is neither futile, nor magical, but a serious attempt to think about humanity's place in the world and our relationship to our environments. Members of this broad confederation differ as to whether this pre-discursive space can be known, or its properties speculated on, but they all assert its existence. ${ }^{189}$ Ultimately, the

\footnotetext{
${ }^{184}$ Cox, Jaskey, and Malik, Realism, Materialism, Art, 15.

${ }^{185}$ Cox, Jaskey, and Malik, Realism, Materialism, Art, 17.

${ }^{186}$ Ibid.

${ }^{187}$ Cox, Jaskey, and Malik, Realism, Materialism, Art, 18.

${ }^{188}$ Jacques Lacan, Michel Foucault, and Jacques Derrida, quoted in Cox, Jaskey, and Malik, Realism, Materialism, Art, 16.

${ }^{189}$ Lemke, 'Materialism Without Matter,' 140-141.
} 
argument that a discourse has referents which exist outside of itself is a return to a revised form of essentialism, but one-as its protagonists hope-that resists the traps of absolutism and bigotry that former variants have demonstrated. ${ }^{190}$

The speculative realist label lost currency as its founders have moved into variegated territory. Meillasoux and Brassier confidently identify themselves as materialists, stressing the importance of matter, material forces, and physical processes as the constituents of a pre-discursive reality. ${ }^{191}$ Meillasoux sees empirical science's ability to 'produce statements about the nature of the world as it was prior to the existence of human thought, human being, and even life itself' as proof positive of that reality. ${ }^{192}$ This thinking is in line with the Anthropocene: a push towards envisioning humanity's place in deep, geological time. Brassier argues that correlationism is a form of anthropocentric narcissism, championing instead the total indifference of matter to human thought, considered 'oblivious to the "values" and "meanings" which we would drape over it in order to make it more hospitable'. ${ }^{193}$

The boldest offshoot of speculative realism, and the one which has garnered the most notoriety outside of philosophical circles, is Harman's Object-Oriented Ontology (OOO). Influenced by Heidegger and Husserl, OOO is realism without materialism. ${ }^{194}$ Instead of reducing the pre-discursive realm to a series of material processes, Harman sees objects as the primary-and sole-constituents of the world. ${ }^{195}$ The central thesis of $\mathrm{OOO}$ is that all objects (object comprising anything from an ant to a desk chair to the internet) 'distort, caricature, or inadequately translate the other things they encounter, leaving the things-in-themselves ... to "withdraw" from any access' ${ }^{196}$ OOO pushes for a flat ontological plane of objects, that 'does not distinguish between different ontological layers or hierarchically ordered spheres' ${ }^{197}$ The interest in OOO, of which Morton is a firm adherent, is in 'allusions' and 'oblique

\footnotetext{
${ }^{190}$ Lemke, 'Materialism Without Matter,' 140.

${ }^{191}$ Cox, Jaskey, and Malik, Realism, Materialism, Art, 21.

${ }^{192}$ Ibid.

${ }^{193}$ Ray Brassier, quoted in Cox, Jaskey, and Malik, Realism, Materialism, Art, 22.

${ }^{194}$ Cox, Jaskey, and Malik, Realism, Materialism, Art, 21.

195 Ibid.

${ }^{196}$ Graham Harman, The Quadruple Object (Alresford: Zero Books, 2011), 44.

${ }^{197}$ Lemke, 'Materialism Without Matter,' 137.
} 
approaches' toward the power of the strange, uncanny, and unknowable essence of objects as a means to rethink the role of the human object. ${ }^{198}$ Although built upon the relational innovations of Bruno Latour's Actor Network Theory, Harman and the protagonists of $\mathrm{OOO}$ are interested in both the relations between objects and the essential, unknowable properties of the objects themselves. The question that arises is not what do we see of an object, but what can we not see at all?

Despite the promises of a Copernican-lite revolution to accompany the pronouncements of new realisms and materialisms, these philosophies are marred by structural flaws and have attracted vocal, vehement criticism. The strongest structural attack, articulated by Andrew Cole, is that the primary assertion of these movements-a critique of correlationism - is nothing more than a misreading of Kant. ${ }^{199}$ The idea that there 'are object relations, yes, but we can't really know or describe them in detail, only allude to them in our inevitably human way' is present in Kant's Critique of Pure Reason, the very source of the supposed 'mortal enemy' of correlationism. ${ }^{200}$ The charge made by Cole is that Harman, Meillassoux, and their associated thinkers have adopted a misleading, acute reading of Kant which creates a philosophical contradiction wherein they merely restate the Enlightenment philosopher's ideas to critique Kant himself. ${ }^{201}$ Correlationism may not actually even be a concern. As Cole would suggest, it is simply the reading of an absolutism in Kant that was never there. ${ }^{202}$

The problems only continue from there. Thomas Lemke argues that OOO's flat ontology ignores the crucial question of how objects affect one another differently. Specifically, how the human object asymmetrically affects everything around it. ${ }^{203}$ This, once again, aligns with the criticisms of the universalist Anthropocene and needs to be taken seriously. What good is a flat ontology for thinking about climate change if it removes all human culpability? Lemke additionally identifies the very real

\footnotetext{
${ }^{198}$ Andrew Cole, 'Those Obscure Objects of Desire: Andrew Cole on the Uses and Abuses of ObjectOriented Ontology and Speculative Realism,' Artforum International 53, no. 10 (2015): 321.

${ }^{199}$ Cole, 'Those Obscure Objects of Desire,' 320.

${ }^{200}$ Ibid.

${ }^{201}$ Ibid.

${ }^{202}$ Ibid.

${ }^{203}$ Lemke, 'Materialism Without Matter,' 144.
} 
danger inherent in a revised essentialism. Essentialism requires a subjectivity, and exactly who is the subject of new realisms? ${ }^{204}$ Stacy Alaimo argues that, particularly in the case of $\mathrm{OOO}$, its protagonists are risking the revival of a 'humanist and masculinist sense of a disembodied subject' ${ }^{205}$ The founders of these movements are invariably Western and male, and it is reasonable to speculate whether they are imbuing this so-called evolution in thought with an androcentric substrate we ought to avoid.

The masculinity of new realisms and materialisms, specifically OOO, is verified by the almost wholesale exclusion of female voices. Many of the ideas expressed by Harman and his cohort can be found in the feminist materialisms of writers such as Donna Haraway, Judith Butler, and Luce Irigaray. ${ }^{206}$ These writers attended to the material consequences of discourse on the concrete bodies of women long before Meillasoux argued against correlationism. Yet their contributions are largely missing from the canon of speculative realism. Feminist writers such as Hélène Cixous have also shown a wariness toward pronouncements of truth or essential reality, as a gendered logocentricism inevitably lies beneath such statements. ${ }^{207}$ This exclusion of the innovations of female thinkers, coupled with a feminist concern about a gendered logic behind posthumanisms, has gone a long way to keeping female voices outside the scope of these movements.

More issues arise. Another danger identified by Cole is that OOO opens the door to anthropomorphising the inanimate. It is well and good to think about what an object may do or act outside of our presence, but when we start to speculate as to what it may feel or think we begin to pass objects through a very human mediative lens-anti-correlationism begetting correlationism. ${ }^{208}$ Carol Taylor suggests that new realisms and materialisms have succumbed to the dangers of 'incestuous mutual citing' ${ }^{209}$ Just as with Morton's flair for neologisms, a superfluity of internal referencing can create the appearance of a movement where one does not exist. ${ }^{210}$

\footnotetext{
${ }^{204}$ Ibid.

${ }^{205}$ Stacy Alaimo, quoted in Lemke, 'Materialism Without Matter,' 145.

${ }^{206}$ Cox, Jaskey, and Malik, Realism, Materialism, Art, 23.

${ }^{207}$ Toril Moi, Sexual/Textual Politics (London: Methuen, 1985), 102-103.

${ }^{208}$ Cole, 'Those Obscure Objects of Desire,' 323.

${ }^{209}$ Carol A. Taylor, quoted in Lemke, 'Materialism Without Matter,' 146.

${ }^{210}$ Ibid.
} 
Finally, Ben Kafka has identified $\mathrm{OOO}$ as an inherently privileged and classist mode of thought, accessible only to those of means, and irrelevant to those in poverty and struggle.

In fact, all of these critics of the posthumanist movements have valid concerns, and they act as a warning to anyone who would wish to adopt a new realist program as a total system of meaning. And yet, they form the very foundation of an aesthetics for the Anthropocene. The Anthropocentrists, particularly Morton, want us to abandon nature, to locate the real, essential matter of the nonhuman beneath. Ecomimesis, and even nature, can be seen as correlationist structures. They are the mediation that keeps us from accessing the real, from even thinking about it. Dark ecology becomes the means to escape it, to disrupt its illusions and obfuscations and grasp at the real world underneath.

\section{$\infty$}

This model for the Anthropocene is the one specifically espoused by Timothy Morton. And while not every Anthropocenist may agree with everything he states, it is the one that deserves discussing for reasons already stated above. The idea of an aesthetic for the Anthropocene is a dream of a world where humanity and nature are no longer in conflict, of a binary dissolved in the face of a changing planet that refuses to allow for such outdated distinctions. The solution, as stated by Morton, is to remove nature from aesthetic expression. While this theory inevitably establishes a new binary (humanity and the nonhuman instead of humanity and Romantic nature), it does so with the support of posthumanist theories that assert the unmediated reality of the nonhuman. The argument follows that the binary of the Anthropocene would not be one between two mediated structures, but between two real, essential things: humanity, and the material, physical, nonhuman environments that surround us.

This is the basis for an aesthetic Anthropocene: an idea, a solution, and a philosophy. I have already identified a number of flaws that would seem to render such a concept unstable, and ultimately untenable. But a step remains. This is to 
measure this theory against contemporary artworks that actively engage with concepts of climate change and, more specifically, the experience of living in an age of greatly expanded human influence. It is a matter of seeing whether the aesthetic Anthropocene can actually produce a constructive and critically useful reading of contemporary art practices. In actively attempting to apply this theory to art, do we find that desired resolution of the Anthropos with the nonhuman world, that promise of the aesthetic Anthropocene? Or do we remain grounded in the Holocene, still caught in the muck of climate change? 


\section{Chapter Two.}

\section{Art Without Nature}

It implies that we crawl back through the current of history, identify points of inflexion, and operate a reorientation of their becomings.

Fabien Giraud and Ida Soulard 
The previous chapter brought together the disparate elements of Anthropocene thought, as they have emerged in the arts, to establish a theory of the aesthetic Anthropocene. This theory, centred around the thinking of Timothy Morton, represents a convergence of a number of complex ideas. A new geological epoch, an outdated conception of nature, posthumanist philosophy, ecomimesis, dark ecology - all form a part of the aesthetic Anthropocene. These ideas come with a promise that the Anthropocene has something new-perhaps something vital-to offer contemporary art: a lens through which we represent a new relationship with nonhuman, one that strips away old fantasies of nature to represent the true, essential qualities of the material world.

This chapter will test that promise by attempting to employ the aesthetic Anthropocene as a methodology for reading contemporary art that attends to the issues of anthropogenic climate change at the centre of the theory. Morton has argued that a truly environmentally conscious society would pass any aesthetic product through an ecological framework, in the way we might with feminist or postcolonial discourses today. ${ }^{211}$ But we are not yet living in that society; and, in order to be as fair as possible to the aesthetic Anthropocene, I will discuss artworks that speak directly to climate change, ecology, and the influence of humanity on the material world.

Pierre Huyghe, Simon Starling, and Conor Clarke are three contemporary artists whose works address such issues. The notions that make up the aesthetic Anthropocene are deployed in a different context and to different effect in each of their practices, but their mutual engagement with the questions of a changing planet suit them to such an evaluation. Testing the aesthetic Anthropocene means applying it with serious vigour-as the proponents of the theory would-to these three artists, in the hope of extracting a reading of their work that is both critically constructive and a true aid for thinking and feeling through the Anthropocene that the theory promises. As such, the following analyses represent an attempt at an unreserved reading, delivered in the style and form of the aesthetic Anthropocene.

${ }^{211}$ Timothy Morton, Ecology Without Nature: Rethinking Environmental Aesthetics (Cambridge: Harvard University Press, 2007), 5. 


\section{Feeling Nature}

Carolyn Christov-Bakargiev did not want the thirteenth iteration of Documenta to be dominated by a central theme. Instead, the artistic director for the 2012 transnational contemporary art exhibition at Kassel offered a program which she likened to an organism. Christov-Bakargiev insisted upon an 'associative structure', which suggested a 'more balanced relationship with all the non-human makers with whom we share the planet and our bodies' ${ }^{212}$ Six years on, it is possible to see with some clarity how the artists and contributors at $\operatorname{OOCUMENTA~(13)~were~caught~in~the~glare~}$ of the posthumanist turn. Object-oriented thinking permeated the hundred days of events, from within the walls of the Fridericianum itself, out on to its grounds and the city of Kassel, and into outposts in Cairo, Kabul, and Banff. ${ }^{213}$ The tragedy of megaexhibitions such as Documenta is that history has a tendency to swallow the constituent works and spit them out as a kind of thematic grotesque-artists and their works are swiftly lost to memory as hundreds of contributions collapse into examples of a central idea.

Even Christov-Bakargiev's approach to Documenta, an exhibition with a structure calibrated to resist the centripetal pull of a dominant theme, has suffered much of this fate. It is difficult to locate references to Emily Jacir's cellphone records of destroyed Palestinian books, Ex Libris (2010-12), or Song Dong's grass-reclaimed rubble mountain, Doing Nothing Garden (2010-12), outside of opaque references to the recurrence of 'collapse and decay' at $d O C U M E N T A(13) .{ }^{214}$ Yet, whether as a result of Christov-Bakargiev's goal of a loose, associative structure or not, a number of works from that exhibition continue to exert a cultural and theoretical pull. Perhaps the strongest of these to emerge from the exhibition unscathed, and to continue to contribute towards a discourse on the role of the visual arts in ecological thinking, is Pierre Huyghe’s Untilled (2011-2012) (figs. 9-13).

\footnotetext{
${ }^{212}$ Carolyn Christov-Bakargiev, quoted in Christoph Cox, Jenny Jaskey, and Suhail Malik (eds), Realism, Materialism, Art (New York: Sternberg Press, 2015), 28.

${ }^{213}$ Daniel Birnbaum, 'Documenta 13,' Artforum, accessed 10 September 2017, https://www.artforum.com/print/reviews/201208/documenta-13-34514.

${ }^{214}$ H. G. Masters, 'Documenta 13,' ArtAsiaPacific 80 (September-October 2012): 128-129.
} 
Since his emergence in the late 1990s as a visual artist associated with Nicolas Bourriaud's relational aesthetics, Huyghe has consistently created works that engage with the construction and passage of time, the presence and manipulation of histories, and concepts of discontinuity, contingency, and interruption. ${ }^{215}$ With Untilled, Huyghe brought those concerns to Kassel, augmented by an engagement with ecological circuitry and the nonhuman which has come to define his recent practice. Huyghe has created other works that interrogate the exertions of the human object on to our environments, often more directly and succinctly than in Untilled. In 2011, Recollection (Zoodram 4 after 'Sleeping Muse' by Constantin Brancusi) (fig. 7) presented a fully functioning aquarium in which a hermit crab-adopting a replica of Brancusi's The Sleeping Muse (1910, New York: Metropolitan Museum of Art) as its shell—drifted past enigmatic rock formations in milky darkness. A cultural artefact became a piece of temporary crustacean anatomy, visually manifesting the ways in which we not only recreate our own world in the human image, but the worlds of those around us. ${ }^{216}$ The film work, Untitled (Human Mask) (2014) (fig. 8), similarly expressed the manipulation and distortion of nonhuman actors. A macaque, Fukuchan, outfitted in a child's dress, wig, and a Noh theatre mask, walks through an abandoned restaurant in Fukushima. ${ }^{217}$ The monkey, trained as a waiter in a Tokyo sake bar, repeats the actions she has been taught in this abandoned environment. As the film progresses, her increasingly erratic actions turn from whimsical to distressing, as Huyghe slowly reveals that this animal has been completely denatured, her original actions and processes stripped entirely.

Huyghe has also addressed the rippling interactions of history and site in other works. Rite Passage (2015), a Roof Garden commission for the New York Metropolitan Museum of Art intersected the histories of the museum's collection with those of Central Park and indigenous American fauna. ${ }^{218}$ And Umwelt, first staged at the

\footnotetext{
${ }^{215}$ Amelia Barikin, Parallel Presents: The Art of Pierre Huyghe (Cambridge: MIT Press, 2012), 3.

${ }^{216}$ Emma Lavigne (ed.), Pierre Huyghe (Paris: Centre Pompidou, 2013-14), 174-175.

${ }^{217}$ Amelia Barikin and Victoria Lynn, Pierre Huyghe (Victoria: TarraWarra Museum of Art, 2015), 44.

${ }^{218}$ Ian Alteever, 'Vestiges in the Rocks: Pierre Huyghe's Mineral Garden,' in Ian Alteever, Meredith Brown, and Sheena Wagstaff, Pierre Huyghe: The Roof Garden Commission (New York: Metropolitan Museum of Art, 2015), 11-21.
} 
Esther Shipper gallery in 2011, introduced an ant colony into the walls, and spiders into its corners. Umwelt contrasted the experiences of being human and nonhuman, but also spoke to the historical exclusion of the nonhuman from the gallery space. ${ }^{219}$ In Huyghe's work, the history of the white cube not only attempts to efface the particularities of race and gender, but even of species. What marks Untilled apart as an artwork of interest to this thesis is its role as a nexus of these ideas. In its strange, contradictory, but ultimately precise intervention into illusory conceptions of Romantic nature, Untilled refused to engage with the artistic inheritance of ecomimesis.

Untilled has been partially restaged in multiple locations since its debut at dOCUMENTA (13). Elements of the work appeared at a retrospective of Huyghe's career at the Centre Pompidou in Paris (2013-2014), along with the exhibition of a film, A Way in Untilled (2012), that documented the project as it was originally staged in Kassel. ${ }^{220}$ In addition, a single sculpture from Untilled was purchased by the New York Museum of Modern Art and displayed in 2015. But its initial appearance at Documenta is thus far the only complete appearance of Untilled, and it is that iteration which has entered the established canon of Huyghe's career. At Kassel, the artist engaged with specific histories of Documenta at multiple points of inflexion throughout its duration, thereby requiring the particular context of the exhibition to fully resonate.

Untilled is a difficult work to describe, primarily because its form and content appear to reject traditional notions of work. As Gregory Stemmrich notes, it is problematic to consider much of Huyghe's artistic practice in terms of 'the production of work' at all. ${ }^{221}$ This is typical of Huyghe's projects. One is often left without the sense of an authorial presence, or even where to situate oneself as a viewer in response. Work is one of many words, conventional to the analysis of art, that feel inadequate in the face of Huyghe's practice. This has the effect of producing a distorted vocabulary when discussing his career. To be fair to the artist, this is not to

\footnotetext{
${ }^{219}$ Barikin and Lynn, Pierre Huyghe, 10.

${ }^{220}$ Lavigne, Pierre Huyghe, 196.

${ }^{221}$ Gregory Stemmrich, quoted in Marie-France Rafael, Pierre Huyghe: On Site (Cologne: Verlag der Buchhandlung Walther König, 2013), 7.
} 
say that there was no work involved in the production of Untilled, but that the work cannot be ascribed to an easily defined human agent. What Huyghe presented to those who came across Untilled at dOCUMENTA (13) was a system, or rather a series of systems, that interacted and combined over time into an indefinable-yet undeniably concrete-heterotopic environment. And so, while it is difficult to describe this project in orthodox terms of work or object, it can be detailed as a series of systems or instances, developing across time, that together constituted the shifting mise-en-scène of Untilled.

The project took place in Kassel's Karlsaue Park, the northern corner of which is dominated by the Orangerie, an early-eighteenth-century baroque palace built for Charles I, Landgrave of Hesse-Kassel. ${ }^{222}$ Aside from this elaborate structure, the park is known for its combination of French formal garden features and English-inspired picturesque elements. Instead of staging Untilled in one of these noted regions of the park, Huyghe's project took place in an area reserved for composting, somewhere he found by accident while walking through the grounds. ${ }^{223}$ While Huyghe contributed many features to the compost area in the construction of Untilled-transforming much of the ground into arable land-the location was not entirely cleansed of its historical use. It remained unclear to the viewer what was art and what was, by conventional standards, rubbish.

Of the introduced features, what Huyghe called 'markers', two have developed into signifiers for the total project, and were prominently featured in the Pompidou and Museum of Modern Art shows. ${ }^{224}$ The first is a sculpture of a reclining female nude, now housed at the Museum of Modern Art (fig. 9). The figure is a concrete replica of a 1930s bronze by the Swiss sculptor, Max Reinhold Weber. ${ }^{225}$ In place of the nude's head, Huyghe cultivated a living, operating beehive-an image that has become synonymous with the artist's oeuvre. The sculpture (if that word can truly apply here) produced by the combination of the concrete figure and the hive can only

\footnotetext{
${ }^{222}$ Masters, 'Documenta 13,' 129.

${ }^{223}$ Barikin and Lynn, Pierre Huyghe, 37.

${ }^{224}$ Wade Saunders and Anne Rochette, 'Pierre Huyghe,' Art in America, accessed 16 January 2018, https://www.artinamericamagazine.com/reviews/pierre-huyghe.

${ }^{225}$ Rafael, On Site, 13.
} 
be described as a collaborative venture. Both Huyghe and the bees were required for its completion, neither being able to create it alone. As Museum of Modern Art curator Laura Hoptman notes, the sculpture 'pointedly brings the natural world to bear on what we assume to be the very human notion of creativity'.26

The second was a white Ibizan hound whose front right leg had been painted a fluorescent pink (fig. 10). The dog—named Human-wandered within the perimeter of Untilled, interacting with the various elements and nursing a second dog, an Ibizan puppy. ${ }^{227}$ Neither Human, nor her puppy, could be said to play any discernible role or function within the world of Untilled. The temptation to bestow sphinxian attributes of guardianship onto Human is a strong one, and Marie-France Rafael's description of the dog as 'reminiscent of a mythical creature from a distant time and an unknown place' attests to as much. ${ }^{228}$ But Human was not there for protection. Like the Weber and the bees, she simply existed within the space of the project; interacting with what was there before Huyghe, what he had produced in the space over months, and the visitors who came to look at both.

While the bee-headed sculpture and the pink-legged dog dominate recollections of Untilled, they were only two aspects of a much larger whole (fig. 11). Other notable markers included a man who has been variously described as a gardener, a caretaker of the dogs, and a miscellaneous figure. ${ }^{229}$ He roamed the compost grounds with seemingly as little direction as the dogs. Puddles, large and small, were occupied by algae and tadpoles. ${ }^{230}$ Mature plants, chosen for their cultural history as medicinal, psychotropic, and aphrodisiac consumables occupied much of the formerly decomposing environment. These included cannabis, Datura, peyote, Brugmansia, deadly nightshade, and rye (not psychotropic on its own but known to harbour ergot, a component in the manufacture of lysergic acid). ${ }^{231}$

\footnotetext{
${ }^{226}$ Museum of Modern Art, 'Pierre Huyghe's Recently Acquired Sculpture Untilled [Liegender Frauenakt] Will be Presented in Moma's Sculpture Garden This Summer,' accessed 17 January 2018, https://www.moma.org/documents/moma_press-release_389297.pdf.

${ }^{227}$ Rafael, On Site, 16.

${ }^{228}$ Ibid.

${ }^{229}$ Ibid.

${ }^{230}$ Rafael, On Site, 17.

${ }^{231}$ Dorothea von Hantelmann, 'Thinking the Arrival: Pierre Huyghe's Untilled and the Ontology of the Exhibition,' On Curating 33 (June 2017): 89.
} 
Two final markers in Untilled firmly anchored the project to Kassel, Documenta, and a specific notion of site. At one of the many points of entry, Huyghe placed an upturned oak tree, its roots left earthen and exposed as if it had just emerged from the soil (fig. 12). The oak was not a randomly selected tree, but one seven-thousandth of an artwork begun in Kassel thirty years prior. For documenta 7 (1982) Joseph Beuys began a project entitled 7000 Oaks - City Forestation Instead of City Administration in which, with the help of volunteers over five years, he planted the titular seven thousand oaks throughout Kassel. ${ }^{232}$ Each oak had as its opposite a large basalt stone, piled together in a local park. As each oak seedling was planted, a stone was removed from the pile. ${ }^{233}$ At $d O C U M E N T A$ (13), Huyghe intervened in Beuys' project on two levels: the upending and displacement of one of the oaks, and the introduction of an ant colony to its base..$^{234}$

The second direct reference to Documenta's history arrived in an area of haphazardly piled cobblestones and broken asphalt that Huyghe named 'the city'. ${ }^{235}$ There a two-metre-long concrete bench, its top surface painted red, lay on its side. Another replica, the red bench copied an element of Park: A Plan for Escape, an installation by Dominique Gonzalez-Foester for documenta 11 (2002) (fig. 13). Gonzalez-Foester's work comprised a central concrete pavilion, around which she placed various elements from the design of Modern park spaces. Among other objects, the bench was accompanied by a painted concrete pool, a Brazilian telephone box, and a rose bush from Le Corbusier's gardens in Chandigarh. ${ }^{236}$ The sum of Huyghe's markers is an uncertain equation; there is no comfortable gestalt or whole to be derived from the constituent parts. We know that something real is there, but it is impossible to conceive of it in tangible terms. The object-oriented focus of much of that year's exhibition encourages the temptation to reduce the opacity and unknown objectives of Untilled into an exercise in the irreducible, inaccessible quality of objects espoused by OOO. But, while posthumanist thinking may help to interpret Untilled, on its own this reading is too

\footnotetext{
${ }^{232}$ Michael Glasmeier and Karin Stengel, 50 Years Documenta, 1955-2005 (Göttingen: Steidl, 2005), 296.

233 Ibid.

${ }^{234}$ Rafael, On Site, 13.

235 Ibid.

${ }^{236}$ Ibid.
} 
simplistic and essentially reductive. There are three particular art-historical debts that Huyghe owed in Untilled. Understanding the operation of those influences is as important a prerequisite to thinking through what Huyghe's work may have to say about nature and ecology, as is the presence of object-oriented thinking.

Robert Smithson's dialectic of site/non-site is ground so heavily trod that it has probably passed into the realm of artistic cliché. However, the path from site, through non-site, and into something else in Untilled, compels its discussion. The notions of site and site-specificity as they emerged during the 1960s opened art up to a new array of aesthetic gestures that anchored both artworks and their viewers to specific notions of place and history. ${ }^{237}$ This, combined with the innovations of minimalist sculpture by the likes of Donald Judd and Eva Hesse-incorporating the viewer into the same three-dimensional space as the artwork-are manifestly evident in much of Huyghe's practice.

Untilled possesses qualities of site-specificity, anchored as it is to the specific histories of Documenta and the environs of Kassel. But it also has the attributes of the 'abstract containers' that populated Smithson's non-sites. ${ }^{238}$ Huyghe's markers are totems of displacement, referents to spaces and histories that exist outside of the work's frame. Central to the site/non-site dialectic is the relational, temporal passage between a material and its original referent, disrupting the stability of the site. ${ }^{239}$ Huyghe's work engages in yet another level of disturbance and transformation. Where the materials employed by Smithson often had straightforward origins, the enigmatic qualities of Untilled's markers resist easy association. Instead, what Huyghe created was a kind of 'site-fiction', a 'completely real artistic situation' whose referents point outward toward something unknown, and ultimately fictitious. ${ }^{240}$ The context of the Karlsaue's compost zone adds to this sense of a displaced fiction. An area dedicated to the decomposition of plant matter, especially in the context of a

\footnotetext{
${ }^{237}$ Fabien Giraud and Ida Soulard, 'The Marfa Stratum: Contribution to a Theory of Sites,' in Davis and Turpin, Art in the Anthropocene, 175.

${ }^{238}$ Robert Smithson, 'A Sedimentation of the Mind: Earth Projects,' in Petra Lange-Berndt (ed.), Materiality (London: Whitechapel Gallery, and Cambridge: MIT Press, 2015), 151.

${ }^{239}$ Ibid.

${ }^{240}$ Rafael, On Site, 36.
} 
large public house and gardens, is analogous to Rem Koolhaas' 'junkspaces': areas left in the wake of modernity that are faceless and defined by absence. ${ }^{241} \mathrm{~A}$ junkspace exists in between the spaces of the Modern city, just as a non-site exists as the absent site to which its representations refer. By staging Untilled in the Karlsraue compost, Huyghe imbued his artwork with this sense of being disrupted between two poles, of being caught in between.

Secondly, despite its composition of objects and materials, Untilled can be read through the lens of the conceptual, post-object artwork. The first wave of conceptual art, emerging from a similar milieu as Smithson in the 1960s, introduced the idea of establishing a system which—although initiated by the artist_operates mechanically, almost autonomously, according to a set of pre-established rules. As Sol LeWitt stated, 'The system is the work of art; the visual work of art is the proof of the system... It isn't what it looks like but what it is that is of basic importance' ${ }^{242}$ The art-objects become the physical documentation of the conceptual system. Untilled, too, is an established system which automatically operates from a point of conception. The various markers that Huyghe introduced to the Karlsaue Park-the plants he grew, the Beuys oak he uprooted, the beehive he cultivated-are like the rules of a conceptual artwork. They predetermine the conditions under which the work will operate, with the park acting as a kind of documentation of the system.

Because of this notion of a system that unfolds over time, it is possible to conceive of Untilled as it quite literally grew into the shape it formed in 2012, and to imagine its progression into the future. The plants will continue to mature, they will be pollinated by the bees and their seeds dispersed by the ants. The puppy will grow into an adult dog, its minder will die. The tadpoles will grow into frogs, which will in turn reproduce again. But the further that Untilled evolves and grows, the less it can be traced back to the original establishment of its conditions by the artist. As Emma Lavigne notes:

The set of operations that occurs has no script. Particular elements, images leak in a contingent reality—physical, biological, mineral—and grow without us. There is

\footnotetext{
${ }^{241}$ Rem Koolhaas, 'Junkspace,' October 100 (Spring 2002): 175-90, accessed 21 January 2018, http://www.jstor.org/stable/779098.

${ }^{242}$ Sol LeWitt, 'Sentences on Conceptual Art,' 0 to 95 (January 1969): 4.
} 
antagonism, association, hospitality and hostility, corruption, separation or collapse with no encounter. There are circumstances and deviations that enable the emergence of complexities. There are rhythms, automatisms, and accidents, invisible and continuous transformations, movements and processes, but no choreography; sonorities and resonances, but no polyphony. ${ }^{243}$

Huyghe is not the omnipotent author who dictates how his artwork operates, nor how the viewer will interact with it. These values are formed by a system that becomes increasingly grounded in chance and contingency, ultimately resulting in a project that, like the bee-headed sculpture itself, is the fruit of collaborative processes between human and nonhuman actors.

Although notions of time and chance appear in nearly all of Huyghe's work, they are specifically represented in Untilled through the avatar of Stéphane Mallarmé's 1897 poem, 'A Throw of the Dice Will Never Abolish Chance'. The poem, which combines free verse, unorthodox layout, and multiple typefaces, was used as inspiration for Untilled (and for Surrealism itself), and can be read as an analogue to the Documenta project. ${ }^{244}$ 'A Throw of the Dice' presaged the advent of European Modernism and spoke to the role that the chaos of random chance would play in the establishment of that uncertain, secular new age. Where Mallarmé and Huyghe intersect is in their relationship to Surrealism

The surrealist innovations of the early twentieth century are conspicuously absent from the new histories of posthumanism and object-oriented thought. Yet the origins of a search for pre-discursive reality, and an interest in the essential qualities of objects, is surely to be found in the explorations and experimentation of André Breton and his associates. In exercises such as automatic poetry, or the famous cadavre exquis, the surrealists attempted to create something authentic, born of random chance, and devoid of the strictures of rational thought. ${ }^{245}$ In their exhibitions-particularly the Surrealist Exhibition of Objects at the Galerie Charles Ratton in 1936-the surrealists brought objects together, without coherent display

\footnotetext{
${ }^{243}$ Lavigne, Pierre Huyghe, 186.

${ }^{244}$ Ibid.

${ }^{245}$ Janine Mileaf, Please Touch: Dada and Surrealist Objects after the Readymade (Hanover: Dartmouth College Press, 2010), 119-120.
} 
categorisation, to confront the viewer with a disjunctive alterity. ${ }^{246}$ In their shared strangeness, and their common disruption of the usual and comfortable, these objects interacted with the visitors to the Ratton gallery. The objects were intended to foster a sense of unease, and to ask questions about what it meant to conceive of art, of objects and of the world, in strictly rational terms.

Huyghe's Untilled shares many of these qualities, and many of the aims of Surrealism's protagonists. Perhaps these affinities are what drew Sophie Knezic to state:

[Untilled's] most compelling image is of a reclining female statue whose entire head is engulfed by a writhing beehive. A trail of bees wending across the figure's torso is as disturbing as the ants that crawl over a man's palm in Salvador Dali and André Breton's notorious surrealist provocation, Un Chien Andalou (1929). ${ }^{247}$

Minimalism, Surrealism, and conceptual art meet in Huyghe's contribution to dOCUMENTA (13). The purpose of drawing these connections is not just to grant Untilled a sense of provenance or heritage, but to bring attention to its function as the site of multiple interacting histories. Huyghe plays with both the specific history of Documenta, and with the numerous art histories his practice inherits. And after months of preparation, once those histories arrived with the viewer to the Karlsaue Park, they coalesced to confront another piece of artistic heritance and the central fascination of Untilled: nature.

Even a cursory description of Untilled's markers demonstrates that Huyghe's work was not a conventional portrait of the nonhuman world, that it did not subscribe to the tenets of ecomimesis. Their presence is felt, however, as Huyghe tampered with and subverted the aesthetic foundations of Romantic nature. The picturesque hovers over much of the Karlsaue Park In Untilled, Huyghe invoked the specific form of the picturesque ruin. From Heraclitus' assertion that 'the most beautiful world is like a heap of debris tossed down at random', to Smithson's fascination with the inevitability of material entropy, there has been a constant

${ }^{246}$ Mileaf, Please Touch, 136.

${ }^{247}$ Sophie Knezic, 'Pierre Huyghe: Tarrawarra Museum of Art,' Artlink, accessed 17 January 2018, https://www.artlink.com.au/articles/4419/pierre-huyghe. 
Western obsession with the aesthetics of ruination. ${ }^{248}$ The picturesque ruin, championed by Thomas Cole and others in artworks like Desolation, is an affirmation of an heroic nature: that ineluctable force that will reclaim what humanity has taken from it. By staging Untilled in the compost of the Karlsaue, surrounded by rubbish and refuse, Huyghe aligned his work with the aura of that particular image of nature. Yet through the form and content of the work itself-through the rejection of ecomimesis and the assertion of a dark ecology—the nature aspired to by Heraclitus, Cole, and even Smithson, was absorbed and rethought.

The purpose to which a work of ecomimesis effaces its aesthetic frame is to grant an illusion of stable presence, and of immediate access to an imagined environment. By contrast, the aesthetic frame of Untilled was forced to the front of the viewer's consciousness throughout its staging at Kassel, constantly denying this kind of access. The strange, disjunctive qualities and relationships between Huyghe's markers acted as a continuous reminder that the viewer was situated inside an artwork, that they were not experiencing site, but site-fiction. One was never entirely aware of what was the result of an artistic intervention, and what was a quality of the site that existed before Huyghe's arrival. An abstruse aesthetic frame was formed, drawing the viewer's awareness towards their presence inside a fiction, but never allowing a solid grasp of what exactly that fiction was, where it began and ended. Instead of providing the surety of presence that arrives with ecomimesis, Huyghe made clear that what he presented was not a real place, and that this was not a world into which the viewer could seamlessly integrate.

Huyghe's references to earlier iterations of Documenta were more than a means by which he could anchor his work to a specific location and history. The Beuys oak and the Gonzalez-Foester bench connect Huyghe to a lineage of artists whose works critically interrogate the nature/culture binary. Both Beuys and Gonzalez-Foester's works spoke to the ways in which nature is constructed by human action and thought. The Beuys oaks are noted as an early example of social sculpture and collective environmental action, but they also attest to the literal construction, destruction, and reconstruction of physical environments through human choice and

${ }^{248}$ Lavigne, Pierre Huyghe, 214. 
action. Each planted oak modified a new nonhuman space, each removed basalt stone (revealing the park beneath) changed the perceived worth of an existing human space. Gonzalez-Foester's work enquired into the arbitrary semiotics of nature. The signifiers of Modernist park design demonstrated how the delineation of different natural areas rests on an arbitrary network of cultural signs. By including references to these works, Huyghe announced Untilled as another kind of construction, another interrogation into the operation of nature as an idealised other.

Ecomimesis generates images that are frozen in time and lack history. The Yosemite photographs of Ansel Adams necessarily lacked any sense of contemporary politics and historical or temporal context in order to freely perpetuate a particular mythology of the American continent. Huyghe's work was not only anchored to specific contexts and histories, but was filled with movement and action. Multiple time scales operated at the Karsaue Park: the time it takes for a viewer to walk through the compost zone and for green waste to decompose. The time it takes for plants to grow and seeds to pollinate. What shifts this sense of time and motion in the direction of dark ecology and the aesthetic Anthropocene is that many of the time scales that confronted the viewer in Untilled did not belong to the Anthropos, nor an anthropocentric view of the world.

Instead, Huyghe's project induced a palpable sense of invasion, of entering into a space to which the human did not belong. Emma Lavigne describes the process of entering Untilled as feeling 'like a burglar' ${ }^{249}$ Marie-France Rafael explained it in terms of a fundamentally instilled sense of doubt. ${ }^{250}$ This atmosphere of transgression-perhaps another marker of Surrealist influence-meant that the vocabulary of viewership or participation does not sit well with the experience of Untilled either. A better term might be witness, of observing a world to which we do not ordinarily belong. Unlike ecomimesis, which attempts to create as open and inviting a sense of access to nature as possible, this form of vision and viewership denies approach, and does not conform to the conventions of seeing the nonhuman that we are used to. Instead of straddling a fictive middle ground between observation

${ }^{249}$ Lavigne, Pierre Huyghe, 214.

${ }^{250}$ Rafael, On Site, 12. 
and imagined participation, Huyghe consciously kept us as outsiders, decentred from Untilled's particular image of the nonhuman world.

Aspects of dark ecological thought enter into Untilled when we consider what exactly those at the Karlsaue were witnessing. Beyond the strange unknowability of Huyghe's markers and interventions, the site itself was loaded with signs of the abject. It is literally a site of decomposition, a space that is culturally designed and isolated to be ignored and not seen. Yet by demarcating it as the location of an artistic projectat an internationally famous art event-Huyghe forced the viewer to bear witness to this location of material entropy. The beautiful soul finds its image as a transaction, as a reflection of perfect nature, but with Untilled, Huyghe directly denied the possibility of allowing that transaction to take place. The only reflections to be found were either signifiers of unpleasant decay or, in the case of the markers, warped constructs of conventional images of nature and human culture.

This dark ecological content is matched by the form of the work. As mentioned, there was no certainty or stillness to Unitlled. Instead, it was punctuated by values of disjunction, contingency, chance, and exchange. Experiencing the work demanded an act of critical navigation. There was no clearly defined entry or exit point, and no sense of direction or a linear path through the work. Instead, each experience altered depending on what was seen, smelled, touched, and heard. How each marker interacted with another changed the experience of the work, depending on when and where you arrived at it. Whether Human was snapping at the bees on the Weber's head, sniffing at the base of a cannabis plant, or nursing her puppy in the city, would change the act of witnessing the world Huyghe helped to compose. This element of chance and contingency in actually witnessing Untilled is what renders the film, A Way in Untilled, an imperfect simulation of the work. The film introduces an illusion of linear progression and finitude to the work, which was not present to visitors who saw it in Kassel.

These values, particularly those of chance and of strange inaccessibility, align with object-oriented thought. This offers $\mathrm{OOO}$ as a constructive lens through which to analyse Huyghe's work. I have mentioned the presence of a literal ecological circuit in the artwork. The process by which ants disperse seeds is a type of biological 
mutualism known as myrmecochory. ${ }^{251}$ It is itself a kind of a distortion, as the interaction between each party fundamentally changes the future development of the other. This ecological loop, a comfortably familiar nonhuman exchange, gestures towards other distortions that are less easily comprehended. All of the objects, even the ones that did not appear linked to the central ecological circuit, such as the algaefilled puddles, had a place in Untilled. Their proximity affected and distorted each other, changing the ways in which an outside witness could comprehend them. Everything at Untilled was a part of a system, but in line with OOO thinking, we did not, and could not, ever have access to their roles or meanings.

What Huyghe's work did allow to be seen was the distortions and confusions created by one force in particular. The human object was the force that animated Untilled, its distortive power being the common variable that united the strange markers with the competing histories of place and artistic heritage. This was an image of nature, not as a Romantic dream, but as we have ultimately made it. Huyghe's project, read through the aesthetic Anthropocene, demonstrated that when we construct nature as a semiotic other-a fantasy cure for the ills of Western life-we inevitably distort and corrupt its material realities, the actual things that lie beneath the dream-object. The compost of the Karlsaue is a remarkably potent metaphor for this concept. To construct the park's Baroque gardens, it was necessary to destroy large swathes of biomass. Plants and trees that simply existed as benign objects in the space, were transformed into excess and unwanted refuse by the process of creating an idealised landscape. Untilled is what happens to the nonhuman when we play with nature. It is a frightening, unsettling collage of us and our surroundings.

In the 1986 David Cronenberg film, The Fly, Jeff Goldblum's character is slowly transformed into a grotesque human/fly hybrid as the inadvertent side-effect of a science experiment. Cronenberg presents the Brundlefly (as the hybrid comes to be known) as something deviant and abhorrent, something unnatural. What Huyghe helps us see in Untilled is that, rather than being pure aberrations, this mode of hybridity is the perfectly logical consequence of Romanticising nature. The Brundlefly is an extreme analogy plucked from science fiction-as extreme as the

${ }^{251}$ Lavigne, Pierre Huyghe, 186. 
markers like Human and the Weber nude. But the principle underneath is apposite for wider considerations of the environment. Nature is not a far-off entity, separate from humanity, and nor is it a fantastic elixir of health and vitality. If it can be said to exist as anything outside of text, it is the uncomfortable, often harmful, intertwinement of the human and nonhuman that arises from the Anthropos' exploitation and manipulation of the other objects with which we share the planet.

In the remaining, deeply forested areas of the natural world, particularly in New Zealand, it is not uncommon to hear people claiming an insight into what life could have been like before the advent of humanity. There is something about the primeval wood, with its deeply entrenched, heterogeneous ecologies that encourages a sense of pre-history. Untilled allowed those present to derive the inverse of such an experience. Instead of suggesting what came before us, Huyghe-with his nonhuman collaborators-gestured towards what might remain in our absence. This experience is where the central loop of dark ecology—that critical spectatorship which encourages a sense of complicity—resides. As a species, we have already warped every object around us. It would not matter if the Anthropos vanished from the earth today, because the ripples of our distortions are irreversible and will continue to pulse outwards for centuries to come. In this way, Untilled was not a science-fiction dystopia-it was a way of visualising the world as it exists today, and a means of experiencing our warped relationship with the nonhuman world.

Read through the theory of the aesthetic Anthropocene, Untilled is not some moralistic prophecy. Nor is it a warning against the destruction of a fictional nature. Interpreting it as such radically reduces the critical worth of the project. Instead, it is a window on to the strangeness of the world as it is today, as it exists right now. Like any artistic act, it is a form of mediation, but one that differs dramatically from the kind that ecomimesis produces. It is a visualisation of what our actual relationship to the nonhuman looks like, a sharp contrast from the experienced provided by the Romantic lens. Huyghe sought to demonstrate the distortions and warpings that our influence has already produced on the nonhuman world, and those which we will continue to produce. In the spirit of dark ecology, Untilled does not preach a gospel of sustainability, and nor does it cry out that we must change our ways before it is too 
late. Through Untilled, Huyghe communicated that the change has already arrived. There is no turning back, only adapting to a modified existence. 


\section{Thinking Nature}

The final act of Andrei Tarkovsky's Andrei Rublev (1966) depicts the construction of a bell. Boriska, the young son of a dead bellfounder and boastful heir to the secret of casting bronze bells, attempts to locate the perfect clay for a mould. After rejecting multiple sites suggested by advisors, Boriska finally claims to have located an impeccable source. At the act's climax, once his bell has rung soundly, Boriska reveals that his miserly father never told him the secret of bellfounding. All his posturing about the clay had merely been a mix of theatre and intuition. The difference between the practices of Pierre Huyghe and the English artist Simon Starling can be demonstrated through this story of Boriska's bell. Huyghe, like Boriska, is concerned with the finished object. It does not matter that the clay's suitability was an instance of luck, the importance is in the total object, and its interaction with others around it. To Starling, the real significance is in the clay-the politics and choices behind the matter itself.

Not only semantic, this contrast reveals a conflict between new realisms and materialisms, and two very different ways of visualising nature through the aesthetic Anthropocene. The protagonists of OOO, particularly Harmon, see the object as the final-and only-constituent of the universe. It is irreducible, and so to enquire into smaller material properties is to deny this fundamental quality and become lost in a theatre of speculation. ${ }^{252}$ The materialist counters this claim by insisting that matter itself is an essential fount of meaning and the source of an array of political, economic, and cultural gestures. To read Starling's work into the aesthetic Anthropocene is to read it through this materialist lens. In particular, his photographic sculptures-a term I use in purposeful distinction to photographscomplicate other photographic depictions of both human and nonhuman subjects. A comparison of Starling's works with the documentary photographer Sebastião Salgado illuminates this complication. Starling's investigations into the material qualities of photography reveal both an inevitable ecomimesis in much Modern

\footnotetext{
${ }^{252}$ Thomas Lemke, 'Materialism Without Matter: The Recurrence of Subjectivism in Object-Oriented
} Ontology,' Distinktion: Journal of Social Theory 18, no. 2 (2017): 135. 
photography, and a core theme of the dark ecological Anthropocene: our complicity in capitalism as a geological force.

Despite their differences, similarities abound between the practices of Huyghe and Starling. Both expose competing, often hidden histories in their artworks. In a work that preceded Huyghe's Untilled by half a decade, Starling's Infestation Piece (Musselled Moore) (2006-08, installed 2008, Toronto: The Power Plant) (fig. 14) also exhibited a replica of a modernist sculpture, manipulated by organic forces. Where Huyghe duplicated Max Weber in concrete, Starling crafted a steel copy of Henry Moore's Warrior with Shield (1953-54, Minneapolis: Minneapolis Institute of Art). The steel sculpture was submerged in Lake Ontario and, upon retrieval, its oxidised surface had been effectively colonised by the titular mussels. The zebra mussel, now a devastating pest in Lake Ontario, arrived from the Black Sea during the expansion of global trade in the 1980s. ${ }^{253}$

With Infestation Piece, Starling forced the utopian vision of international economic co-operation-a product of modernist thought-into a confrontation with the destructive realities of capitalist globalisation. Similar thematic threads run through Starling's practice. The flawed ideals of Modernism and globalisation are faced with the consequences wrought by their wholehearted adoption by Western power structures. ${ }^{254}$ Moore has been a perennial foil for Starling, but Brancusi and Duchamp also make regular appearances. He assembles a cast of agents whose thought and practice helped to shape the world - particularly the natural world - that we are coming to terms with today. In Project for a Masquerade (Hiroshima) (2011, Hiroshima: Hiroshima City Museum of Contemporary Art) (fig. 15) Moore is quite literally represented as a mask, in the Japanese Noh theatre style. ${ }^{255}$ He becomes an actor in the play of Modernism that, though staged almost a century ago, remains fundamental to the relationship many of us have with the social and physical worlds. The antagonistic quality of much of Starling's practice-the way he draws combatants into the arena of his projects-results in work that is often more polemic and explicit

\footnotetext{
${ }^{253}$ Dieter Roelstraete, 'Survey,' in Roelstraete, Janet Harbord, and Francesco Manacorda, Simon Starling (London, New York: Phaidon Press, 2012), 68.

${ }^{254}$ Terence Dick, 'Simon Starling,' Border Crossings 27, no. 3 (2008): 183.

${ }^{255}$ Dieter Roelstraete, 'Metamorphology,' in Dieter Roelstraete, Simon Starling: Metamorphology (Chicago: Museum of Contemporary Art Chicago, 2014), 20.
} 
than an artist like Huyghe. The scope of Starling's career, and the ideas he expresses (including those confronted in the works just mentioned) are too varied to be adequately addressed in this thesis. As stated above, the discussion of Starling as he relates to an art of the Anthropocene is primarily based around his interactions with materialism and photography. Such a statement raises two obvious questions: why matter, and why photography?

New materialism is something of a misnomer for the concept it supposedly represents. Self-proclaimed new materialists are engaged with the same philosophies of a monist ontology and the vitality of materials that have always existed in materialist thought. ${ }^{256}$ New also carries the undesirable implication of reducing-or neglecting entirely-the contemporary vitality and import of two major sources of materialist thought: non-Western, animist philosophies, and material feminisms. ${ }^{257}$ What is actually new about new materialism is a wider contemporary acceptance of taking matter seriously at all. Like the other posthumanist realisms, it is a concerted reaction against the ostracism of essentialism by an intellectual landscape dominated by post-structuralist thinking and the alleged solipsism of the postmodern linguistic turn. A total materialist ontology is the inverse of a total linguistic ontology: rather than a world produced and maintained by social forces (language, text), it is one entirely run by material, physical forces. Both are powerful ideas, and both inevitably end as critically unproductive. Their extreme reductions of all human and nonhuman interaction leave us in a soup of determinism from which we would be unlikely to emerge. But, as with $\mathrm{OOO}$, choosing between a total system or none at all is an informal fallacy. Instead, as Diana Coole suggests, new materialism can be seen as an 'insistence on the recalcitrance and vitality of matter and thus on its role in constraining and engendering the ways it is understood and handled' ${ }^{258}$ Posed more succinctly, it 'means giving matter its due'. ${ }^{259}$

\footnotetext{
${ }^{256}$ James Ladyman, 'Things Aren't What They Used to Be: On the Immateriality of Matter and the Reality of Relations,' in Cox, Jaskey, and Malik, Realism, Materialism, Art, 35-40.

${ }^{257}$ Cox, Jaskey, and Malik, Realism, Materialism, Art, 23.

${ }^{258}$ Diana Coole, 'From Within the Midst of Things: New Sensibility, New Alchemy, and the Renewal of Critical Theory,' In Cox, Jaskey, and Malik, Realism, Materialism, Art, 41.

${ }^{259}$ Coole, 'From Within the Midst of Things,' 42.
} 
Taking matter seriously means removing the veneer that matter is somehow apolitical, or inert. It is inevitably connected to a network of political and commercial economies and-as we and other species affect it—it in turn begins to affect us. For example, the contemporary art world begins and ends as an economy of matter. As Dieter Roelstraete observes, in reference to Michael Baxandall's influential 1972 text, Painting and Experience in Fifteenth-Century Italy:

The early economic history of art is therefore a 'natural' history of sorts, its economy a matter, first and foremost of (organic) materials found, quarried, traded—and magically transformed. The peculiarly 'magical' quality of this transformation-the mysterious crux of which constitutes the creation, seemingly ex nihilo, of that most elusive of artistic qualities, value — has been a consistent, defining presence throughout the history of art ever since. ${ }^{260}$

This alchemy at the heart of art-making that Roelstraete identifies, professionalised during the European Renaissance, is the altar we worship at during every international biennial, art fair, and multi-million-dollar auction. At the heart of this alchemical sleight of hand in the contemporary global art market-a major difference from its Renaissance origins-is a willing separation of the finished art-object from its material sources.

Every material used by the artist who depicts nature has a source, an origin, and an economy. This is important for the Romantic progenitors of ecomimesis, but it becomes entirely vital to understanding the contemporary artist who operates within a global economy that itself has profound effects on the object of their practice. This is what Starling's art, with its focus on the politics and power of matter, may reveal. Shown at the Neugerriemschneider gallery in Berlin in 2009, The Long Ton (fig. 16) exemplifies this process of interrogating the economies of matter, and art's historical relationship with the same. The work consists of two blocks of marble suspended in the air at equal heights by a rudimentary pulley system. The larger of the two is exported marble from China, weighing approximately the work's titular ton. The other, at roughly a quarter the weight of its counterpart, is European art's historically

${ }^{260}$ Roelstraete, 'Metamorphology,' 15. 
beloved Carrara marble. ${ }^{261}$ The smaller piece was precision cut to mimic the Chinese block at scale. What connects the two objects-aside from their strict material similarity-is their equal financial worth. ${ }^{262}$

Starling demonstrates through this careful balancing act that the transmutation of material into art value is not itself a valueless action. The identity of the artist and material are central to the process. For all the proclaimed material excellences of the Carrara stock over the centuries, the cost differential from its Chinese doppelgänger is as much a quality of China's role in the global economyand a Western disdain for Chinese manufactured goods-as it is a testament to the petrological superiority of the Italian rock. ${ }^{263}$ In discussing Starling's practice, Robert Leonard has identified the persistent presence of Marx's commodity fetishism; the process by which 'commodities are magically imbued with independent personalities, concealing the fact that they were produced by alienated labour' ${ }^{264}$ What The Long Ton reveals-as with much of Starling's work-is the arbitrary 'impenetrable vagaries of value' that this fetishism imbues in matter itself as the base constituent of art practice and global art economies. ${ }^{265}$

Photography, or at least the type of chemical image-making that came to artistic prominence in the modernisms of the later-nineteenth and twentieth centuries, is rarely conceived of in material terms. This is reflective of critical stances like Clement Greenberg's, that photography is an inherently narrative medium, that its objects are 'historical, anecdotal, reportorial, observational before they are purely pictorial' ${ }^{266}$ This popular position is one of the deeper ironies of an image-making which began as a partially material pursuit: the earliest forms of photography were valued as much for what they were as for what they depicted. ${ }^{267}$ Yet somewhere in the

\footnotetext{
${ }^{261}$ Roelsraete, 'Metamorphology,' 21-22.

${ }^{262}$ Ibid.

${ }^{263}$ Ibid.

${ }^{264}$ Robert Leonard, 'Please Explain,' in Max Delay and Patrice Sharkey (eds) In Speculum (Melbourne, Brisbane, Wellington: Monash University Museum of Art, Institute of Modern Art, City Gallery Wellington Te Whare Toi, 2013-2014), 26.

${ }^{265}$ Roelsraete, 'Metamorphology,' 22.

${ }^{266}$ Clement Greenberg, quoted in Mark Godfrey, 'Prints, Particles, Palaces, and Planets: Simon Starling and Photography,' in Roelstraete, Metamorphology, 115.

${ }^{267}$ See Geoffrey Batchen, Forget Me Not: Photography and Remembrance (New York: Princeton Architectural Press, 2006).
} 
myth-making and hero-worship of the modernist period, photography lost some of this self-reflexive, mediative quality and the tools of analysis were turned overalmost exclusively—to the subject and author. Some of this, surely, is the alchemy of art-making, that will to believe that an art object is a fully formed, pre-packaged entity, and not the product of so many materials and economies.

In the previous chapter I discussed the inveterate myth of photography's pseudo-verity, with particular reference to Ansel Adam's Yosemite park works. What the ideas of art-value and transformation expressed by Roelstraete (through Baxandall) add to that discussion is some of the explanation as to why-despite innumerable challenges - that particular myth retains such strength. ${ }^{268}$. Bringing these ideas together, back to the discussion of the artistic depiction of nature, photography can be seen as the arch-medium of ecomimesis-the apex of its deceptive potential. In no way is this intended to denigrate photography as a bankrupt medium, nor to suggest that all photographs of nature are inherently ineffectual or deceptive. But neither is it to say that once art photography entered into its postmodern phase these myths were entirely eliminated. Photography and Modernism matured together, and they share many of the same foundational constructs which affect art-making outside and beyond their original influence.

Sebastião Salgado is one of the most prolific and commercially lucrative photographers of the twentieth century. Although his practice is labelled as 'documentary', it exists in the space which reveals that 'documentary' and 'art' photography are, more often than not, comfortable synonyms. Salgado is not Ansel Adams. His works take place in a world that has rejected much of the modernist photographer's ethos, and he shows the nonhuman and human worlds through a lens that attempts to fix them in context and time. But, for a photographer like Salgado, Adams' is a remarkably long shadow to escape. The same perfect tonal control, epic scale, and emphasis on what will emerge as a large-scale print, suffuses both artists' practice. Salgado, the embodiment of highly popular and accessible art photography, is a representative of how the exploitative tricks and mythologies of ecomimesis have remained embedded in much documentary photographic practice.

${ }^{268}$ Including one of the most influential pieces of art history written, Barthes' Camera Lucida. 
Salgado's photobook, Genesis (2013), presents a model of ecomimetic photography that operates in a similar fashion to Adams' Yosemite works. Shafts of divine light pierce undulating valleys, intricate icebergs thrust out of the waves like Bavarian castles, seals yawn, and unnamed, unclothed men canoe into the mist. ${ }^{269}$ In the book's foreword, written by Salgado's partner Lèlia Wanick Salgado, she asserts that the photographs enclosed 'explore the beauty of nature across the globe'. ${ }^{270}$ Salgado himself expresses a wish to '[follow] a romantic dream to find and share a pristine world that all too often is beyond our eyes and reach' ${ }^{271}$ Such sentiments are the apex of Romantic environmentalism's retreat into ecomimetic fantasy. Salgado attempts to provide us with access to 'unspoilt' environments. Yet, as a documenter of environmental and labour exploitation, he should be aware more than most that these do not exist.

With the images of indigenous life that proliferate within Genesis, Salgado provides us with that other insidious myth of ecomimesis: green primitivism. The images imply that these cultures have the answer that 'civilized' societies lack, they possess the right way to live in harmony with nature. Christopher Ball describes the series as 'primitivist realism', as the assumed transparency of Salgado's photographic images purport to gift us a real, unmediated view of hidden peoples. ${ }^{272}$ These criticisms of a certain brand of ecomimetic photography could equally be levelled at Adams, or any other photographer from within this tradition. Genesis is so patently a child of this type of image-making that any further critique would simply repeat arguments already mounted by this thesis. Salgado's earlier series, which offer some attempt at upending or disrupting the Modernist model that Genesis ultimately employs, are of greater critical interest.

Released in 1993, Workers: An Archaeology of the Industrial Age is a photographic survey of labour. Salgado's photobook captured, through luscious,

\footnotetext{
${ }^{269}$ Sebastião Salgado, Genesis (Cologne: Taschen, 2013).

${ }^{270}$ Lélia Wanick Salgado, quoted in in Salgado, Genesis, 9.

${ }^{271}$ Salgado, Genesis, 7.

${ }^{272}$ Christopher Ball, 'And There Was Light: Sebastião Salgado's Genesis and (Ehtno)Primitivist Realism,' American Anthropologist 118, no. 3 (2016): 641, accessed 18 February 2018, doi: 10.1111/aman.12679.
} 
tonally-controlled black-and-white prints, images of the last pre-industrial workforces across the globe. ${ }^{273}$ In a particularly confronting series of images, Salgado's camera surveys the now abandoned Serra Pelada goldmines in Brazil. The mines, infamous for the cruelty of their working conditions and the loss of life suffered there, are rendered in the photographic language of an historical epic. Salgado claims to have depicted, 'an extraordinary and tormented view of the human animal: 50,000 men sculpted by mud and dreams' ${ }^{274}$ The Gold Mine, Brazil (1986, London: Tate Modern) (fig. 17) depicts the mine as a Boschian hellscape. Thousands of mud-soaked workers are reduced to a teeming mass of limbs and bodies that ascend ladders up mist-covered cliff faces.

Salgado's defenders could-I believe quite rightly—argue that Workers does represent a subversion of ecomimesis' objective face. Images such as The Gold Mine still manufacture the illusion of an immediate and real environment, effacing the restrictions of the aesthetic frame in the classic ecomimetic mode. But while doing so, they depict a vision of humanity quite literally changing the nonhuman objects around it. Nature here is neither permanent nor unassailable-as it is in Adams' work-instead it bends to the will of the Anthropos. However, these images fall short in that they restate the subjective face of ecomimesis, the beautiful soul. In simply presenting a supposedly unmediated image of exploited labour (ignoring of course that photography is all mediation) Salgado makes natural the circumstances of such employment. Consequently, he refuses to indict the industrialists that profit from oppressive working conditions, and the system of globalist capitalism that they operate within.

Even had Salgado chosen to manifest such an indictment in his practice, it would do little to assault the moralised detachment of the beautiful soul in the photographs' viewers. We, the consumers who-wittingly or otherwise-encourage and perpetuate the system that creates the extreme poverty shown in Salgado's photographs, and the extreme affluence inferred as their by-product, are insulated from all guilt and responsibility. Beyond a manufactured pang of sympathy or a

\footnotetext{
${ }^{273}$ Sebastião Salgado, Workers: An Archaeology of the Industrial Age (London, New York: Phaidon Press, 1993).

${ }^{274}$ Salgado, Workers, 17.
} 
forced simulation of pathos, nothing exists in these photographs, to encourage any sense of complicity in the creation and continuation of this poverty or its associated destruction of the natural environment. Nor do they foster the conditions to elicit a sense of responsibility required to effect any change. What remains in their absence is what Barthes described as 'the scandal of horror, not [the] horror itself' ${ }^{275}$ And, as each image of a kind of laboured atrocity marches in procession through the pages of Workers, we are exposed to what Susan Sontag identified as an anaesthetic through repetition, a numbing to specificity. ${ }^{276}$ Even though the nature depicted is not beautiful, we are not directly implicated in its existence. Without those critical ingredients of an actualised complicity and responsibility for the atrocity shownwhether it be towards humans or the natural environment-we, as viewers, are free to ascend to the throne of the beautiful soul.

Salgado's example demonstrates an inadequacy of photography in combatting the deceptive mythologies of ecomimesis, as the form itself can subvert any attempt to do so. While the iniquities that appear in Salgado's Workers are distinctly human, similar issues arise when considering environmental degradation. In reference to general images of atrocity, Geoffrey Batchen has asked the following questions:

How can photography narrate an historical event, rather than just represent it? How can it represent horror without simply repeating that horror as spectacle; that is, without itself being horrible? ?77 $^{277}$

Batchen's questions are not easily answerable, and there are likely many potential solutions. Batchen himself offers photography that looks at atrocity askance, by pointing towards horrific acts rather than directly depicting them. ${ }^{278}$ Another option is to take a reflexive turn, once again, to the materiality of photography and the photographic object—-to push back against the alchemy of modernist value. Many of

\footnotetext{
${ }^{275}$ Roland Barthes, quoted in Geoffrey Batchen, Photography Degree Zero: Reflections on Roland Barthes's Camera Lucida (Cambridge: MIT Press, 2009), 6.

${ }^{276}$ Susan Sontag, 'In Plato's Cave,' in Sontag, On Photography (New York: Farrar, Straus, and Giroux, 1977), 19-20.

${ }^{277}$ Geoffrey Batchen, 'Looking Askance,' in Batchen, Mick Gidley, Nancy K Miller, and Jay Prosser (eds), Picturing Atrocity: Photography in Crisis (London: Reaktion Books, 2012), 230.

${ }^{278}$ Batchen, 'Looking Askance,' 227-239.
} 
Simon Starling's photographic artworks do just this, and in a way that can speak to contemporary ideas of nature.

Self-reflexive photography has its own history. As Mark Godfrey notes, there exists a fruitful period of reflexive practice in the late 1960s with works such as Michael Snow's Authorization (1969, Ottawa: National Gallery of Canada) (fig. 18). ${ }^{279}$ In that work, Snow took a photograph of himself in a mirror, placed the print on the mirror and took another shot, repeating this process until various depths of a miseen-abyme covered the surface. But where early self-reflexive works like Authorization interrogated the form of photography, Starling attends to the materiality of the prints themselves, the matter of the photographic process.

Starling's Silver Salts, Platinum Salts (2008, Cologne: Ludwig Museum) (fig. 19 ) is the most deceptively straightforward demonstration of this attention to matter. The work comprises two prints, one showing a molecular model of silver bromide, and the other one of ammonium chloroplatinate. ${ }^{280}$ The former print is gelatin silver, while the latter is platinum. The salt molecules shown are representations of those embedded in the surface of the respective prints. ${ }^{281}$ Consequently, what the viewer sees are the constituent elements of the larger prints in front of them. This strange, simple circuit subverts what we assume to be a fundamental principle of photography. Instead of the photograph acting as a referent to something else, somewhere else, it represents only itself, albeit in microscopic form. Barthes proclaimed the photograph to be an emanation of the referent but, when the referent is the photograph itself what becomes of this emanation? Is it some further distillation of the photograph's essence, or, does Starling's work attempt to take us to an imagined end-point of photography? If so, on our arrival we will not find deathas Barthes proclaimed-but matter.

In the above work, Starling's fixation on matter appears academic, detached from politics of labour, exploitation, and environmental degradation. However, in a site-specific commission for the Massachusetts Museum of Contemporary Art (MASS MoCA) from the same year (2008), Starling demonstrated how this shift in attention

\footnotetext{
${ }^{279}$ Godfrey, 'Prints, Particles, Palaces, and Planets,' 115.

${ }^{280}$ Ibid.

${ }^{281}$ Ibid.
} 
toward photographic matter can amount to more than an intellectual exercise. Starling is no stranger to convolution in his titles, and this work is accordingly named The Nanjing Particles (After Henry Ward, View of C.T. Sampson's Shoe Manufactory, with the Chinese Shoemakers in working costume, North Adams and vicinity, circa 1875) (figs 20-21). While researching at the site, Starling discovered a stereograph of Chinese immigrant workers brought to Massachusetts to break a strike at the Sampson Shoe Company, the nineteenth-century occupant of the land on which MASS MoCA now sits. ${ }^{282}$ A circular hole was cut from each of the two photographs, and Starling extracted a silver grain from each. Using an electron microscope, he captured a single silver particle from each grain at various angles. With these images, Starling 'had the forms rendered as massive stainless-steel sculptures at a million times their original scale' ${ }^{283}$ These amorphous, reflective configurations were fabricated with cheap labour in Nanjing, China.

Starling then reproduced the original stereoscopic images at an enormous scale, which were affixed to a wall bifurcating the exhibition space at MASS MoCA. The holes cut from the photographs were replicated on these enlargements, transformed into apertures through which the viewer first confronted the stainlesssteel sculptures. ${ }^{284}$ Just as in Silver Salts, Platinum Salts, when the viewer aligned themselves correctly with the sculptures and the enlarged photographs, they were confronted by an image of an internal referent. When they looked at the photographs, they saw the sculptures, and when they looked at the sculptures, they saw the photographs. Unlike the chemical models of the former work, however, the overlapping layers of meaning in The Nanjing Particles revealed a number of intersections - of global art, global capital, and the exploitation of labour that the straightforward depictions of Salgado could never achieve.

The oft-cited sequence of Ridley Scott's Blade Runner (1982) in which Rick Dickard enhances a photograph-to an unrealistic degree of magnification-to locate a vital piece of information is a prophecy. Consistently repeated in science-fiction, the action represents a promise that a truth can be found in the material depths of

\footnotetext{
${ }^{282}$ Leonard, 'Please Explain,' 25.

283 Ibid.

${ }^{284}$ Ibid.
} 
photography. In 2008-when the technology existed to expose the molecular building blocks of a photographic print-Starling revealed in The Nanjing Particles that what we find in those depths is not a concrete data-point, but a sea of abstract material shapes. His critical achievement in The Nanjing Particles is to unite this abstraction with a particular time, context, and history. The two steel sculptures represent, at simultaneously macro and micro scales, the scene of the imported Chinese shoemakers shown in the enlarged stereograph. They document the moment that the image was fixed into two prints and, subsequently, the moment that the image was captured in time by a photograph. The result is materialist time-travel. By thrusting this instant of capture into the centre of the viewers' perception-drawing us into the moment when these workers were brought to the United States and exploitedStarling's artwork denies the buffer of temporal distance that a traditional photograph provides with its implication of an image taken in the past.

This quality is compounded by the fabrication of the sculptures themselves. Cheap, Chinese labour is a second link that binds the steel abstractions to the enlarged stereograph. Where the original photographs depict a form of human exploitation at the dawn of globalisation, the shining, reflective sculptural abstractions reflect an aspect of its maturation in the international art world. Starling's two sculptures conjure an immediate aesthetic resonance with the work of international art stars such as Anish Kapoor, Thomas Schütte, or Jeff Koons. ${ }^{285}$ And by choosing to have the works manufactured in Nanjing, Starling created a conscious link with the contemporary Western art-world practice of outsourcing much of the material work of art-making. As Roelstraete notes:

The Nanjing Particles brings to mind both the sinophobia that underlies much of America's anxiety around the rise of China as a new economic superpower, and the more specialist issue of the post-Fordist outsourcing that has become an integral aspect of contemporary art production, with much more art 'made in China' than just Chinese art or art by Chinese artists. ${ }^{286}$

${ }^{285}$ Roelstraete, 'Survey,' 87.

${ }^{286}$ Ibid. 
More than just bringing these issues to attention, as any photograph may do, Starling's emphasis on matter pulls his audience into these overlapping circuits of labour and exploitation. Standing in front of these shapes, seeing our reflections distorted back at us in immaculately polished stainless steel, we are forced to confront our roles in an exploitative art market and reflect on its parallels with a history of exploitative globalised labour-a history that has contributed in no small way to the contemporary climate crises.

Silver Salts, Platinum Salts and The Nanjing Particles demonstrate the different kind of alchemy that occurs in Starling's works, which occupy a space between sculpture and photography; the artist himself has stated that these works are 'photographs, but they're very much sculptures too' ${ }^{287}$ Instead of metamorphosing material into an abstract value-in the manner Baxandall described the Renaissance artist as achieving-Starling takes us to the point of this transformation and forces us to witness the arbitrary quality of this artistic chemistry. Consequently, the object of his practice is often this very process of material transformation rather than the resultant image, object, or value. Or, in the argot of the aesthetic Anthropocene, instead of effacing the aesthetic frame to permit his audience an illusion of immediate presence and access, Starling takes the viewer to the site of that frame's construction. That is why he could be described, somewhat oxymoronically, as a conceptual materialist. His interest in and presentation of matter, particularly the matter of photography, is not designed as catalyst for an artwork but as its beginning and end, its source and product.

This meticulous presentation of alchemy as a method of artistic mediation runs counter to the ecomimetic formulae of documentary photography in the style of Salgado. The Nanjing Particles demonstrates this difference in relation to the politics of labour between humans. But more than simply a gauge of social and economic relations, the evolution of labour politics and environments is one of the indices by which we may measure the impact of the Anthropos on the natural world. In One Ton II (Five handmade platinum/palladium prints of the Anglo American Platinum Corporation mine at Potgietersrus, South Africa, produced using as many platinum

${ }^{287}$ Francesco Manacorda, 'Interview,' in Roelstraete, Harbord, and Manacorda, Simon Starling, 27. 
group metal salts as can be derived from one ton of ore) (2005, Vancouver: Rennie Museum) (figs 22-23), Starling uses this materialist accentuation to punctuate the relationship between labour and nature, achieving this with a distinctly dark ecological flourish.

The work's long, overtly explanatory subtitle reveals the conceptual system within which the project was framed. Starling travelled to Potgietersrus, photographed the open-cast mine, and then produced the five prints of that image that one ton of ore would allow. ${ }^{288}$ The image itself adopts the aesthetic language of Salgado. The prints are rich, tonal, high-contrast black-and-white vistas of an epic scene of human engineering in the manner of The Gold Mine. And, while there are no humans to be seen, traces of humanity dominate the image. Miscellaneous vehicles and mining machinery, too small to be readily identified, occupy the photograph's centre, surrounded by concentric, descending rings of cut earth. This is a scene of environmental atrocity. The terraced steps of the mine's perimeter appear as an amphitheatre of environmentally exploitative capitalism, viewing platforms for our seemingly inexorable march toward species-suicide.

Taken at face value, these prints are vulnerable to the same criticisms attracted by Salgado's practice. They could be seen as yet another example of atrocity pornography, paying lip-service to our moral centres but asking nothing more of us than detached sympathy. What the previous discussion demonstrates, however, is that Starling's practice does not aim to bring us to the image or the object, but rather to the cultural and physical processes which created it. Although the prints in One Ton II appear to be of a distant place, they also function as internally referencing photographic sculptures in the manner of Silver Salts, Platinum Salts and The Nanjing Particles. The viewer is confronted, not only by an image of a site, but also material from it. These prints carry Potgietersrus with them wherever they go, and so it is impossible to extricate the images from their material and geographic origin. Consequently, it becomes measurably more difficult to detach ourselves from the ecological and economic circuits at play in both the mine and contemporary art environments. By literally bringing the platinum mine into the gallery, Starling makes

${ }^{288}$ Roelstraete, 'Metamorphology,' 22. 
us, the art viewer, complicit in the themes of environmental destruction and labour exploitation that are embedded in the image. We cannot say we are innocently witnessing an image of atrocity from a distance once we are thrust into the uncomfortable position of realising-inside the usual safety of the gallery space-that we take pleasure from its fruits.

Leonard has noted a crucial 'wall-text effect' in Starling's practice. ${ }^{289}$ There is a confrontation with enigma upon first sighting his works, followed by an all-important sense of having 'gotten it' after reading the wall-text. ${ }^{290}$ An implication of this reading is that Starling's works require specialised knowledge in order to properly function to a viewing audience. This could be seen as problematic, as knowledge requirements are inevitably prohibitive and exclusionary. But, as Leonard rightly identifies, ‘[a]s much as commentators highlight Starling's central theme of transformation, they strangely shy away from addressing the way his work remakes the viewer, reframing spectatorship' ${ }^{291}$ Like the artworks themselves, the viewer's goal is not the eventual arrival at content and understanding, but the passage there. These works do not reward knowledge, so much as discovery and navigation. Once we go through this process, we cannot 'return to our innocent pre-click engagement with the object' ${ }^{292}$ And what is this 'click' if not another iteration of the Brechtian verfremdungseffekt, the form of disjunction and contradiction that Morton calls for in his dark ecology?

In Roelstraete's discussion of One Ton II, he demonstrates a noteworthy affinity with the themes of Morton's scholarship:

Here, in these images of a mine whose contents actually enabled-it truly is a kind of magic - the production of the images in question, we find ourselves ... in the company of our old friend Ouroboros, the tail-biting serpent that has long acted as a symbol for the alchemist's secret knowledge of the unity of opposites. ${ }^{293}$

That Roelstraete would employ Morton's favoured ecological metaphor when talking about Starling should hardly come as a shock. The repeated, circuitous form of the

\footnotetext{
${ }^{289}$ Leonard, 'Please Explain,' 23.

${ }^{290}$ Leonard, 'Please Explain,' 25.

${ }^{291}$ Ibid.

${ }^{292}$ Ibid.

${ }^{293}$ Roelstraete, 'Metamorphology,' 22.
} 
artist's materialist works summons the image of the serpentine loop with ease. It demonstrates how Starling's practice fits comfortably within a dark ecological mould. With one hand, Starling rejects the objective face of ecomimesis by making visible the abject ripples that lie in the wake of modernity and globalist capitalism. With the other, he firmly positions the viewer inside those ripples, denying our withdrawal into the beautiful soul. This is partially achieved through the wall-text effect. The point of transformation in front of his artworks is an analogy for the moment that the Ouroboros bites its own tail, forcing the viewer into that instant of noir self-realisation that they are an integral component of the systems of oppression and destruction depicted in Starling's works. Yet it also requires the elevation of the importance of the material in his practice. Matter, presented as a political, active, and vibrant force in these artworks draws us into that loop of dark ecology and encourages the critical spectatorship of the aesthetic Anthropocene.

Jeremy Davies suggests that, thinking with the Anthropocene, capitalism can be conceived of as a strange-but powerful—geological force. ${ }^{294}$ Starling's materialist, photographic sculptures remove some of the alienating quality from this conception. Works like The Long Ton, The Nanjing Particles, and One Ton II reveal capitalism as an interaction between humanity and the nonhuman matter around us, as much as it is an interaction between people and class groups. Beyond this, they demonstrate the inability for producers and consumers of art to separate themselves from these interactions. They bring us into the mine, the sweat shop, and the gallery, all at the same time, refusing to allow the comfortable isolation of distance to establish itself. Starling encourages us to treat matter, human and nonhuman, with greater respectseeing within it a world of politics, history, and exploitation that has walked us to a moment of existential peril.

${ }^{294}$ Jeremy Davies, The Birth of the Anthropocene (Berkeley: University of California Press, 2016), 196. 


\section{Seeing Nature}

Pierre Huyghe and Simon Starling's practice can be read as subversions of the felt and thought experience of Romantic nature. They disrupt the myth of nature as a feminine, nurturing space that heals the corruptions of modern living. But nature is, above all else, something that we see. Visually, Romantic nature exists as the mediative lens through which we view-or more accurately, read-the nonhuman environment. Conor Clarke, a New Zealand photographer of Kai Tahu descent, now living in Berlin, directly addresses this process of reading nature through a Romantic aesthetic language. As Morton's argument suggests, this language, a typology of signifying forms, is embedded in artistic depictions of the nonhuman. Therefore, a function of the aesthetic Anthropocene is to move away from this language, to eject nature and its Romantic misconceptions from contemporary art.

Clarke completed her studies at Elam School of Fine Arts in 2005 and, thus far in her career, has produced a diverse body of photography that attends to issues of climate, environment, and human interaction with the land. She frequently addresses the visual language and politics of nature, employing a diverse set of formal techniques and a varied set of subjects to do so. The two series I have chosen to address in this discussion (In Pursuit of the Object, at a Proper Distance (2012-2014) and Scenic Potential (2014-2015)) respond directly to this question of what it means to see nature, and what it means when our vision is guided by Romantic typologies.

Before exploring the way Clarke's practice may subvert engrained conventions of visualising the natural world, it is necessary to examine those habits themselves. Here, the art historian and theorist Amanda Boeztkes offers a useful expansion of the theories of aesthetic perception developed by art historians E. H. Gombrich and Michael Baxandall, and cognitive psychologist James J. Gibson. Where these earlier theorists reveal the basic habits inherent in the way we see Romantic nature, Boetzkes offers an alternative perceptual construct, ecologicity, to suit the act of seeing in the Anthropocene. The work of these theorists, particularly Gibson, is relevant because it suits a posthumanist, new realist mode of thinking through art. Second, a modified reading of the typological practice of the German photographic duo, Bernd and Hilla Becher, illustrates how aesthetic typologies (such as the 
Romantic language of nature) are formed, and how they may be disrupted. Reading Clarke's photographs in the light of these theories-and this interpretation of the Bechers-offers the space to see her practice as an incisive indictment of the visual conventions of Romantic nature, told through a new realist lens.

Two quotations, already reproduced in this thesis, demonstrate the distinction between vision as an individual's passive reception of optical information and as an active cultural process of visualising nature. The first is Wordsworth's description of the Lakes District as 'a sort of national property in which every man has a right and interest who has an eye to perceive and a heart to enjoy' ${ }^{295}$ The second is Gombrich's observation that "nature could never have become "picturesque" for us unless we, too, had acquired the habit of seeing it in pictorial terms' ${ }^{296}$ The conception shared by these quotations is that the eye-specifically the Euro-American eye-does not possess an a priori capacity for visualising Romantic nature. Instead, it has learned to read-and subsequently translate-certain features from a given physical environment. A reciprocal relationship unfolds between a desire to read Romantic features into a nonhuman environment, and a set of Romantic aesthetic ideals found in art and literature. The popularity of the Claude glass is an apt demonstration of this reciprocity in action. The holder of the glass used the object as an aid to recreate in the physical world what they had been taught to see through art.

Gombrich's suggestion of a trained vision loaded with 'perceptual readiness', gestures towards a combination of the individual, physiological act of seeing and the ability to recognise culturally inscribed signifiers. ${ }^{297}$ Boetzkes refers to these two phenomena as vision and visuality:

[Gombrich] identified a reciprocal relationship between vision as such and visuality, a term that is more commonly associated with style, but which implies more profoundly, both individual and historical ways of seeing. For Gombrich, art operates

\footnotetext{
${ }^{295}$ William Wordsworth, quoted in Saeko Yoshikawa, William Wordsworth and the Invention of Tourism, 1820-1900 (Burlington: Ashgate, 2014), 3.

${ }^{296}$ E. H. Gombrich, Art and Illusion: A Study in the Psychology of Pictorial Representation, 4th ed. (London: Phaidon, 1972), 266.

${ }^{297}$ E. H. Gombrich, The Image and the Eye: Further Studies in the Psychology of Pictorial Perception (Oxford: Phaidon Press, 1982), 28.
} 
from visual schema that are geared to trigger pattern recognition, a skill we have in spite of environmental variances. ${ }^{298}$

To Gombrich's 'perceptual readiness' we can add Baxandall's concept of the 'period eye': the idea that the arts of a given historical and cultural moment reflect the visual competencies and priorities of that time. ${ }^{299}$ As summarised by Boetzkes, 'a painting both deploys a specialized visual skill and depicts it for a culture that is oriented to see that skill in action' ${ }^{300}$ Ecomimetic depictions of the nonhuman world are pictorial evidence of such: the skill of reading Romantic nature in action.

Our most persistent ideas about nature matured within a Romantic milieu, and its aesthetic priorities are distinctly of that period. The 'visual skill' of showing Nature in art was to demonstrate those qualities of the picturesque and sublime that dominated Romantic thought. ${ }^{301}$ As a cultural construct, Romantic nature blanketed the land and ocean with its contradictory illusions of invariance, power, harmony, and so on. To read nature was to identify a visual typology of Romantic aesthetic features, from storm-cloaked mountain peaks to bucolic valleys. What Morton identifies in his formulation of ecomimesis is that contemporary green Romanticisms-in guises such as environmentalism, conservation, and sustainability-have all continued to repeat these aesthetic priorities, and so have been unable to jettison the Romantic ideals of nature. ${ }^{302}$ Consequently, while the concept of a period eye would suggest that in the twenty-first century we should no longer desire to see the same visual skills employed as those of the nineteenth century, the persistent aesthetic restatement of nature as a cultural, visual obsession has ensured the sovereignty of these outdated and overworked Romantic typologies.

Boetzkes relies on the notion of 'ecological affordance' developed by Gibson between the 1950s and '70s. Affordance can demonstrate how these concepts of perceptual readiness and the period eye relate to ecological perception. Although

\footnotetext{
${ }^{298}$ Amanda Boetzkes, 'Ecologicity, Vision, and the Neurological System,' in Davis and Turpin, Art in the Anthropocene, 277.

${ }^{299}$ Michael Baxandall, Painting and Experience in Fifteenth-Century Italy: A Primer in the Social History of Pictorial Style, second ed. (Oxford, New York: Oxford University Press, 1988), 29-103.

${ }^{300}$ Boetzkes, 'Ecologicity, Vision, and the Neurological System,' 278.

${ }^{301}$ Once again, the Claude glass demonstrates this point.

${ }^{302}$ Morton, Ecology Without Nature, 83.
} 
Gibson's work on perception clearly predates the current preoccupation with revised realisms, it aligns itself well with these contemporary ideas. Gibson conceived of a 'perceiving subject whose actions and interpretations are interwoven with the environment'.$^{303}$ Boetzkes continues:

Gibson's perceiving subject is decidedly active; it continuously samples the ambient surroundings, obtains information from the optic array, and separates changes in the environment from its invariant structure. But the activity of perception does not limit or distort the objectivity of the world. ${ }^{304}$

This model offers room both for individual and cultural phenomenology, and for a pre-discursive realm. ${ }^{305}$ We should, as always, be cautious when approaching any theory that propounds a resolution between the dichotomy of subject and object. Yet, from a new realist perspective, Boetzkes' reading of Gibson's theory achieves the desired ideological pendulum swing away from strict correlationism. It accepts the pervasive authority of linguistic mediation, but does not reduce the totality of existence to that mediation.

Ecological affordance is, according to Boetzkes, this 'process of information pick-up at the threshold between the sense-system of the organism and the invariance of the environment' ${ }^{306}$ An environment may afford a limitless number of possible actions to a perceiver, but the perceiver will only afford those that are attuned to their biological and cultural priorities. As such, affordance is both 'a fact of the environment and a fact of behaviour' ${ }^{307}$ What a perceiver ultimately affords is a behavioural quality of the organism, but the visual information it affords from belongs to a physical world that exists independent of the viewer. ${ }^{308}$ Affordance and the period eye are useful concepts for understanding the way we look at nature and artistic depictions of such. To our encultured eyes, a mountain may afford evidence of geological upthrust, or the impossible majesty of God's creation and the immortal

${ }^{303}$ James J. Gibson, The Ecological Approach to Visual Perception (New York: Taylor \& Francis Group, 1979), 141.

${ }^{304}$ Boetzkes, 'Ecologicity, Vision, and the Neurological System,' 273.

305 Ibid.

${ }^{306}$ Ibid.

${ }^{307}$ Gibson, The Ecological Approach, 129.

${ }^{308}$ Boetzkes, 'Ecologicity, Vision, and the Neurological System,' 27. 
power of natural formations. A pastoral landscape may afford the disruptive encroachment of industry on to delicate ecosystems, or the picturesque beauty of humanity integrated in nature. The enduring influence of Romanticism in artistic depictions of nature is a Western, capitalist (predominantly androcentric) eye that is perceptually ready to afford a typology of Romantic aesthetics out of the physical world. Romantic nature remains a part of our period eye.

What happens when the second half of Gibson's perceptual model, the invariant environment, begins to vary? This is what the melting icecaps, unprecedented storm systems, and acidifying oceans of the Anthropocene represent. The world that exists outside of discourse is transforming at a rate that our species has not previously confronted. Ecological affordance could offer one of the answers as to why we find it so difficult to visualise these changes, and to constructively incorporate them into our cultural visualities. Images frequently designated as examples of the 'industrial sublime' illustrate some of this difficulty. Edward Burtynsky's Nickel Tailings \#34 (1996, Cleveland: Cleveland Museum of Art) (fig. 24) is a prime demonstration of this genre of images. The print, produced from a photograph taken outside a whiteware factory in Ontario, reframes a stream of industrial waste within a Romantic aesthetic language ${ }^{309}$ Burtynsky's combination of framing, perspective, and post-production digital manipulation manufactures an image that is vast, epic, and distinctly sublime. Noted for their perverse beauty, Burtynsky's images of industrialism's wake offer an aesthetic pleasure that is derived from the worst of human activity, a pleasure experienced in spite of ourselves. ${ }^{310}$

Such an aesthetic response surely cannot derive from the subject matter itself. Industrial waste is an ugly consequence of capitalism, something that is traditionally kept from view. Instead, the pleasure arises from reframing this distasteful subject within the Romantic typology of nature. The tailings appear in the same benign form as Cole's Oxbow. We are so accustomed to afford beauty from these forms, and to associate them with the best of our dreams of nature, that it is possible to do so even

\footnotetext{
${ }^{309}$ Elisia French, 'Sights of Desire; Sites of Demise The Environment in the Works of Edward Burtynsky and Olafur Eliasson,' Master's Thesis (Ontario, Queen's University: ProQuest Dissertations Publishing, 2012), 26, accessed 27 February 2018, https://search.proquest.com/docview/1513232111. ${ }^{310}$ Ibid.
} 
when confronted with human actions that run counter to its continued survival. In reading the natural world through this lens, as in thinking it, the ability to derive an aesthetic pleasure from the despoiled environment keeps the objective face of ecomimesis intact. We may be forced into a direct confrontation with the consequences of climate change, but the language of these images is contingent on a previously established language of Romantic beauty. Such images show us a corrupted nature, but they are built on a positive framework of Romantic type that will always undercut negative messages.

These images are victims of the same weaknesses as Salgado's attempts to depict laboured exploitation. By themselves, photographs such as Burtynsky's do little to encourage any actual sense of responsibility for, or complicity in, the devastation they depict. It is always someone else's problem, somewhere else. Once again, this inevitably offers moral assumption to the viewers of these works, to ascend towards the beautiful soul. Subjective ecomimesis of this kind always encourages this paradoxical flicker between aesthetic engagement in an imagined environment and moral detachment from its politics. The concern posed by these images is that, within our currently dominant, Euro-American informed cultural visuality, we will never be able to see the nonhuman nor anything closely resembling it. Instead, we will consistently return to a vision of Romantic nature.

Boetzkes' concept of ecologicity is an attempt to recognise, and potentially resolve, this contradiction:

If this new epoch calls us to imagine the impact of modern human life beyond the parameters of individual phenomenology, to account for systemic activity on micro and macro scales, and in relation to geological time, then there is equally a desire on the part of artists to redefine the limits of vision in order to incorporate and represent new orientations. I would suggest that the Anthropocene cannot simply be represented in art (as in, for example, images of anthropogenic landscapes), but that art is the means by which this ecological perspective is incorporated into vision and becomes a visuality. That is to say, art does not simply make ecological information and scale available to the eye, but, more forcefully, it consolidates a cultural orientation-a way of seeing. ${ }^{311}$

${ }^{311}$ Boetzkes, 'Ecologicity, Vision, and the Neurological System,' 272. 
Her suggestion is an end point: it would represent a kind of art-making that registered both ecological perception (affordance) and larger environmental changes through vision. ${ }^{312}$ A priority for the aesthetic Anthropocene, particularly in light of Morton's theories, is that before we strive for such utopian revisions in art and art-making there is a necessary reckoning to be had with the historical conditions of art and its relationship to nature. Conor Clarke's photography should not be read as this final goal, as the totality of a revised ecological vision. Rather, it serves best as an initial step toward ecologicity, as this necessary investigation into the historical visual structure and vocabulary of nature.

Clarke's works can be read as an interrogation of an ingrained desire to afford the Romantic, and to transform the most mundane or forlorn environments into sites of beautiful nature. Crucially, this occurs through a manipulation of the Romantic typologies of Nature as they have manifested in art history. With In Pursuit of the Object, at a Proper Distance (figs 26-28) and Scenic Potential (figs 29-33), Clarke draws attention to the vocabularies of the picturesque and sublime in framing our visions of the world. ${ }^{313}$ It is, however, impossible to talk about aesthetic typologies-especially with regard to art photography - without first discussing Bernd and Hilla Becher, the German husband and wife team who turned typological photography into a popular object of artistic enquiry.

The Bechers' famed inventories of Western post-industrial landscapes are typically discussed within a conceptual art discourse. Beginning in the 1950s, the couple travelled the world, producing monotonous, stark, black-and-white photographs of water towers, gas tanks, blast furnaces, Arts and Crafts domiciles, and a further array of neglected architectural tropes of the prior century (fig. 25). ${ }^{314}$ Their photographs, taken in the early morning from a uniform angle, against unvarying

${ }^{312}$ Boetzkes, 'Ecologicity, Vision, and the Neurological System,' 280-281.

${ }^{313}$ Three of the images from In Pursuit of the Object were first shown at the duo exhibition, Winter/Winter (2014), with Sam Hartnett at PLAZA, Auckland. The full series first appeared as a part of the group exhibition, Typologien (2014), at Jarvis Dooney Gallerie, Berlin, alongside Boris Eldagson, Henry Trumble, Nadine Hattom, and Zoe Spawton. Scenic Potential was first exhibited at Two Rooms, Auckland, in 2015 at an exhibition of the same name.

${ }^{314}$ Thierry de Duve, 'Bernd and Hilla Becher or Monumentary Photography,' in Gabriele Shor (ed.), Held Together With Water: Art from the Sammlung Verbund (Ostfildern: Hatje Cantz, 2007), 286. 
overcast skies, were designed with an eye to homogeneity. The Bechers emerged from a distinctly European tradition, rejecting the subjective fotografie tradition employed by a previous generation of German photographers. ${ }^{315}$ Yet they have been ritualised into a canon of conceptual art-more suited to British and American practicebecause, when stacked together in grids, hung along lines, or reproduced side-byside in photobooks, the Bechers' works assume the status of a system. ${ }^{316}$ Their analogue repetitions-images produced under a set of rules designed to remove the appearance of style and subjectivity—culminate as a taxonomical gestalt.

From their first published collection of photographs in 1970, Anonyme Skulpturen (Anonymous Sculptures), the Bechers' indices of type have been read as both Modern and Romantic. ${ }^{317}$ Modern, in their pseudo-objective renunciation of personal affectation that Thierry de Duve expresses as the 'reserve of the Bechers' photos, their unique way of being devoid of style, their formal uniformity' ${ }^{318}$ And Romantic, in that these images are so willingly read into the framework of the Kantian sublime. The assemblage of a limited typology, especially within the form of a grid, comes to imply in itself a kind of limitlessness. There is an assumption that, once a gridded sample of a form has been established, it can—in theory—continue $a d$ infinitum. ${ }^{319}$ Once we have been made aware of a typology, through the Bechers' work, we can imagine the possibility of infinite variations, and so marvel at our ability to do so. Again, de Duve offers something of this sentiment when he states, 'I like the fact that [the Bechers'] aesthetic is a moral principle and that it takes the intrinsic humbleness of photography to the pitch of incandescence'. ${ }^{320}$ This combination of deadpan Modernism and sublime Romanticism, primarily established by the Bechers, is the basis for an aesthetic vocabulary of type.

\footnotetext{
315 Ibid.

${ }^{316}$ Geoffrey Batchen, 'Ordering Things,' in Brian Wallis (ed.), The Order of Things: Photography from the Walther Collection (Göttingen: Steidl Publishers, 2015), 333.

${ }^{317}$ Bernhard and Hilla Becher, Anonyme Skulpturen: A Typology of Technical Constructions (Düsseldorf: Art-Press, 1970).

${ }^{318}$ De Duve, 'Bernd and Hilla Becher or Monumentary Photography,' 288.

${ }^{319}$ This concept of a grid implying its own infinite centrifugal expansion comes from Rosalind Krauss' essay, 'Grids,' October 9 (1979): 50-64.

${ }^{320}$ De Duve, 'Bern and Hilla Becher or Monumentary Photography,' 288.
} 
Yet there is something missing from many assessments of the German photographers that is fundamental to both Clarke's practice and the theories of ecological and artistic perception discussed above. The Bechers are consistently gifted archaeological and archival epithets, granting them connotations of uncovering, documenting, or revealing the typologies they present. This arises from a comparison between their assiduous attempts to remove a subjective presence from their work, and the archivist's detached, ordered labours. Contrary to this position, Geoffrey Batchen rightly argues that, in relation to the Bechers' practice, lack of style is itself a stylistic stance. ${ }^{321}$ Although the images assume a formal simulacrum of the archaeologist's objectivity, their artistic choices amount to a practice that manufactures types, far more than it could be said to discover them. ${ }^{322}$ As Batchen notes, 'it becomes clear from an examination of their methods that the Bechers have ... invented each type they appear to merely document, carefully eliminating from their photographic taxonomies any structures that don't comply with a prescribed set of aesthetic desires' ${ }^{323}$ Consequently, the 'comparative gaze' invited by the Bechers' typologies is not one which reveals the inherent characteristics of a form, but one encouraged by a subjectively constructed vocabulary of form. ${ }^{324}$

Batchen concludes that this fact of construction is 'taxonomy's worst kept secret, the fact that it is a system of order (a uniformity of presentation) imposed by the act of representation, not a faithful trace of the world as it is' ${ }^{\prime 25}$ This is, in itself, a fairly straightforward postmodern critique. He identifies the subjectivity undergirding Modernist photographic practices that ultimately sabotages all appeals to objective detachment. However, his most incisive observation concerns perception, noting that 'we learn little from looking at [the Bechers'] work other than about our own act of looking' ${ }^{326}$ Batchen intended this statement to be pejorative, but if we return to Gibson and Baxandall's concepts of how we read the world-affording that to which we are culturally predisposed-it can yield a modified interpretation of the Bechers'

\footnotetext{
${ }^{321}$ Batchen, 'Ordering Things,' 338-39.

${ }^{322}$ It is worth noting that these appeals to archaeology and archiving are flawed in themselves, as those professions are inevitably as subjective as artistic creation.

${ }^{323}$ Batchen, 'Ordering Things,' 338.

${ }^{324}$ Batchen, 'Ordering Things,' 333.

${ }^{325}$ Batchen, 'Ordering Things,' 338.

${ }^{326}$ Batchen, 'Ordering Things,' 333.
} 
practice. Confronting their post-industrial indices as constructed statements, as opposed to revealed documents - with cynicism rather than awe-it is possible to steal a glimpse into the actual production of aesthetic typologies. Rather than simply receiving a culturally embedded series of signs, looking at the Bechers can take us to the site of these signs' manufacture, wherein the repeated insistence of comparison between forms forges signifiers where none existed before. Through the Bechers, we can observe how afforded typologies are rarely inevitable or essential, but exist as fabricated semiotic structures.

Extrapolating outwards, this general principle applies as readily to mountains as it does to water towers, to clouds as it does to gas tanks. The Bechers generated an interest in a kind of art photography that turned its attention to the traces humanity leaves on the environment, that did not shy away from anthropogenic encroachment, in contrast to the likes of Ansel Adams. Their inclusion in William Jenkins' seminal 1975 exhibition, New Topographics: Photographs of a Man-Altered Landscape, at George Eastman House-alongside the Stephen Shore, Robert Adams, and Frank Gohlke and others-is testament to this. ${ }^{327}$ But the Bechers' influence extends further, into contemporary photography, with Conor Clarke counting herself as one such artist informed by their practice ${ }^{328}$ Her photographic series reveal, in geological and meteorological forms, what the Bechers did for the post-industrial landscape, demonstrating that we are trained to afford Romantic nature, but that this affordance is just as arbitrary as a Becher grid.

In much of Clarke's work, the typological strategy of the Bechers is matched by an interest in the aesthetic of specific Romantic visual languages. As such, her subjects become both the structures and formations depicted, and the gestalt created by their contiguous presentation. With In Pursuit of the Object, Clarke expands outward from the innovators of the art-photographic typology, and into this crucible of Romantic language. The series consists of sixteen images, each depicting the vertical extremity of an industrial smokestack, quenching, or cooling tower. The title

\footnotetext{
${ }^{327}$ Chloe Cull, 'Conor Clarke at Two Rooms,' Eye Contact, accessed 27 February 2018, http://eyecontactsite.com/2015/05/conor-clarke-at-two-rooms.

${ }^{328}$ Conor Clarke, 'The Attempt to Convey Sublime Experience,' Art News New Zealand (Autumn 2016): 87.
} 
of each work reveals no more than the location of each tower, assuming the purely descriptive language of taxonomy. Although taken from their uniform, extremely low angle, the subjects of these photographs are less the towers, than their emissions. In each, steam emerges from a single source, but with a variety of intensities and tones. Works such as Schkopau, Saalekreis, Sachsen-Anhalt (2013) (fig. 26) show steam as a lethargic emergence, diffused by buffeting winds and quickly adopting the appearance of the surrounding clouds. Others, like Duisburg-Hamborn, NordrheinWestfalen (2014) (fig. 27), suggest a kind of gaseous plasticity, more cotton than cloud. Unlike the Bechers, the uniformity of Clarke's photographs is tempered by interruption. The weather conditions and time of day vary. Foreign agents, such as birds, sometimes enter the frame. The combination of colour and the sharp, distinctive imagery of a medium-format camera render the emerging capitals of each tower as individual entities rather than monochrome repetitions. Yet despite these variations, what we see in each are clouds.

Cloud formations have always offered an ideal subject for hunters of the natural picturesque. The obvious precedent is John Constable, who in his search for scientific accuracy in the depiction of nature undertook a programme of numerous cloud sketches. ${ }^{329}$ Additionally, chemist and amateur meteorologist Luke Howard's 1803 Essay on the Modifications of Clouds provided the original formulation of a cloud taxonomy. ${ }^{330}$ This text, a possible influence on Constable, was accompanied by lithographic plates that demonstrated the varying forms of cumulus, stratus, and cirrus. ${ }^{331}$ The isolated cloud-as opposed to, say, a storm front-is a near-perfect enunciation of picturesque principles. It is irregular and asymmetrical, yet calm and unthreatening, signifying rain, water, and nurture. The cloud occupies a seat in the upper pantheon of nature's infinite metonymy, being one of the more prominent signifiers of the picturesque landscape. Clarke, as the 'post-industrial picturesque tourist', hunted and captured the cloud, recording for her viewers its variations and

\footnotetext{
${ }^{329}$ John Constable, quoted in Barbara Novak, Nature and Culture: American Landscape and Painting 1825-1875 (London: Thames and Hudson, 1980), 78.

${ }^{330}$ Ada Smailbegović, 'Cloud Writing: Describing Soft Architectures of Change in the Anthropocene,' in in Davis and Turpin, Art in the Anthropocene, 99.

${ }^{331}$ Ibid.
} 
similarities. ${ }^{332}$ Unlike her Romantic predecessors, Clarke did not need to wait for the meterological cloud, such as Wordsworth's which 'floats on high o'er vales and hills', to appear in the landscape. She was able to visit a static series of locations at which humanity now manufactures one of these most enduring Romantic forms.

The billowing shapes of In Pursuit of the Object are both cloud and steam. The chimneys emerging from the bottom of the frame should immediately declare these forms as artificially manufactured steam. And yet, so readily do they assimilate into an established Romantic vocabulary, that to the eye developed in a society dominated by Euro-American culture and vision, the meteorological cloud stakes a convincing claim. The second half of the series' title, at a Proper Distance, demonstrates this encultured affordance on two levels. The first is the physical distance from which Clarke took the photographs, which becomes the distance the viewer occupies as we stand in for the photographer in the act of viewing. ${ }^{333}$ This aligns with an element of the Burkean sublime, in which an object of terror-in this case, smokestacks emitting immense quantities of scalding steam-is transformed into a pleasing aesthetic by the safety of physical distance. ${ }^{334}$ The second can refer to the distance at which Clarke's images are first confronted. These are large prints, measuring 1200 x $960 \mathrm{~mm}$, but when seen from afar, without prior knowledge of their content, it is difficult to determine whether they show steam emerging from a tower, or simply cloud.

At this juncture, the possibility exists to afford either formation. We could see a billowing smokestack: a potent symbol of anthropogenic climate change and symbolic agent of a globe-spanning petrocapitalist industry that contributes daily to the increasingly visible signs of a changing planet. Or we could see a cloud, the comforting visual symbol of a healing, eternal nature. This ability to afford either reading at all is a testament to the pervasive authority of the Romantic aesthetic language-its ability to manipulate forms into ideas that suit an eighteenth- and

\footnotetext{
${ }^{332}$ Jakob Shiller, 'Smokestack Photos Make Pollution Look Strangely Beautiful,' Wired, accessed 27 February 2018, https://www.wired.com/2015/03/conor-clarke-smokestacks.

${ }^{333}$ This effect is somewhat diminished, however, by the zoom of Clarke's long lens, collapsing the distance between photographer and subject.

${ }^{334}$ Edmund Burke, A Philosophical Enquiry into the Sublime and Beautiful, rev. ed. with introduction and notes by James. T. Boulton (London, New York: Routledge Classics, 2008), 40.
} 
nineteenth-century ideology, ill-fit for our contemporary ecological moment. Importantly, what allows for such an affordance in Clarke's work, distinct from other images of the 'industrial sublime', is the believability of the proposition. In Burtynsky's Nickel Tailings \#34, industrial waste is framed within the form of a Romantic aesthetic vocabulary, but its garishly incorrect colours immediately announce the image as a distinctly unnatural artifice. By contrast, Clarke's images adopt both the form and style of the cloud type, fully assimilating them into the aesthetic language of Romantic nature.

Clarke states of the series, 'you are attracted to [the photographs] but at the same time you feel guilty. I've heard them described as horribly pleasing' ${ }^{335}$ What exactly is this horrible pleasure? A substantial danger exists that this is Barthes' 'scandal of horror', or Sontag's anaesthesia through the repetition of atrocity, an entirely uncritical artifice. In a recent article for Art New Zealand, Holly Best identifies as much when she remarks that although Clarke's 'intention is subtly to invoke an uncomfortable feeling, the risk of mediating our experience through photography is that we unwittingly become less affected by the reality of the subject' ${ }^{336}$ How are these images any more suited to depicting our relationship to nature than Salgado's or Burtynsky's? The risk remains that our ability to derive aesthetic pleasure from the images is what ensures the force of ecomimesis, and that the titular distance we occupy from these industrial settings secures the authority of our retreat into the beautiful soul.

The decisive difference between the horrible pleasure rendered by In Pursuit of the Object, and that of other images of environmental atrocity, is a precise confusion in the distinction between real and imagined, between nature and culture. Because of the believable appearance of Clarke's forms, it takes some combination of close inspection-Leonard's wall-text effect, or Brecht's verfremdungseffekt-to confidently peel back the layers of Romantic fog and actually see industrial effluence, the true, material subject of Clarke's photographs. In this reading, the horrible pleasure is not a reaction to the actual subjects of the images, but our willing

\footnotetext{
${ }^{335}$ Shiller, 'Smokestack Photos Make Pollution Look Strangely Beautiful.' Emphasis added.

${ }^{336}$ Holly Best, 'Photographing Nature: The Slippery Topographics of Conor Clarke,' Art New Zealand (Winter 2018): 77.
} 
capability to afford something so benign from such potent symbols of environmental destruction. It is in the realisation that, instead of confronting the seemingly inconceivable magnitude of climate change and our complicity in the structures that have begun to manifest its deleterious effects, we just want to see clouds. The site of this realisation marks the beginnings of a dark ecological spectatorship and an attendant acceptance of how truly unnatural Romantic nature is.

Clarke's adoption of Bernd and Hilla Bechers' techniques takes this critical spectatorship a crucial further step. A single image from this series is enough to prompt a sense of confusion, a distrust of what we afford from the nonhuman, and a revision of what we assume so easily to see as natural. But to repeat this statement over and over, constructing a typology in the manner of the Bechers, says something more. Where the Bechers invented aesthetic typologies, Clarke restates an established Romantic one. But her subversion of the type refuses to allow it any firm establishment, grounded in reality. The total effect of the series is a repetitious interruption of an encultured visual language. As the images progress, each one a variation of the cloud typology, the Romantic authority of the type begins to dissipate. The viewer is forced into a position of cynicism by the disconnect between an affordance of Romantic type and the reality of a disturbing industrial banality. We must confront the arbitrary system of signs that constitute the semiotic whole of Romantic nature's vocabulary.

In this reading, the ability to carve a conceptual distance for ourselves is complicated by an awareness of artificiality fostered by the total series. How does one willingly efface an aesthetic frame when the aesthetics within it have been proven arbitrary, and thus lost some of their power? How does one separate oneself from the guilt associated with mistaking the destructive for the quaint? Surely, only the unease of a horrible pleasure remains. There is a pedagogical dimension to In Pursuit of the Object, a lesson to be absorbed in how easy it is for us to read into the physical environment an artificial language that does not suit this moment of climate crisis. The message is that there is no solid, invariant footing upon which the way we have been taught to read nature is based. It is all just ephemeral: clouds and steam.

Scenic Potential operates in a similar fashion to Clarke's previous series, but for a different Romantic typology and to an even higher degree of artificiality. The ten 
images that comprise the series were taken from mounds of sand and dirt in the streets and construction sites of Berlin. Through digital post-production, Clarke isolated these forms from their backgrounds, combining multiple images and locations into single scenes. The final prints strip the objects of their urban context, and place them squarely within the vocabulary of the Romantic mountainscape. They combine the Romantic form of the mountain with the style of Modernist landscape photography (a Romantic trope in its own right). The resultant black-and-white prints mimic the high contrast and tightly controlled tonal variations of Adams, the progenitor of that style, with the banal industrial repetitions of the Bechers-and again, each image is titled with the taxonomist's descriptive detachment.

There are a number of photographic and filmic references at play in this series. Adams' Yosemite works are the inescapable point of origin. In Peak III, Berlin (2015) (fig. 29), an ascending chevron of sand assumes the imposing jagged crest of Cathedral Peak, while the 'ridge' of Peak I, Berlin (2014) (fig. 30) is suggestive of the stolid gradient of El Capitan's southwest face. Another kind of Modernist mountain appears in the form of Edward Weston's dunescapes. The dried-out sand crest of Peak II, Berlin (2015) (fig. 31) is an evocation of the formation which straddles the background of Weston's Dunes, Oceano (1936, New York: Metropolitan Museum of Art) (fig. 34). Other images in the series pull back from the constructed mountain peaks, revealing otherworldly valleys marked by tire tracks of industrial machinery that betray the true origins of the imagery. In her review of Scenic Potential, Chloe Cull compares one of these images, Landscape I, Berlin (2014) (fig. 32) to a scene from Franklin J. Schaffner's Planet of the Apes (1968). ${ }^{337}$ Douglas Trumbull's colour inverted extra-terrestrial landscapes from the final act of Stanley Kubrick's 2001: A Space Odyssey (1968) could be added to the comparison. Something of the ill-fated utopianism of cinematic science fiction pervades these images.

Just as with In Pursuit of the Object, Clarke takes Modernist style as a point of departure from which to interrogate a Romantic typology. The mountain, even more than the cloud, is a staple of Romantic nature's aesthetic language, lending itself to

${ }^{337}$ Cull, 'Conor Clarke at Two Rooms'. 
both sublime and picturesque ideology. Ruskin's observation that, 'Mountains are the beginning and the end of all natural scenery', as succinct as it is self-assured, attests to the fixation with the mountain in the Romantic mind ${ }^{338}$ In painted imagery, from Rosa, to Friedrich, Turner, and the Cozens, the mountain offered the best of Nature's sublimity. Their unassailable antiquity and unchanging visage offered a window into the uncompromising endurance of time and the unspeakable majesty of the Christian God's creation. ${ }^{339}$ William Gilpin, father of the aesthetic picturesque, fit the rugged asymmetrical peaks of his native Cumbria into his principles of picturesque imagery. ${ }^{340}$ Clarke consciously operates in this Romantic wake, directly describing the series as 'landscape compositions based on William Gilpin's picturesque ideal' ${ }^{341}$

As with Clarke's previous series, the same process of affordance unfolds. The subjects of these images are piles of dirt and sand, but when reframed within the visual form and style of the language of Romantic nature they appear first and foremost as mountains. That same critical revelation of a manufactured typology is generated on closer inspection, or by comprehending the true origin of the works through the attached wall-text. Again, through the Becher-like repetition of the form, the construction of our encultured vision of nature reveals itself. However, the same reading in Scenic Potential shifts this message to a further level of cynicism, opening the artificiality of Romantic nature's fictive typology to a greater degree of scrutiny.

These images are better described as photomontages than photographs. The high degree of digital manipulation and the collation of multiply sourced images recalls the photomontage practices of Jeff Wall or Andreas Gursky, in which a seamless patch-worked whole emerges from many constituent images. For In Pursuit of the Object Clarke travelled to locations where these typological forms, previously provided by geological and meteorological phenomena, are now produced as the industrial by-product of our societies. Even though it is easy to create a fiction from

\footnotetext{
${ }^{338}$ John Ruskin, quoted in Schama, Landscape and Culture, 384.

${ }^{339}$ Clark, Landscape into Art, 151.

${ }^{340}$ Cull, 'Conor Clarke at Two Rooms'.

${ }^{341}$ Conor Clarke, 'Scenic Potential,' accessed 27 February 2018, https://www.conorvonclarks.com/scenic-potential.
} 
those images-to make clouds from steam-the subjects themselves still have a physical, material existence. As Clarke notes of the subject, '... this landscape exists in the real world, here is analogue proof' ${ }^{342}$ The prints that comprise Scenic Potential can never act as such documents of 'analogue proof', because their subjects are fictive in every sense. There is no external referent to which we can travel to see the scene captured by the photographer; its only existence is within the framed artifice of the photomontage. The artificiality of Nature's typologies multiplies. Cull notes this distinction between Clarke and the originator of the picturesque:

Gilpin sketched landscapes that were worthy of recording, in that they fulfilled his principles of what constituted the picturesque. Clarke, however, has created the picturesque from unremarkable landscape scenes by using contemporary photographic technology. ${ }^{343}$

Romantic nature is not indigenous to the environment. It could not, as the picturesque hunters believed, be found there by simply looking. It is created, born as an ideological fiction, sculpted into a semiotic structure placed in opposition to humanity and its cultures. Through Scenic Potential, Clarke recreates this act of construction. She takes us to the very point of manufacture, showing how each idea of a form that has entered the Romantic lexicon has done so as an act of design, rather than discovery.

Clarke's photography is not a perfect representation of Boetzkes' ecologicity. It should not be read as an alternative visuality for a new age, nor as an expansion or retraction of the phenomenology of cultural or individual vision. It does, however, manifest a certain kind of ecological perception that speaks to the same contradictions as does ecologicity. Affording the Romantic from nature was a viable strategy for eighteenth- and nineteenth-century thinkers because the environmental structure from which an individual read information possessed a stability which today no longer exists. To continue to look at the world through this Romantic lens is to deny the realities of a changing planet. Boetzkes uses the example of Nunavut Inuit

\footnotetext{
${ }^{342}$ Conor Clarke, 'In Pursuit of the Object, At a Proper Distance,' accessed 27 February 2018, https://www.conorvonclarks.com/in-pursuit-of-the-object.

${ }^{343}$ Cull, 'Conor Clarke at Two Rooms.'
} 
communities to demonstrate impossibilities of continuing to favour such a redolent visual language:

\begin{abstract}
Hunters observe that the sun sits in the sky at an unusual angle and that it sets in a different place than it did several decades ago. It casts a different light in the atmosphere, which complicates the practice of spearing fish and seals in the water, a skill that requires a grasp of the relationship between the ray of light and its refraction from the surface of the water. Those experiences at night-hunting note that the stars appear in new positions, and that the tips of snow drifts ... that they have been accustomed to following like points on a compass cannot be trusted. ${ }^{344}$
\end{abstract}

The visual anchors that tied a culture to its environment are transforming, losing their stability and practical utility. Old methods of seeing can no longer suit a new phenomenology.

In bringing attention to the arbitrary construction of Romantic typologies, Conor Clarke's artworks speak to this contradiction between ways of seeing. They reveal the strange power that a Romantic vocabulary still holds over the way we see nature, and how uneasily this language sits with our contemporary world. Vitally, they do so by addressing the role that artists and their works have played in shaping these false forms and manufactured typologies. By casting back through art-historical models, forms, and techniques, Clarke forces these antiquated ideological structures to defend their shaping of the material world. Invariably, they come up short.

Ultimately, the case for reading Clarke's photography through a new realist lens is not that she somehow conjures an image of the pre-discursive, or that these photographs manage to exist outside of correlation or mediation. As already discussed, it is nearly impossible for photographs themselves to do so. Rather, it is that they may point towards the impossibility of correlationism in the twenty-first century—the core argument of many posthumanisms. Just like affordance, correlation exists in the mediation between subject and object. Clarke's work demonstrates that this space is no longer as stable as it might once have been. As a new realist like Meillassoux would argue, geological fact exists outside of discourse, outside of mediation. And these facts are beginning to alter in a fashion and with a frequency that neither Kant, Hegel, nor the post-structuralists could ever have

${ }^{344}$ Boetzkes, 'Ecologicity, Vision, and the Neurological System,' 271. 
conceived. Clarke's two photographic series challenge the status of a visual language that has dominated Western perceptions of nature for over two centuries. Ultimately, they ask the same question that was raised by the Nunavut Inuit. How are we supposed to look at the world when the language we use to do so no longer fits?

Each of these artists attends to the concerns of our current ecological crisis. In doing so, they align with the central concerns of the aesthetic Anthropocene. Yet each does so in a different way. Huyghe's Untilled toys with our preconceptions of what it means to be in nature, to feel the primeval and the unknown. Starling's photographic sculptures complicate the ability to separate the gallery space from the causes and consequences of anthropogenic climate change. Clarke's aesthetic typologies reveal the arbitrary values we place on natural forms. These variations allow for distinct readings of the aesthetic Anthropocene into their respective practices.

Each demands an engagement with the Romantic conceptions of nature that Morton sees as the fundamental obstacle to a revised relationship with the nonhuman world. Through the readings of these three artists, the aesthetic Anthropocene offers a kind of methodology for interrogating and investigating the thought, felt, and viewed experience of Romantic nature. Yet flaws perforate these readings. They arise from the issues identified in the previous chapter with the theory itself, but merge into a single concern. The aesthetic Anthropocene seeks to do away with Romantic nature in order to resolve a false binary between humanity and the nonhuman world. But once a binary has established its roots in language, can it really be resolved, merged, or dissolved? Derrida rightly observed that once a binary is established, any attempts to extricate ourselves from its operations inevitably replicate its offences. ${ }^{345}$ And so, we are left with a final question. Does the aesthetic Anthropocene truly provide a novel and constructive reading of contemporary art as

${ }^{345}$ Jacques Derrida, The Truth in Painting, trans. Geoff Bennington and Ian McLeod (Chicago and London: University of Chicago Press, 1987), 2. 
an aid to thinking through climate change, or does it merely dress an old problem in a new clothing? 


\section{Conclusion.}

The Mariana SPAM's vigil is not a lonesome one. The can shares the trench with a Budweiser can and a plastic bag. ${ }^{346}$ These few, material testaments to the reach of the human grasp sit in watery darkness, sinking slowly into mud while the world above them changes. Over the past twelve months, three major hurricanes brought devastation to the Americas, new weather extremes were recorded across the planet, an historically large iceberg split from the Larsen C ice shelf in Antarctica, and Cape Town approached the brink of becoming the first developed city in the world to lack a supply of fresh water. Isolated events coalesce into the mosaic of climate catastrophe. In response to the sublime magnitude of this crisis, the aesthetic Anthropocene offers undeniable potential and irresistible appeal. It is, above all else, a reaction to a suite of very real problems that exist in our physical environments, and in the visual arts with which we depict them.

The dissonance between a resolute set of ideas about the constitution of environmental nature and the material realities of our changing planet is unsustainable. Eventually, one or both will give. The aesthetic Anthropocene responds to this too. Timothy Morton is correct in his assertion that our conceptions of nature are informed by outdated Romantic fantasies, and he is equally correct that these ideas 'take shape and dissolve' in artistic representations of the natural world. ${ }^{347}$ The nature of The Oxbow is the nature of Clearing Winter Storm is the nature of Nickel Tailings \#34. They are one and the same imaginary refuge of the picturesque and the sublime, the pristine and the wild, something to exploit and something to preserve. This Romantic ideal of nature as a semiotic other to human society-the healing balm for destructive civilisation-is a real part of the problem of climate change. The artistic contributions to this fallacy require our immediate attention.

\footnotetext{
${ }^{346}$ Damian Carrington, the Guardian, “"Extraordinary” Levels of Pollutants Found in 10km Deep Mariana Trench,' accessed 10 March 2017, https://www.theguardian.com/environment/2017/feb/13/extraordinary-levels-of-toxic-pollutionfound-in-10km-deep-mariana-trench. ${ }^{347}$ Timothy Morton, Ecology Without Nature: Rethinking Environmental Aesthetics (Cambridge: Harvard University Press, 2007), 1.
} 
It is important to recognise the realised potential of the aesthetic Anthropocene in this regard. Ecologically minded contemporary art can be read as a disruption and subversion of these Romantic preoccupations. And the philosophical innovations of posthumanism are a part of this reading. The radical indeterminism of the environment Huyghe cultivated in Untilled, with its irreducible, peculiar ambiguities and unknowable relationships, rejects the confident prophecies of Thoreau or Muir that humanity could find itself in wild nature. With the material and commercial circuitry of One Ton II and The Nanjing Particles, Starling brought nature into the gallery space. Not as a distant ideal of nurture and recovery, but as the corrupted product of labour and material exploitation to which we contribute every day. And in her photographic series, Clarke revealed just how arbitrary and constructed these visual signifiers of beautiful, Romantic nature truly are.

Yet despite this promise, the many flaws that perforate each aspect of the aesthetic Anthropocene undermine the theory to the point of collapse. By themselves, each does not necessarily represent an insurmountable obstacle. But taken together, the concept crumbles under the weight of interrogation. The rapid expansion of the new geological epoch's popularity over the last decade has stripped it of meaning and purpose. The contradictory conceptions-utopian, apocalyptic, and universalist-and their attendant criticisms, pull at each other, producing a body of statements on art and the Anthropocene that signify everything and nothing at once. Each use of the term is now beset by contradiction and competition. Which Anthropocene do we mean, and whom does it serve?

Morton's concepts of ecomimesis and dark ecology are novel tools for interrogating the continued influence of Romantic thought and aesthetics in contemporary environmentalisms and artistic depictions of nature. But they cannot be used without conceding the uncorroborated, isolated logic of Morton's scholarship. When he asserts that Romantic fantasies of nature have impeded a proper relationship with nature, what does a this actually entail? Is it one where, in the dark ecological mode, we embrace the values of irony, contradiction, and grief? These are Morton's values, and they have little foundation outside of Morton's 
theories. In the realm of 'woozy, unsupported hypothesis', the promise of a 'proper relationship' rapidly loses authority. ${ }^{348}$

Morton's contributions also point to a contradiction at the centre of the aesthetic Anthropocene. The theory promises the resolution of the harmful, arbitrary classification of nature and humanity as separate entities by doing away with one half of this destructive binary. But by calling nature out-naming it, historicising it, giving it form-Morton and the Anthropocenists reaffirm its epistemological status as a unique, independent entity. Proclaiming to destroy something by defining its presence is a logical deception that fundamentally undermines the claims of the aesthetic Anthropocene.

The response to this criticism is that the posthumanist philosophical foundations of the theory resolve this contradiction. Nature is neither conjured into being, nor destroyed. Rather, it is only the suite of antiquated Romantic mythologies that face eradication. The real, essential, material, physical nonhuman remains intact. Even if we ignore the myriad criticisms that have been levelled against posthumanist thinking (including androcentrism, class privilege, and selective (mis)readings of Kant), the contradiction of the aesthetic Anthropocene remains unresolved. The Anthropocenists can call nature by whatever name they wish; it still remains nature. The binary is so deeply engrained in our languages that it cannot be wished away through a fresh vocabulary. The nonhuman is just another word for the same structure that was there before Romantic thought and will exist after. It is just another fantasy.

The binary of nature and culture is a destructive and inequitable fallacy. It manufactures a difference between humanity and nature when-as the microorganisms that call our bodies home would attest—there should be no logical separation. And, as with all binaries, it is underpinned by a logocentrism that privileges one half over the other-the human over the natural. Yet this separation exists because it is a part of our language, a part of our structures of thought. This is

\footnotetext{
${ }^{348}$ Jennifer Peterson, 'A Mutable Cloud: On "Dark Ecology” and "Confessions of a Recovering Environmentalist and Other Essays”,' Los Angeles Review of Books, accessed 27 October 2017, https://lareviewofbooks.org/article/a-mutable-cloud-on-dark-ecology-and-confessions-of-arecovering-environmentalist-and-other-essays/.
} 
the post-structuralist hurdle that posthumanisms will never be able to jump. Pretending to discontinue one half of the binary will only ever replicate its offences, calling the opposition back into being by another name. This renders the theory an essentially reductive, conservative folly. What good can art, a form of mediation tied up in the politics of representation, offer against such impossibility?

The flaws of the aesthetic Anthropocene are reflected in the final conclusion to be drawn about its reading into contemporary art. For all their assistance in helping to disrupt Romantic preoccupations and strip some of the anthropocentric hubris from our conceptions of the natural world, the works of Huyghe, Starling, and Clarke never come close to removing nature from art. No binary is collapsed, no dichotomy is resolved, no nonhuman is discovered beneath correlation. Ultimately, these works have little to say about nature, but everything about ourselves.

Walk alongside a pink-legged dog past an upturned oak. Smell damp earth and Brugmansia in bloom. See your face a fun-house distortion, reflected back to you in brilliant, radiant steel. Look upon a cloud of steam, and steam in the shape of a cloud. In the work of these three artists-practitioners of an ecologically conscious art-it is humanity that is the central subject, not nature. The Anthropos has been so successful as a species at replicating ourselves and our image that we are literally reflected in every facet of every environment we occupy. Everything in nature has been corrupted-for better or worse-by some aspect of our influence. The theory that evolved from the earth sciences, informed by Morton and posthumanism, gestures towards this influence without ever truly prioritising it, focusing instead on its own fantasy of the nonhuman. This theory juggles an old problem in a new way, but the issue remains in the air, unstable, with an unsustainable solution. The potential for an aesthetic Anthropocene may remain, but it would be one that looked first at humanity, rather than at its constructed other: nature. 


\section{Bibliography.}

Adams, Ansel, The Negative (1955; repr., Boston: Bullfinch Press, 1995).

Alinder, James, and John Szarkowski, Ansel Adams: Classic Images (Boston: Little, Brown and Company, 1984).

Alteever, Ian, 'Vestiges in the Rocks: Pierre Huyghe's Mineral Garden,' in Ian Alteever, Meredith Brown, and Sheena Wagstaff, Pierre Huyghe: The Roof Garden Commission (New York: Metropolitan Museum of Art, 2015), 11-21.

Ball, Christopher, 'And There Was Light: Sebastião Salgado's Genesis and (Ehtno)Primitivist Realism,' American Anthropologist 118, no. 3 (2016): 641-645, accessed 18 February 2018, doi: 10.1111/aman.12679.

Barikin, Amelia, Parallel Presents: The Art of Pierre Huyghe (Cambridge: MIT Press, 2012).

Barikin, Amelia, and Victoria Lynn, Pierre Huyghe (Victoria: TarraWarra Museum of Art, 2015).

Barrell, John, The Dark Side of the Landscape: The Rural Poor in English Painting 1730-1840 (Cambridge: Cambridge University Press, 1980),

Barthes, Roland, Camera Lucida: Reflections on Photography, trans. Richard Howard (London: Jonathan Cape, 1982).

Batchen, Geoffrey, Forget Me Not: Photography and Remembrance (New York: Princeton Architectural Press, 2006).

, 'Ordering Things,' in Brian Wallis (ed.), The Order of Things: Photography from the Walther Collection (Göttingen: Steidl Publishers, 2015).

Photography Degree Zero: Reflections on Roland Barthes's Camera Lucida

(Cambridge: MIT Press, 2009).

Baxandall, Michael, Painting and Experience in Fifteenth-Century Italy: A Primer in the Social History of Pictorial Style, second ed. (Oxford, New York: Oxford University Press, 1988).

Becher, Bernhard and Hilla, Anonyme Skulpturen: A Typology of Technical Constructions (Düsseldorf: Art-Press, 1970).

Best, Holly, 'Photographing Nature: The Slippery Topographics of Conor Clarke,' Art New Zealand (Winter 2018): 76-79.

Birnbaum, Daniel, 'Documenta 13,' Artforum, accessed 10 September 2017, https://www.artforum.com/print/reviews/201208/documenta-13-34514.

Blasdel, Alex, '“A Reckoning for Our Species”: The Philosopher Prophet of the Anthropocene,' the Guardian, accessed 19 July 2017, https://www.theguardian.com/world/2017/jun/15/timothy-morton-anthropocenephilosopher. 
Boetzkes, Amanda, 'Ecologicity, Vision, and the Neurological System,' in Davis and Turpin, Art in the Anthropocene, 271-282.

Burke, Edmund, A Philosophical Enquiry into the Sublime and Beautiful, rev. ed. with introduction and notes by James. T. Boulton (London, New York: Routledge Classics, 2008).

Burns, Ric (dir.), Ansel Adams: A Documentary Film (Boston: PBS, 2002).

Carducci, Vince, 'Ecocriticism, Ecomimesis, and the Romantic Roots of Modern Ethical Consumption,' Literature Compass 6, no. 3 (2009): 632-646.

Carrington, Damian, “"Extraordinary” Levels of Pollutants Found in 10km Deep Mariana Trench,' the Guardian, accessed 10 March 2017, https://www.theguardian.com/environment/2017/feb/13/extraordinary-levels-of-toxicpollution-found-in-10km-deep-mariana-trench.

Chakrabarty, Dipesh, 'The Climate of History: Four Theses', Critical Inquiry 35, no. 2 (2009): 197-222, accessed 15 July 2017, http://www.jstor.org/stable/10.1086/596640.

Clark, Kenneth, Landscape into Art, 1949, rev. ed. (London: John Murray, 1976).

Clarke, Conor, 'The Attempt to Convey Sublime Experience,' Art News New Zealand (Autumn 2016): 86-89.

Clarke, Conor, 'In Pursuit of the Object, At a Proper Distance,' accessed 27 February 2018, https://www.conorvonclarks.com/in-pursuit-of-the-object.

Clarke, Conor, 'Scenic Potential', accessed 27 February 2018, https://www.conorvonclarks.com/scenic-potential.

Clayre, Alasdair, (ed), Nature \& Industrialization (Oxford: Oxford University Press, 1977).

Cole, Andrew, 'Those Obscure Objects of Desire: Andrew Cole on the Uses and Abuses of Object-Oriented Ontology and Speculative Realism,' Artforum International 53, no. 10 (2015): 319-323.

Coole, Diana, 'From Within the Midst of Things: New Sensibility, New Alchemy, and the Renewal of Critical Theory.' In Cox, Jaskey, and Malik, Realism, Materialism, Art, 2015, 41-46.

Cox, Christoph, Jenny Jaskey, and Suhail Malik (eds), Realism, Materialism, Art (New York: Sternberg Press, 2015).

Crutzen, Paul 'Geology of Mankind,' Nature 415 (2002): 23, accessed 23 April 2017, http://www.nature.com/nature/journal/v415/n6867/full/41523a.html?foxtrotcallback=true.

Crutzen, Paul, and Eugene Stoermer, 'The “Anthropocene",' Global Change Newsletter 41 (May 2000): 17, accessed 23 April 2017, http://www.igbp.net/download/18.316f18321323470177580001401/1376383088452/NL4.pdf.

Cull, Chloe, 'Conor Clarke at Two Rooms,' Eye Contact, accessed 27 February 2018, http://eyecontactsite.com/2015/05/conor-clarke-at-two-rooms. 
Davies, Jeremy, The Birth of the Anthropocene (Berkeley: University of California Press, 2016).

Davis, Heather, and Etienne Turpin (eds), Art in the Anthropocene: Encounters Among Aesthetics, Politics, Environments and Epistemologies, (London: Open Humanities Press, 2015).

'Art \& Death: Lives Between the Fifth Assessment \& the Sixth Extinction', in Davis and Turpin, Art in the Anthropocene, 2015, 3-30.

De Duve, Thierry, 'Bernd and Hilla Becher or Monumentary Photography,' in Gabriele Shor (ed.), Held Together With Water: Art from the Sammlung Verbund (Ostfildern: Hatje Cantz, 2007).

Derrida, Jacques, The Truth in Painting, trans. Geoff Bennington and Ian McLeod (Chicago and London: University of Chicago Press, 1987).

Deutches Museum, 'Welcome to the Anthropocene: The Earth in Our Hands,' accessed 27 April 2017, http://www.deutsches-museum.de/en/exhibitions/specialexhibitions/archive/2015/anthropocene.

Dick, Terrence, 'Simon Starling,' Border Crossings 27, no. 3 (2008): 183-185.

French, Elisia, 'Sights of Desire; Sites of Demise The Environment in the Works of Edward Burtynsky and Olafur Eliasson,' Master's Thesis (Ontario, Queen's University: ProQuest Dissertations Publishing, 2012), accessed 27 February 2018, https://search.proquest.com/docview/1513232111.

Foreman, Dave, Rewilding North America: A Bold, Hopeful Vision for Conservation in the $21^{\text {st }}$ Century (Washington: Island Press, 2004).

Garza, Mariel, 'There's a Garbage Patch at the Bottom of the Ocean. Is There No Place We Won't Trash?' the Los Angeles Times, accessed 10 March 2017, http://www.latimes.com/opinion/opinion-la/la-oe-spam-pollution-mariana-trench20170213-story.html.

Gibson, James J., The Ecological Approach to Visual Perception (New York: Taylor \& Francis Group, 1979).

Giraud, Fabien, and Ida Soulard, 'The Marfa Stratum: Contribution to a Theory of Sites,' in Davis and Turpin, Art in the Anthropocene, 2015, 167-180.

Glacken, Clarence J., Traces on the Rhodian Shore: Nature and Culture in Western Thought from Ancient Times to the End of the Eighteenth Century (Berkeley, Los Angeles, London: University of California Press, 1967).

Glasmeier, Michael, and Karin Stengel, 50 Years Documenta, 1955-2005 (Göttingen: Steidl, 2005).

Godfrey, Mark, 'Prints, Particles, Palaces, and Planets: Simon Starling and Photography,' in Roelstraete, Metamorphology, 2014, 111-127. 
Gombrich, E. H., Art and Illusion: A Study in the Psychology of Pictorial Representation, 4th ed. (London: Phaidon, 1972).

Gombrich, E. H., The Image and the Eye: Further Studies in the Psychology of Pictorial Perception (Oxford: Phaidon Press, 1982).

Grindon, Gavin, Victoria and Albert Museum, 'Art and Activism in the Age of the Anthropocene,' accessed 27 April 2017, https://www.vam.ac.uk/blog/disobedientobjects/art-and-activism-in-the-age-of-the-anthropocene.

Hantelmann, Dorothea von, 'Thinking the Arrival: Pierre Huyghe's Untilled and the Ontology of the Exhibition,' On Curating 33 (June 2017): 89-96.

Harman, Graham, The Quadruple Object (Alresford: Zero Books, 2011).

Harraway, Donna, Staying with the Trouble: Making Kin in the Chthulucene (Durham: Duke University Press, 2016).

, in conversation with Martha Kenney, 'Anthropocene, Capitalocene,

Chthulucene,' in Davis and Turpin, Art in the Anthropocene, 2015, 255-270.

The Invisible Committee, To Our Friends (Los Angeles: Semiotext(e), 2015).

Kjærulff, Aslak Aamot, and David Hilmer Rex, 'Organizing in the Anthropocene,' The Distance Plan 2 (2014): 29-38.

Kirby, Vicki, Quantum Anthropologies: Life at Large (Durham and London: Duke University Press, 2011).

Koolhaas, Rem, 'Junkspace,' October 100 (Spring 2002): 175-90, accessed 21 January 2018, http://www.jstor.org/stable/779098.

Knezic, Sophie, 'Pierre Huyghe: Tarrawarra Museum of Art,' Artlink, accessed 17 January 2018, https://www.artlink.com.au/articles/4419/pierre-huyghe.

Kruse, Jamie, and Elizabeth Ellsworth, 'Design Specs in the Anthropocene: Imagining the Force of 30,000 Years of Geologic Change,' in Davis and Turpin, Art in the Anthropocene, 2015, 155-156.

Kruse, Jamie, and Elizabeth Ellsworth (eds), Making the Geologic Now: Responses to Material Conditions of Contemporary Life (New York: Punctum Books, 2012).

Lavigne, Emma (ed.), Pierre Huyghe (Paris: Centre Pompidou, 2013-14).

Ladyman, James, 'Things Aren't What They Used to Be: On the Immateriality of Matter and the Reality of Relations,' in Cox, Jaskey, and Malik, Realism, Materialism, Art, 35-40.

Latour, Bruno, in conversation with Heather Davis, 'Diplomacy in the Face of Gaia,' in Davis and Turpin, Art in the Anthropocene, 2015, 43-56.

Lemke, Thomas, 'Materialism Without Matter: The Recurrence of Subjectivism in ObjectOriented Ontology,' Distinktion: Journal of Social Theory 18, no. 2 (2017): 133-152. 
Leonard, Robert, 'Please Explain,' in Max Delay and Patrice Sharkey (eds), In Speculum (Melbourne, Brisbane, Wellington: Monash University Museum of Art, Institute of Modern Art, City Gallery Wellington Te Whare Toi, 2013-2014), 23-52.

LeWitt, Sol, 'Sentences on Conceptual Art,' 0 to 95 (January 1969): 4.

Lotringer, Sylvère, in conversation with Heather Davis and Etienne Turpin, 'The Last Political Scene,' in Davis and Turpin, Art in the Anthropocene, 2015, 371-378.

Malm, Andreas, and Alf Hornborg, 'The Geology of Mankind? A Critique of the Anthropocene Narrative,' The Anthropocene Review 1, no. 1 (2014): 62-69 , accessed 15 July 2017, http://journals.sagepub.com/doi/abs/10.1177/2053019613516291.

Manacorda, Franceso, 'Interview,' in Roelstraete, Harbord, and Manacorda, Simon Starling, 2012, 7-39.

Marsh, George Perkins, Man and Nature: Or, Physical Geography as Modified by Human Actions, 1864. Facsimile of first edition, ed. David Lowenthal (Cambridge: Harvard University Press, 1965).

Masters, H. G., 'Documenta 13,' ArtAsiaPacific 80 (September-October 2012): 128-129.

McAvoy, Emil, '“Ground Water Mirror” - An Interview With Conor Clarke, 2018,' Photoforum, accessed 27 February 2018, https://www.photoforum-nz.org/blog/2018/3/18/ground-watermirror-an-interview-with-conor-clarke.

Meillassoux, Quentin, After Finitude: An Essay on the Necessity of Contingency, trans. Ray Brassier (London: Continuum, 2008).

Mileaf, Janine, Please Touch: Dada and Surrealist Objects after the Readymade (Hanover: Dartmouth College Press, 2010).

Miller, Angela, The Empire of the Eye: Landscape Representation and American Cultural Politics, 1825-1875 (Ithaca and London: Cornell University Press, 1993).

Mirzoeff, Nicholas, How to See the World (London: Pelican Books, 2015).

Mitchell, W. J. T., 'Imperial Landscape,' in Mitchell (ed.), Landscape and Power (Chicago and London: Chicago University Press, 1994), 5-34.

Moi, Toril, Sexual/Textual Politics (London: Methuen, 1985).

Morton, Timothy, Dark Ecology: For a Logic of Future Coexistence (New York: Columbia University Press, 2016).

The Ecological Thought (Cambridge: Harvard University Press, 2010).

Ecology Without Nature: Rethinking Environmental Aesthetics (Cambridge:

Harvard University Press, 2007).

Humankind: Solidarity with Nonhuman People (New York: Verso, 2017). 
Hyperobjects: Philosophy and Ecology after the End of the World

(Minneapolis: University of Minnesota Press, 2013)

New York Museum of Modern Art, 'Pierre Huyghe's Recently Acquired Sculpture Untilled [Liegender Frauenakt] Will be Presented in Moma's Sculpture Garden This Summer,' accessed 17 January 2018, https://www.moma.org/documents/moma_press-

release_389297.pdf.

Novak, Barbara, Nature and Culture: American Landscape and Painting 1825-1875 (London: Thames and Hudson, 1980).

Park, Geoff, Theatre Country: Essays on Landscape \& Whenua, ed. Geoff Park (Wellington: Victoria University Press, 2006).

Pereira, Henrique M., and Laetitia M. Navarro, Rewilding European Landscapes (Cham: Springer International Publishing, 2015).

Peterson, Jennifer, 'A Mutable Cloud: On "Dark Ecology" and "Confessions of a Recovering Environmentalist and Other Essays",' Los Angeles Review of Books, accessed 27 October 2017, https://lareviewofbooks.org/article/a-mutable-cloud-on-dark-ecology-and-confessions-ofa-recovering-environmentalist-and-other-essays/.

Pilkington, A. E., '“Nature” as Ethical Norm in the Enlightenment,' in Ludmilla Jordanova (ed.), Languages of Nature: Critical Essays on Science and Literature (London: Free Association Books, 1986) 51-85.

Rafael, Marie-France, Pierre Huyghe: On Site (Cologne: Verlag der Buchhandlung Walther König, 2013).

Roelstraete, Dieter, 'Metamorphology,' in Roelstraete (ed.), Simon Starling: Metamorphology (Chicago: Museum of Contemporary Art Chicago, 2014), 13-23.

, 'Survey,' in Roelstraete, Janet Harbord, and Francesco Manacorda, Simon Starling (London, New York: Phaidon Press, 2012), 41-87.

Salgado, Sebastião, Genesis (Cologne: Taschen, 2013).

Phaidon Press, 1993).

Workers: An Archaeology of the Industrial Age (London, New York:

Saunders, Wade, and Anne Rochette, 'Pierre Huyghe,' Art in America, accessed 16 January 2018, https://www.artinamericamagazine.com/reviews/pierre-huyghe.

Schama, Simon, Landscape and Memory (London: Harper Collins, 1995).

Scranton, Roy, Learning How to Die in the Anthropocene: Reflections on the End of a Civilization (San Francisco: City Light Books, 2015).

Shiller, Jakob, 'Smokestack Photos Make Pollution Look Strangely Beautiful,' Wired, accessed 27 February 2018, https://www.wired.com/2015/03/conor-clarke-smokestacks. 
Shinichiro, Asayama, 'Ambivalent Climate of Opinions: Tensions and Dilemmas in Understanding Geoengineering Experimentation,' Geoforum 80 (2017): 82-92, accessed 17 July 2017, https://doi.org/10.1016/j.geoforum.2017.01.012.

Sloterdijk, Peter, 'The Anthropocene: A Process-State at the Edge of Geohistory?' trans. AnnaSophie Springer in Davis and Turpin, Art in the Anthropocene, 2015, 327-340.

Smailbegović, Ada, 'Cloud Writing: Describing Soft Architectures of Change in the Anthropocene,' in in Davis and Turpin, Art in the Anthropocene, 93-108.

Smithson, Robert, 'A Sedimentation of the Mind: Earth Projects,' in Petra Lange-Berndt (ed.), Materiality (London: Whitechapel Gallery, and Cambridge: MIT Press, 2015), 149-152.

Sontag, Susan, 'In Plato's Cave,' in Sontag, On Photography (New York: Farrar, Straus, and Giroux, 1977), 3-26.

Suter Art Gallery Te Aratoi o Whakatū, 'Who's Watching: Omelette Country Icon V; Geoff PARK; 1977; 655,' accessed 4 September 2017, http://www.nzmuseums.co.nz/account/3001/object/586205.

Szarkowski, John, The Portfolios of Ansel Adams (Boston:Little, Brown and Company).

Thoreau, Henry David, 'Walking,' the Atlantic, accessed 12 September 2017, https://www.theatlantic.com/magazine/archive/1862/06/walking/304674.

Turpin, Etienne, and Valeria Federighi, 'A New Element, A New Force, A New Input: Antonio Stoppani's Anthropozoic,' in Kruse and Ellsworth, Making the Geologic Now, 34-41.

Tyrrell, Toby, On Gaia: A Critical Investigation of the Relationship Between Life and Earth (Princeton: Princeton University Press, 2013).

Yoshikawa, Saeko, William Wordsworth and the Invention of Tourism, 1820-1900 (Burlington: Ashgate, 2014). 


\section{List of Illustrations.}

fig. 1 A can of SPAM in the Mariana Trench. Photograph: US National Oceanic and Atmospheric Association Office of Ocean Exploration, 2016

fig. 2 Geoff Park, Who's Watching: Omelette Country Icon V, 1977 (Nelson: Suter Art Gallery Te Aratoi o Whakatū)

fig. 3 Thomas Cole, Destruction, 1836 (New York: New York Historical Society) fig. 4 Thomas Cole, Desolation, 1836 (New York: New York Historical Society) fig. 5 Thomas Cole, View from Mount Holyoke, Northampton, Massachusetts, after a Thunderstorm-The Oxbow, 1836 (New York: Metropolitan Museum of Art)

fig. 6 Ansel Adams, Clearing Winter Storm, Yosemite National Park, 1944 (New York: Museum of Modern Art)

fig. 7 Pierre Huyghe, Recollection (Zoodram 4 after 'Sleeping Muse' by Constantin Brancusi), 2011. Installation view, Pierre Huyghe, Centre Pompidou, 2013

fig. 8 Pierre Huyghe, Untitled (Human Mask) (still), 2014, 19:00 min

fig. 9 Pierre Huyghe, Untilled, 2011-12. Installation view, dOCUMENTA (13), Kassel, 2012

fig. 10 Pierre Huyghe, Untilled, 2011-12. Installation view, dOCUMENTA (13), Kassel, 2012

fig. 11 Pierre Huyghe, Untilled, 2011-12. Plan, dOCUMENTA (13), Kassel, 2012

fig. 12 Pierre Huyghe, Untilled, 2011-12. Installation view, dOCUMENTA (13), Kassel, 2012

fig. 13 Pierre Huyghe, Untilled, 2011-12. Installation view, dOCUMENTA (13), Kassel, 2012

fig. 14 Simon Starling, Infestation Piece (Musselled Moore) 2006-08 (Toronto:

The Power Plant). Installation view, The Power Plant, Toronto, 2008

fig. 15 Simon Starling, Project for a Masquerade (Hiroshima), 2011 (Hiroshima:

Hiroshima City Museum of Contemporary Art). Installation view, Hiroshima City Museum of Contemporary Art, 2011

fig. 16 Simon Starling, The Long Ton, 2009. Installation view, Neugerriemschneider, Berlin, 2009

fig. 17 Sebastião Salgado, The Gold Mine, Brazil, 1986 (London: Tate Modern)

fig. 18 Michael Snow, Authorization, 1969 (Ottawa: National Gallery of Canada)

fig. 19 Simon Starling, Silver Salts, Platinum Salts, 2008 (Cologne: Ludwig Museum). Detail

fig. 20 Simon Starling, The Nanjing Particles (After Henry Ward, View of C.T.

Sampson's Shoe Manufactory, with the Chinese Shoemakers in working costume, North Adams and vicinity, circa 1875), 2008. Installation view, Massachusetts Museum of Contemporary Art, North Adams, 2008.

fig. 21 Simon Starling, The Nanjing Particles (After Henry Ward, View of C.T. Sampson's Shoe Manufactory, with the Chinese Shoemakers in working costume, North Adams and vicinity, circa 1875), 2008. Installation view, Massachusetts Museum of Contemporary Art, North Adams, 2008.

fig. 22 Simon Starling, One Ton II (Five handmade platinum/palladium prints of the Anglo American Platinum Corporation mine at Potgietersrus, South Africa, produced using as many platinum group metal salts as can be derived from one ton of ore), 2005 
(Vancouver: Rennie Museum). Installation view, Centro de Arte Contemporáneo de Málaga, 2010

fig. 23 Simon Starling, One Ton II (Five handmade platinum/palladium prints of the Anglo American Platinum Corporation mine at Potgietersrus, South Africa, produced using as many platinum group metal salts as can be derived from one ton of ore), 2005 (Vancouver: Rennie Museum). Detail

fig. 24 Edward Burtynsky, Nickel Tailings \#34, 1996 (Cleveland: Cleveland Museum of Art)

fig. 25 Bernhard and Hilla Becher, Winding Towers, 1966-97 (New York:

Museum of Modern Art)

fig. 26 Conor Clarke, Schkopau, Saalekreis, Sachsen-Anhalt, 2013 (Auckland: Two Rooms)

fig. 27 Conor Clarke, Duisburg-Hamborn, Nordrhein-Westfalen, 2014 (Auckland: Two Rooms)

fig. 28 Conor Clarke, In Pursuit of the Object, at a Proper Distance, 2012-14.

Installation view, Outer Space, Two Rooms, Auckland, 2014

fig. 29 Conor Clarke, Peak III, Berlin, 2015 (Auckland: Two Rooms)

fig. 30 Conor Clarke, Peak I, Berlin, 2014 (Auckland: Two Rooms)

fig. 31 Conor Clarke, Peak II, Berlin, 2015 (Auckland: Two Rooms)

fig. 32 Conor Clarke, Landscape I, Berlin, 2014 (Auckland: Two Rooms)

fig. 33 Conor Clarke, Scenic Potential, 2014-15. Installation view, Scenic Potential, Two Rooms, Auckland, 2015

fig. 34 Edward Weston, Dunes, Oceano, 1936 (New York: Metropolitan Museum of Art) 


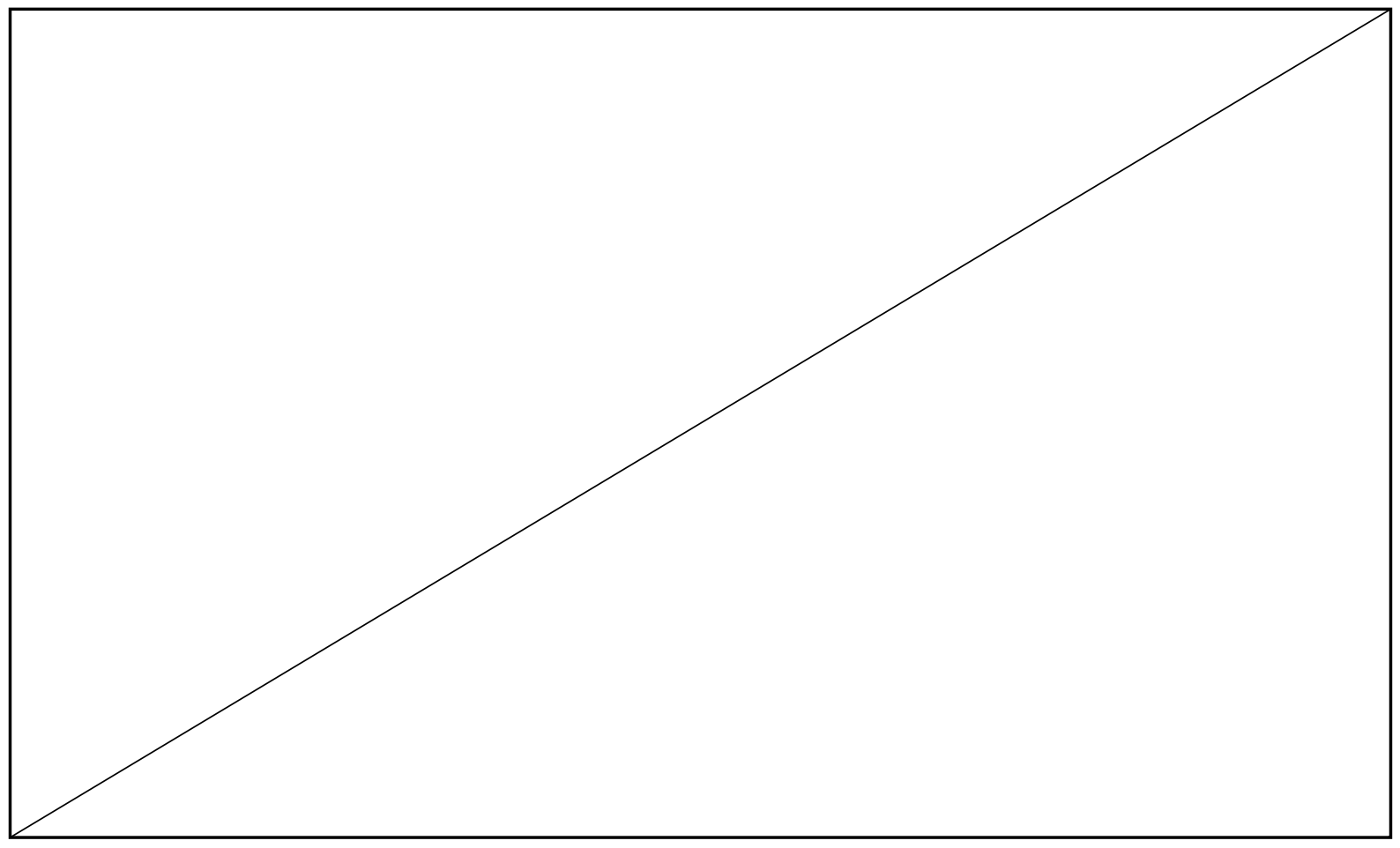

fig. 1 A can of SPAM in the Mariana Trench. Photograph: US National Oceanic and Atmospheric Association Office of Ocean Exploration, 2016 


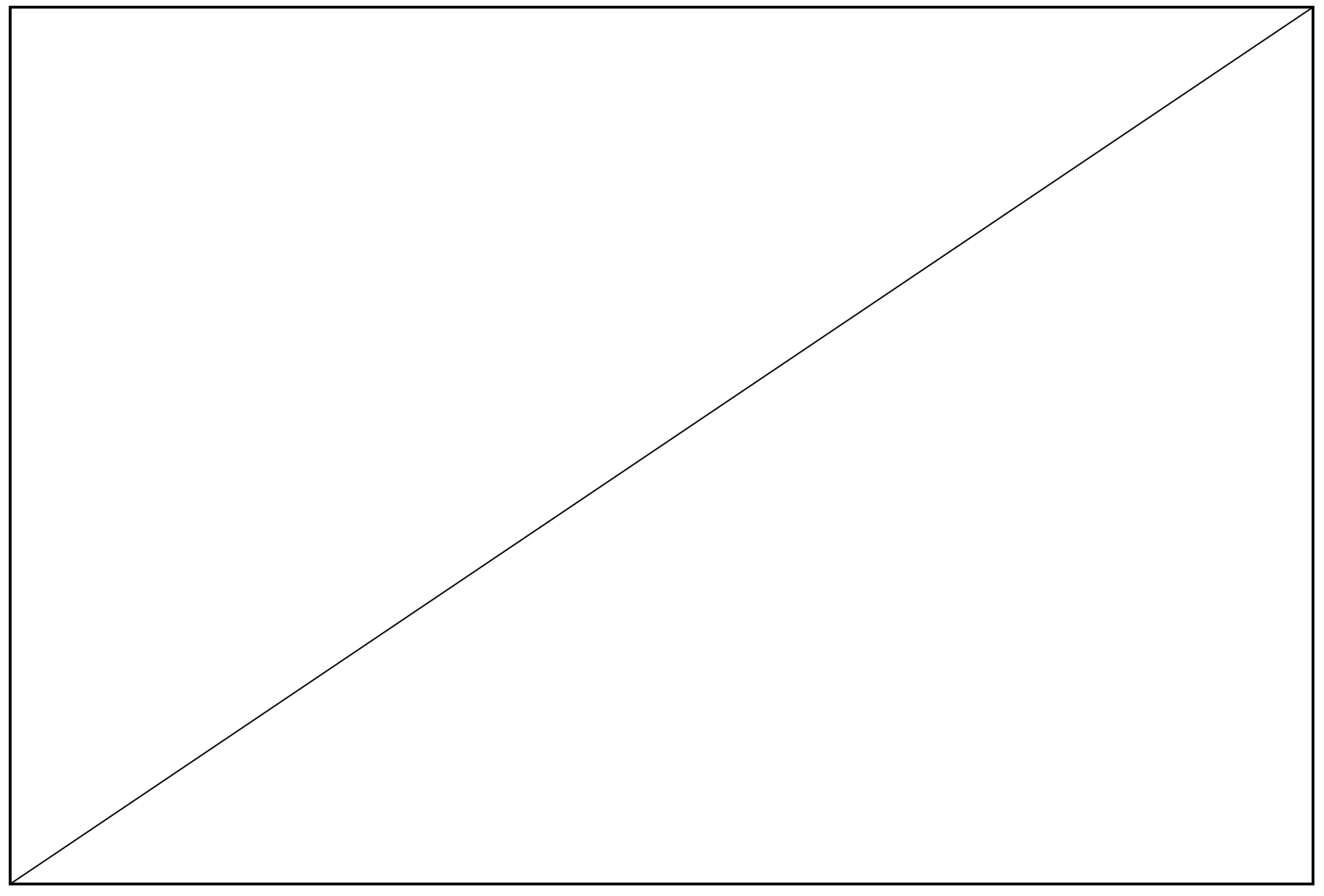

fig. 2 Geoff Park, Who's Watching: Omelette Country Icon V, 1977 (Nelson: Suter Art Gallery Te Aratoi o Whakatū) 


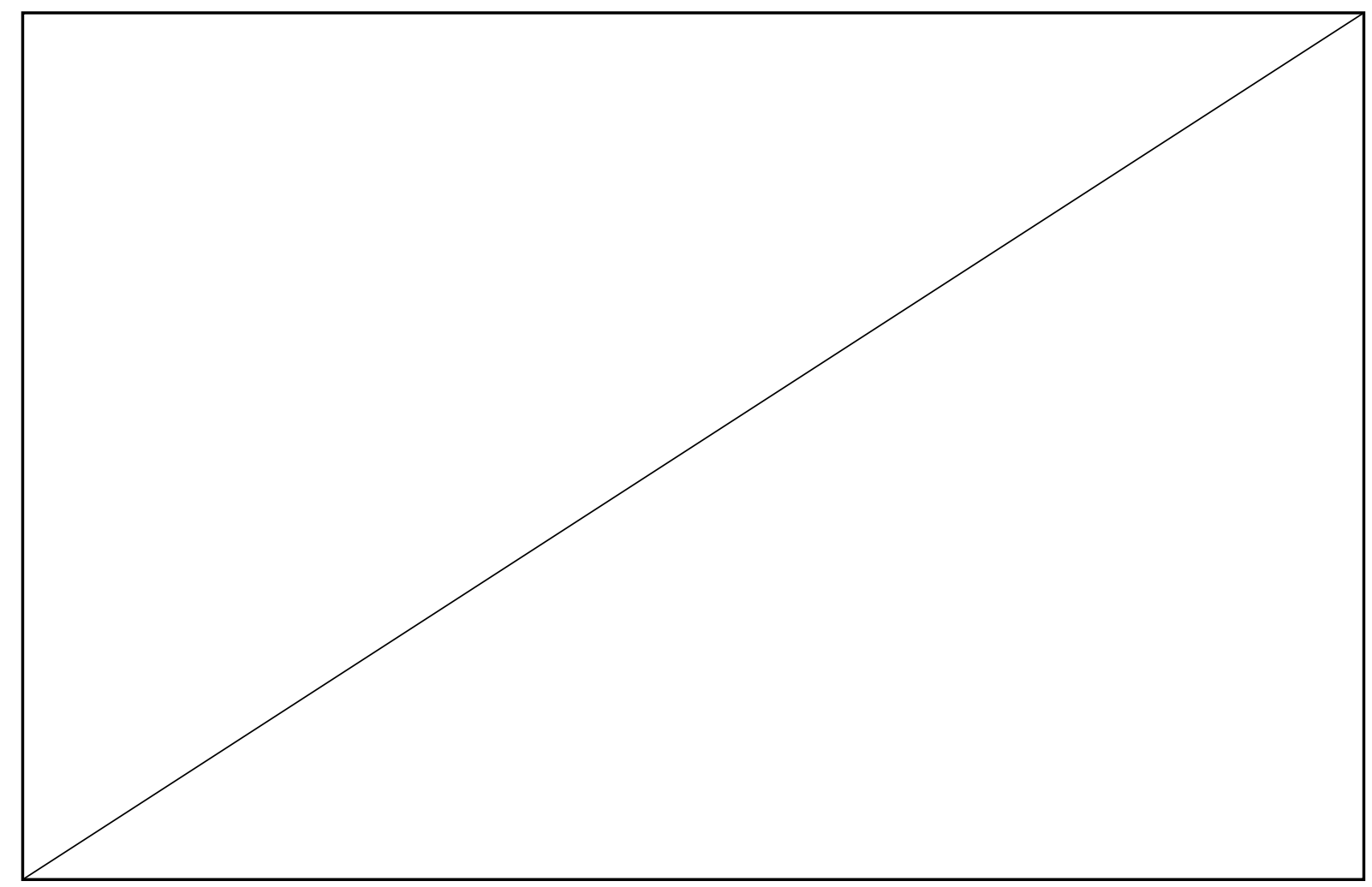

fig. 3 Thomas Cole, Destruction, 1836 (New York: New York Historical Society) 


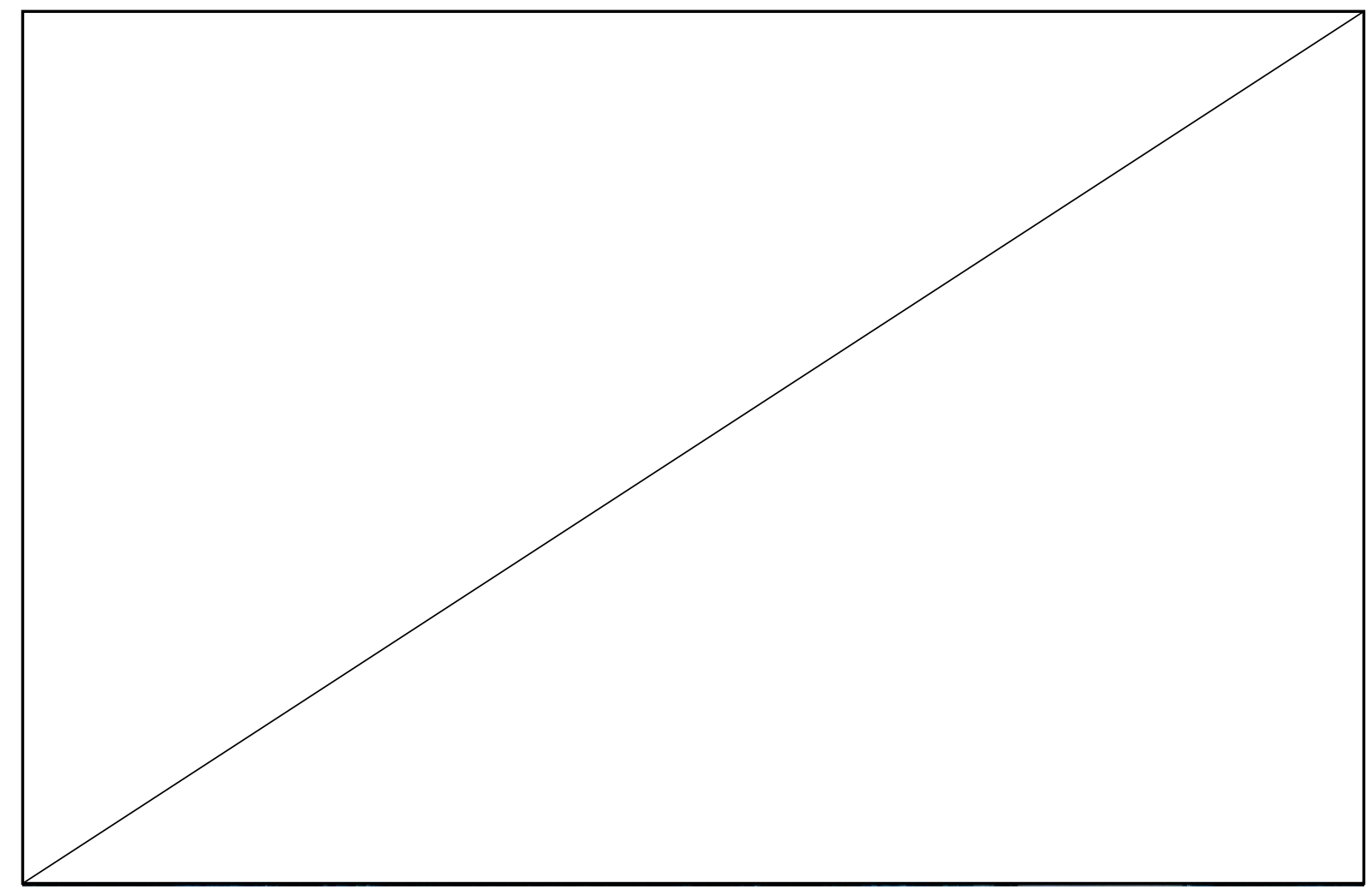

fig. 4 Thomas Cole, Desolation, 1836 (New York: New York Historical Society) 


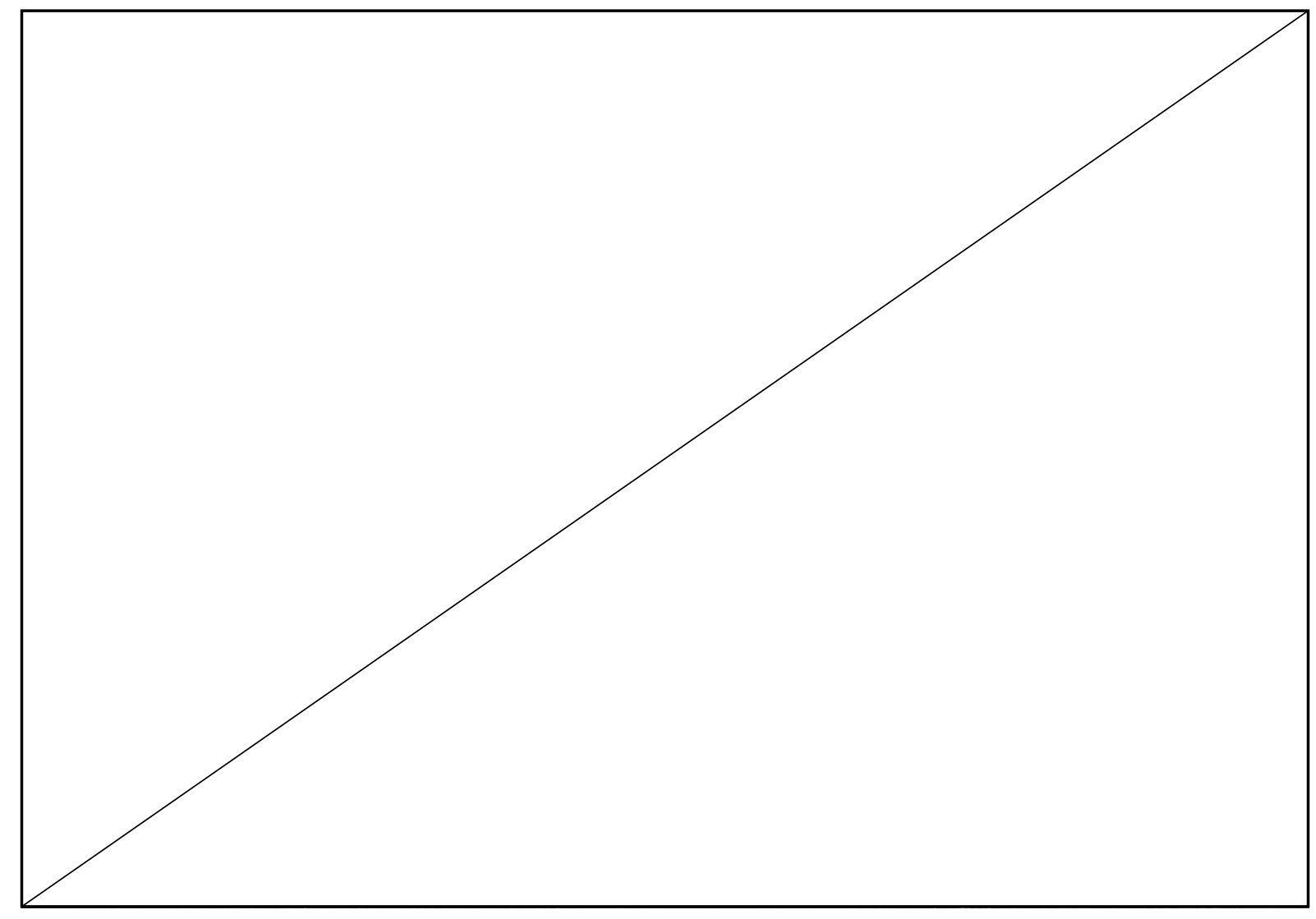

fig. 5 Thomas Cole, View from Mount Holyoke, Northampton, Massachusetts, after a Thunderstorm-The Oxbow, 1836 (New York: Metropolitan Museum of Art) 


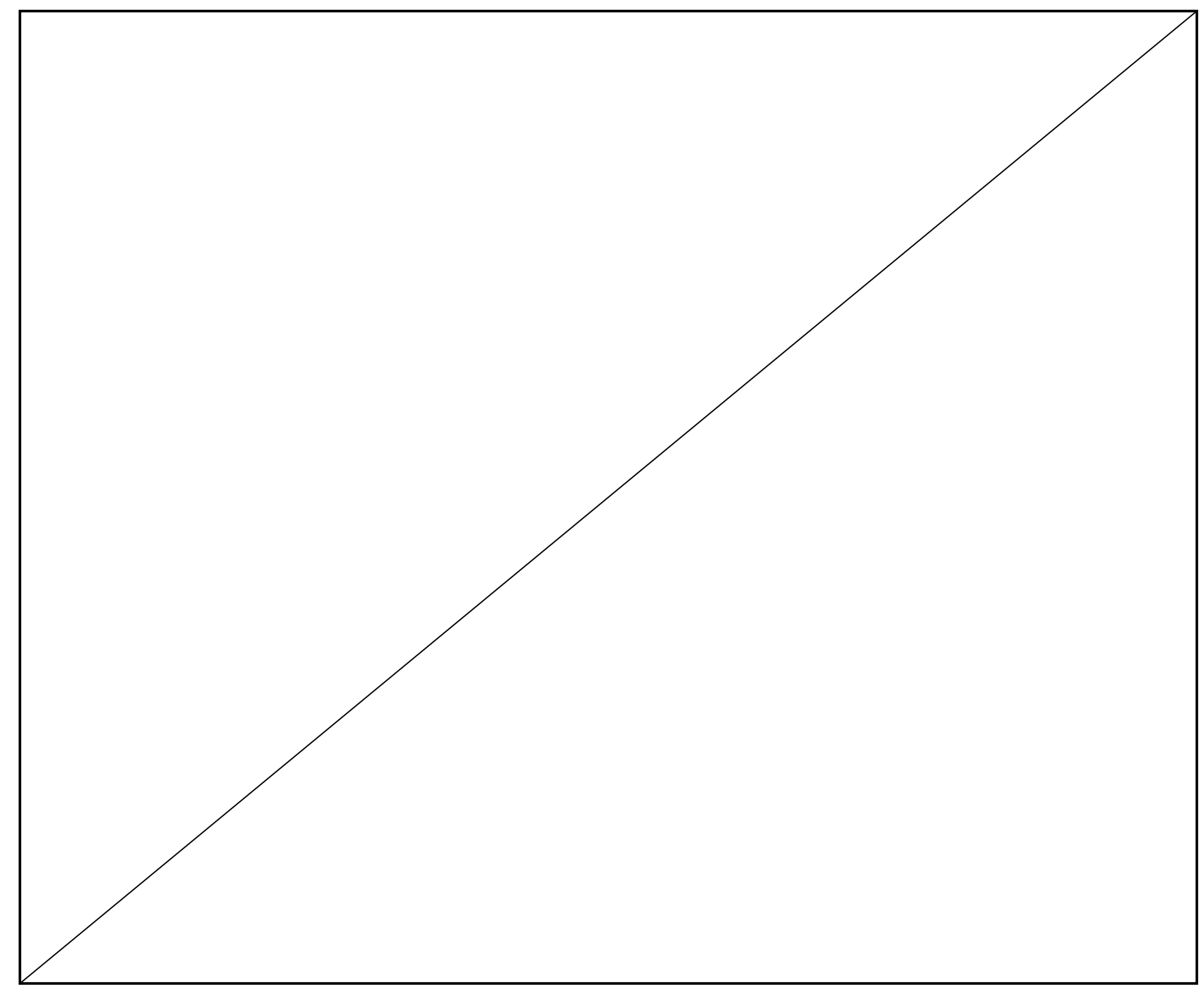

fig. 6 Ansel Adams, Clearing Winter Storm, Yosemite National Park, 1944 (New York: Museum of Modern Art) 


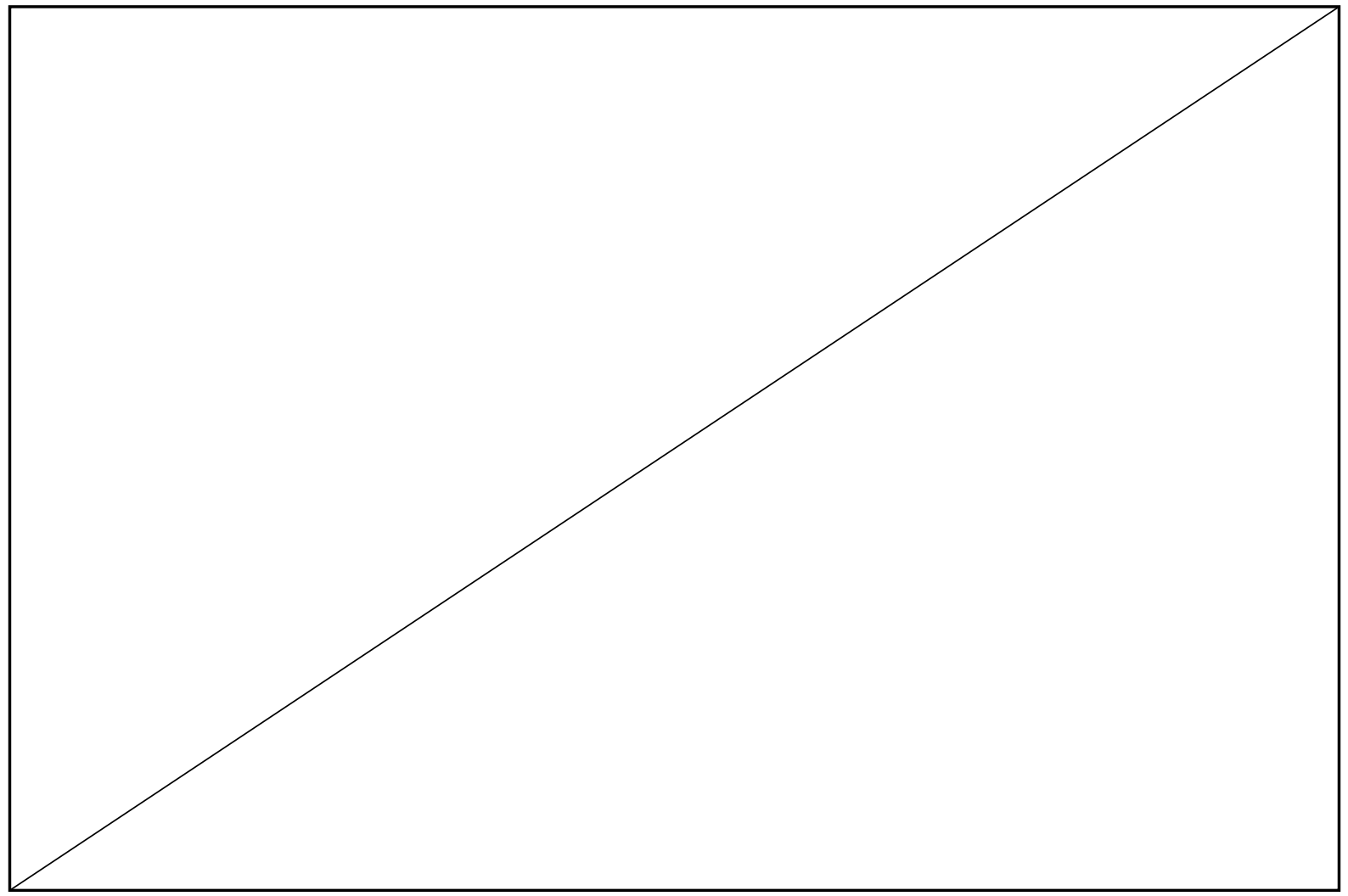

fig. 7 Pierre Huyghe, Recollection (Zoodram 4 after 'Sleeping Muse' by Constantin Brancusi), 2011. Installation view, Pierre Huyghe, Centre Pompidou, 2013 


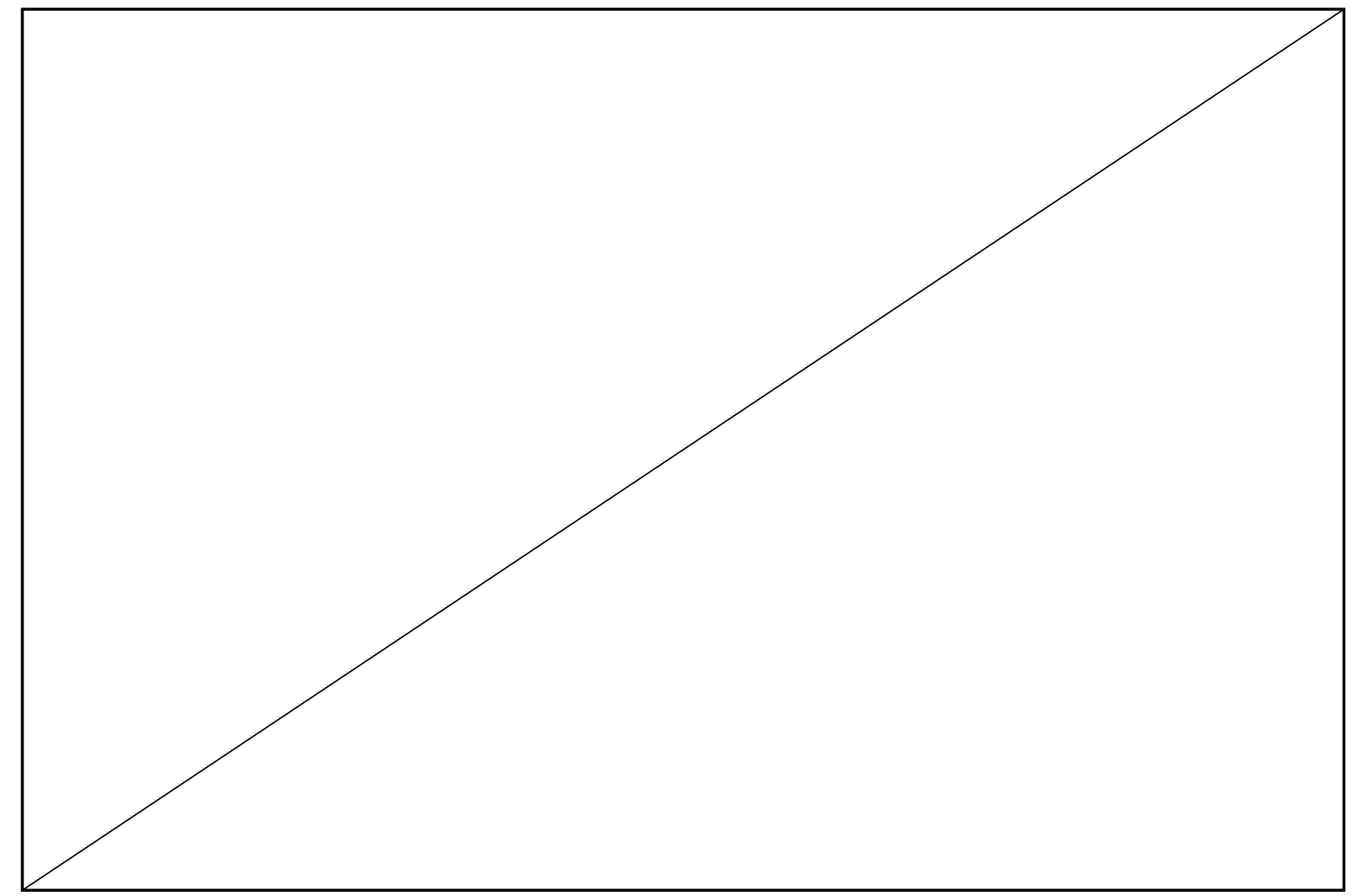

fig. 8 Pierre Huyghe, Untitled (Human Mask) (still), 2014, 19:00 min 


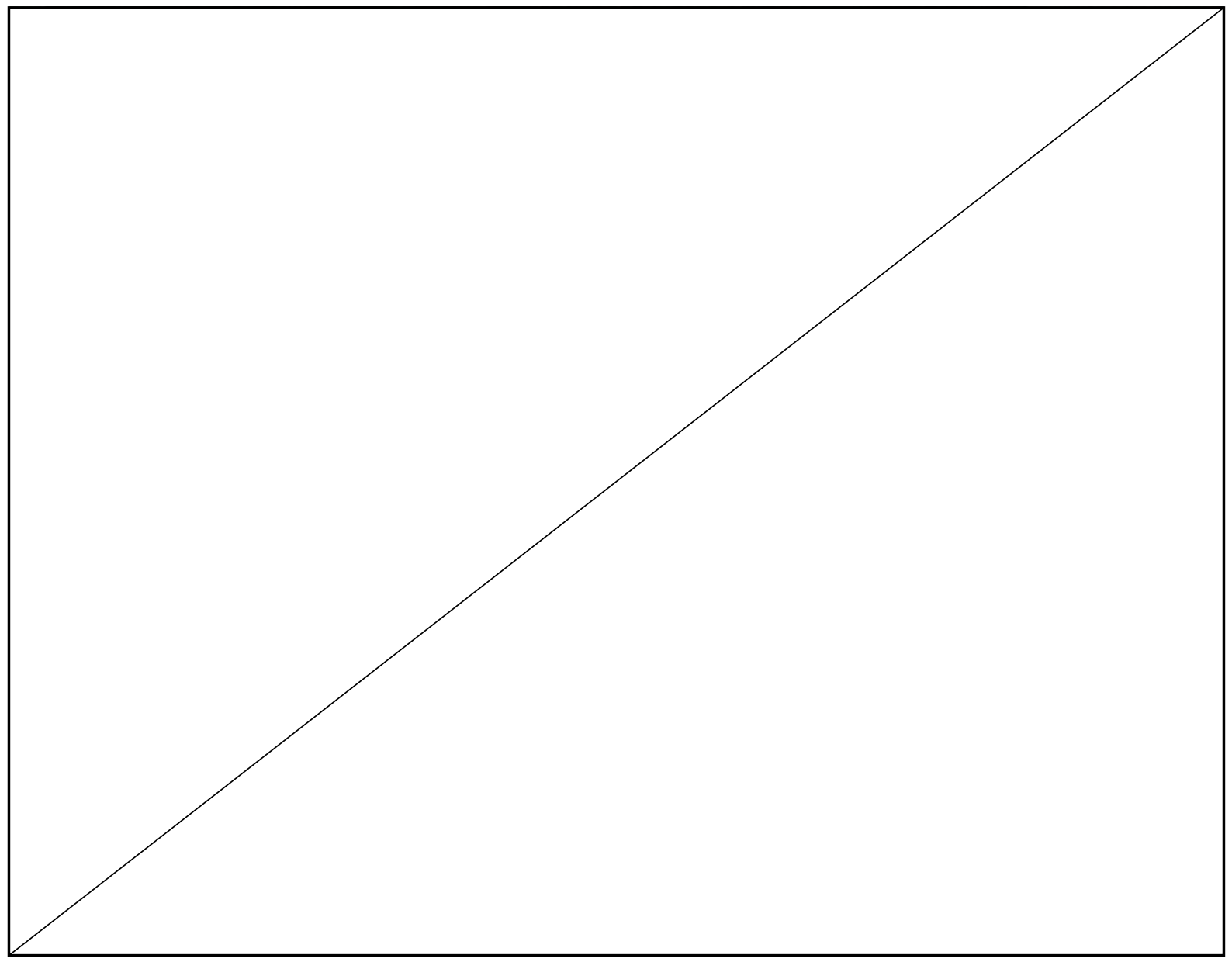

fig. 9 Pierre Huyghe, Untilled, 2011-12. Installation view, dOCUMENTA (13), Kassel, 2012 


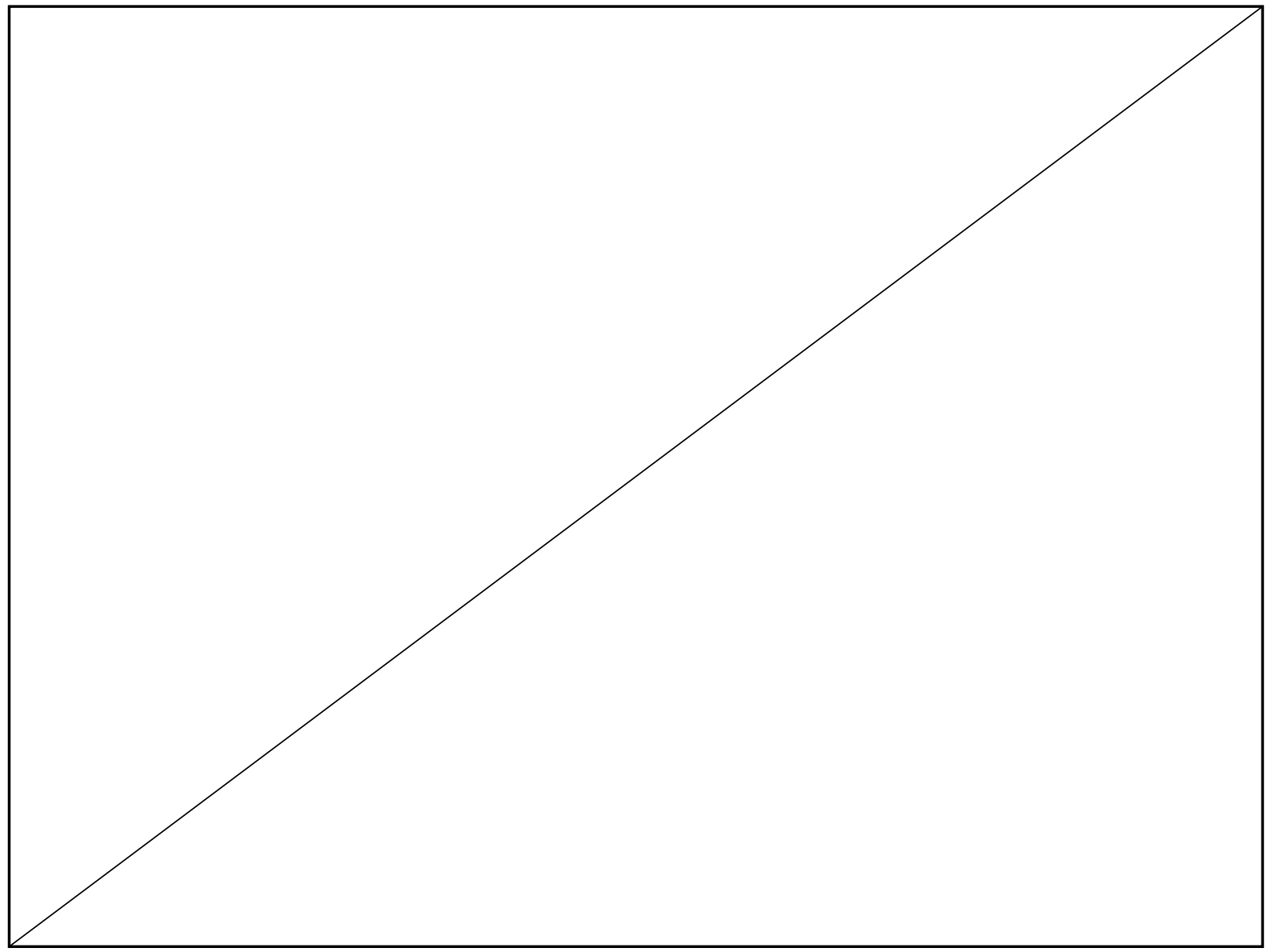

fig. 10 Pierre Huyghe, Untilled, 2011-12. Installation view, dOCUMENTA (13), Kassel, 2012 


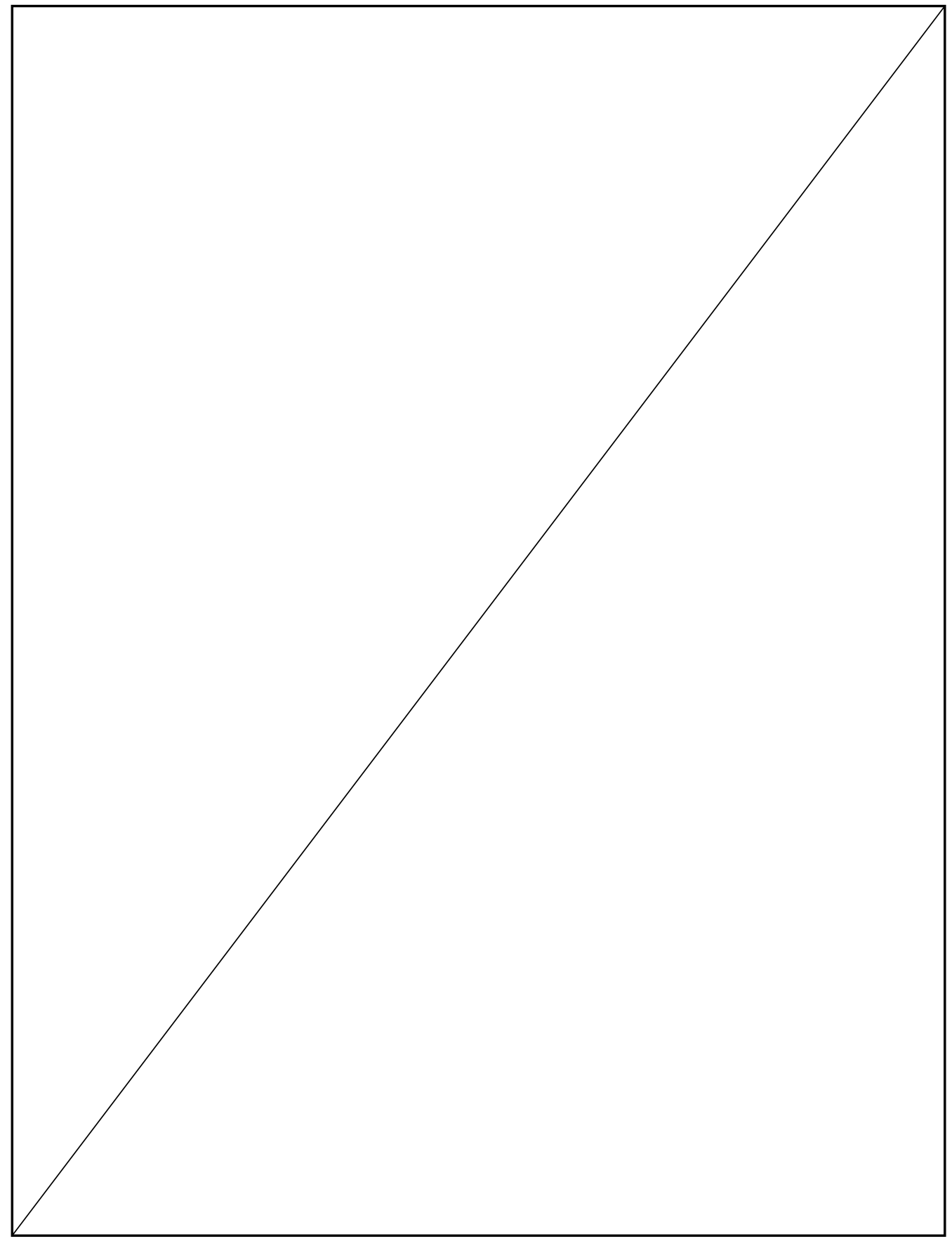

fig. 11 Pierre Huyghe, Untilled, 2011-12. Plan, dOCUMENTA (13), Kassel, 2012 


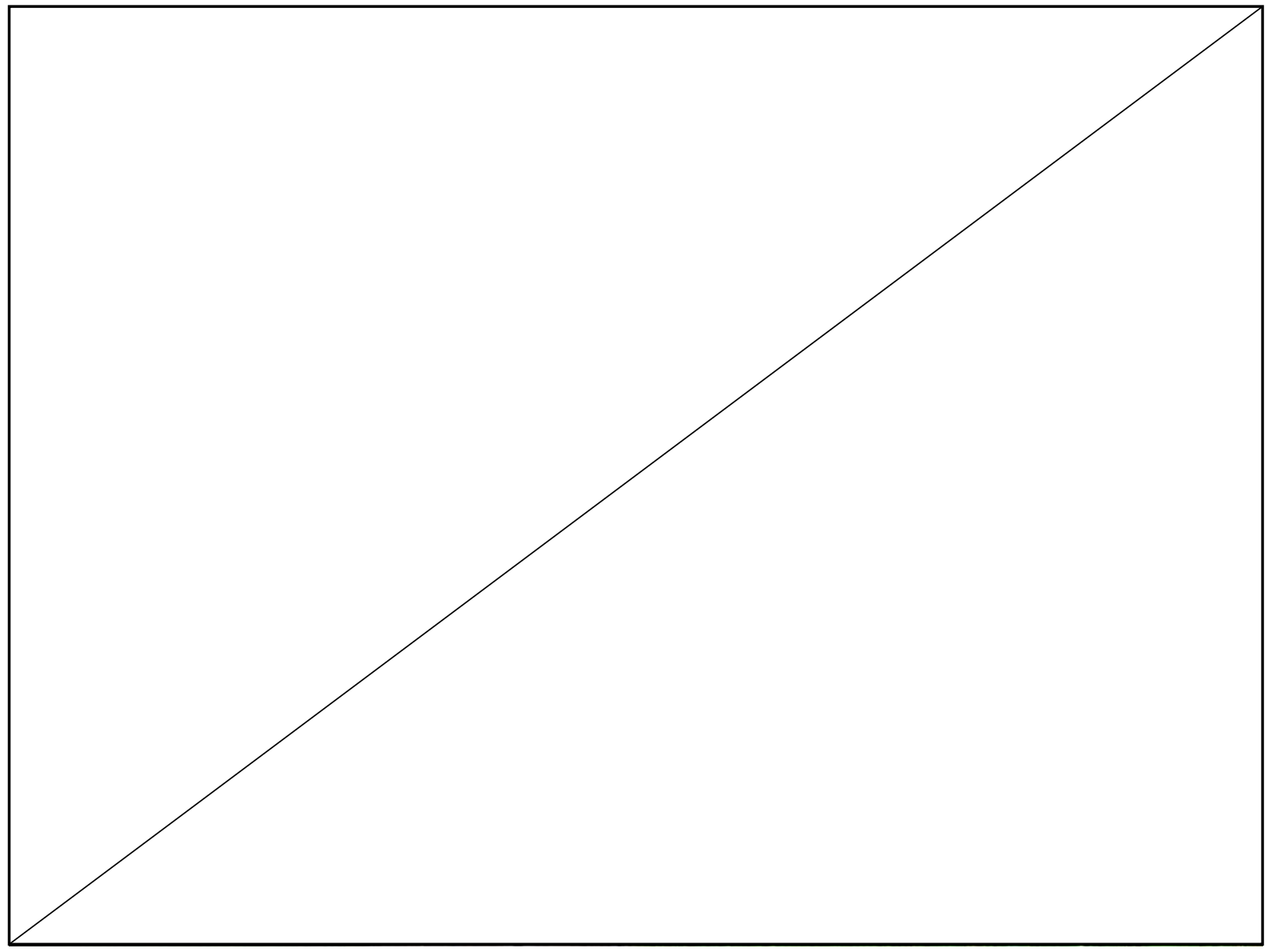

fig. 12 Pierre Huyghe, Untilled, 2011-12. Installation view, dOCUMENTA (13), Kassel, 2012 


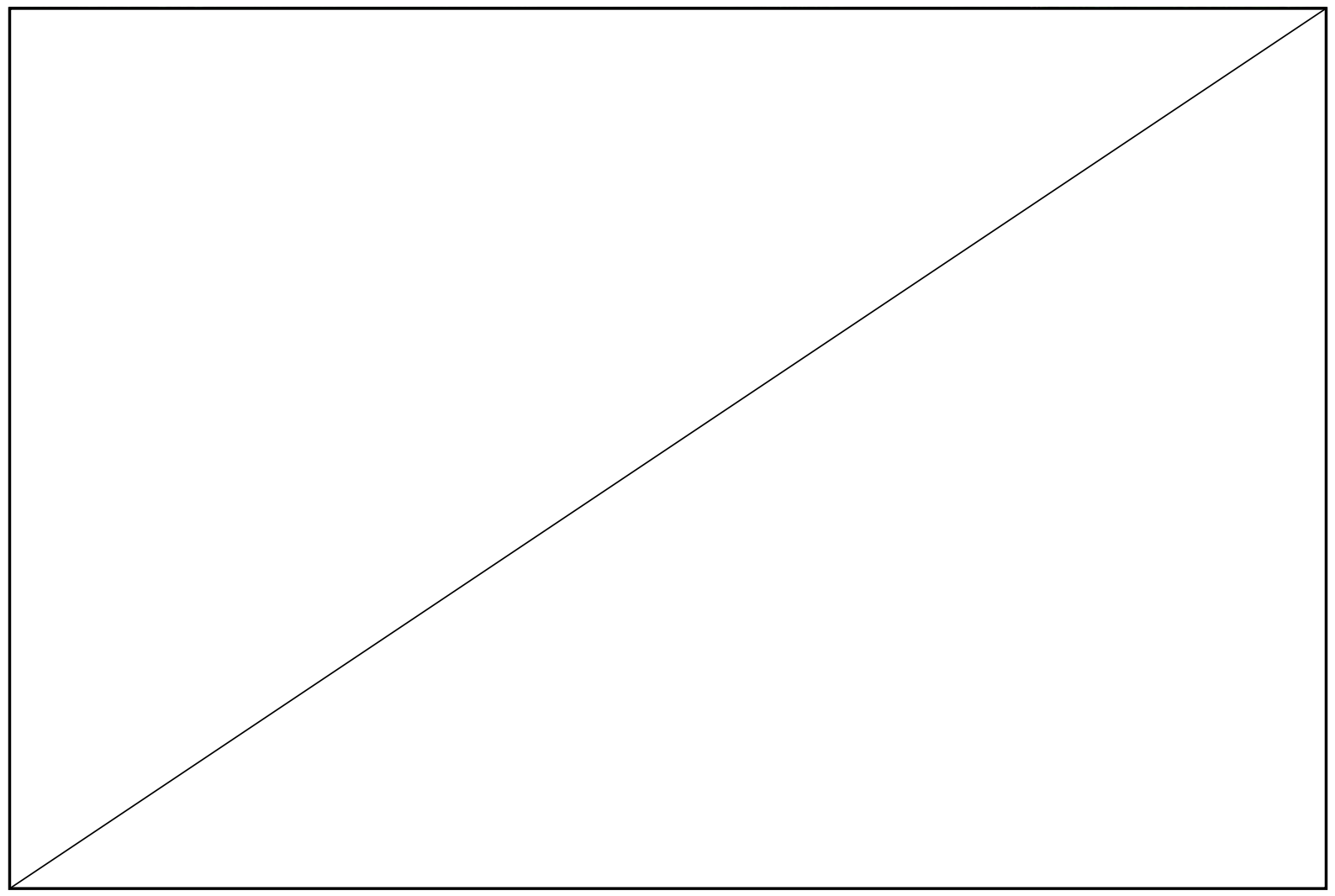

fig. 13 Pierre Huyghe, Untilled, 2011-12. Installation view, dOCUMENTA (13), Kassel, 2012 


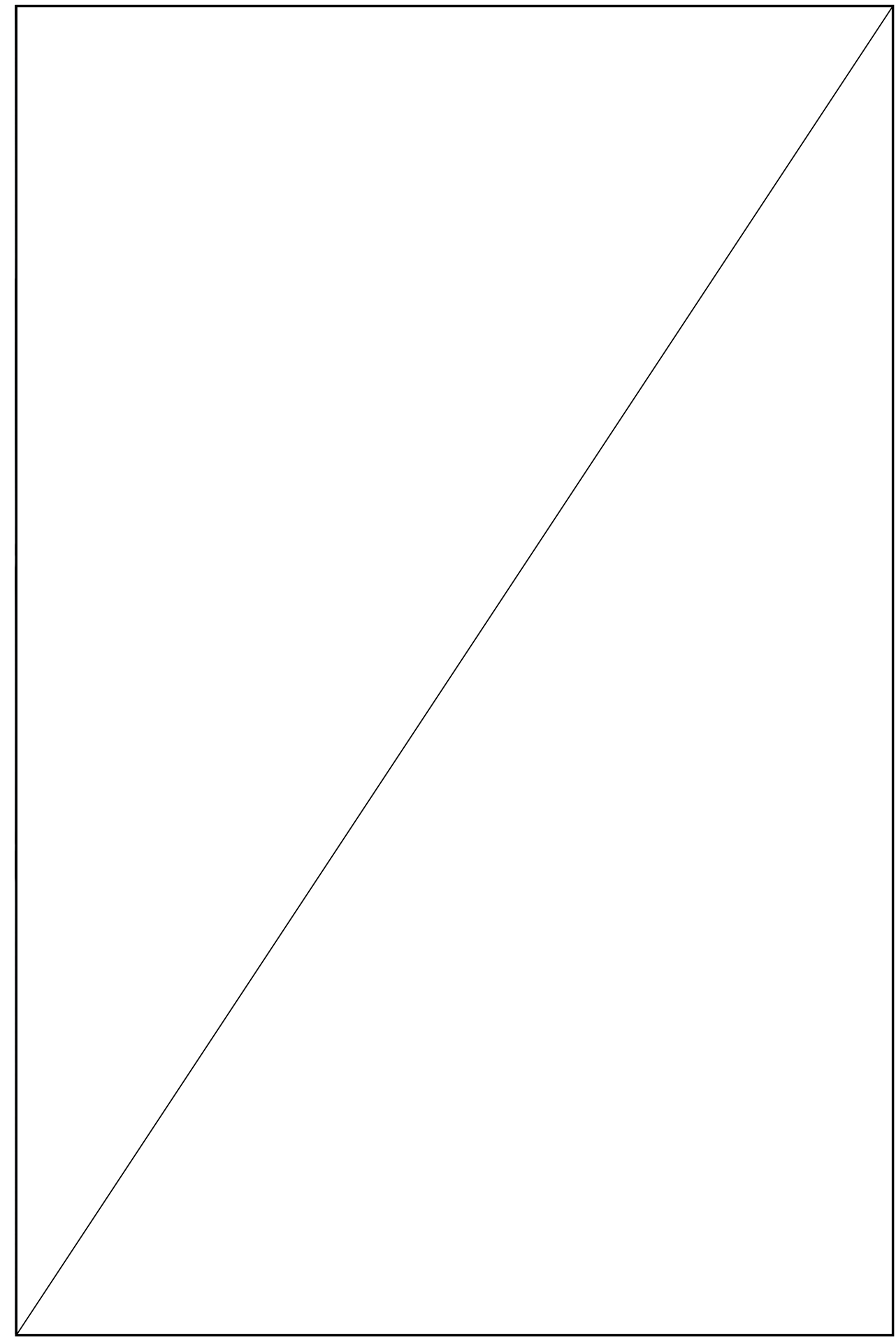

fig. 14 Simon Starling, Infestation Piece (Musselled Moore) 2006-08 (Toronto: The Power Plant). Installation view, The Power Plant, Toronto, 2008 


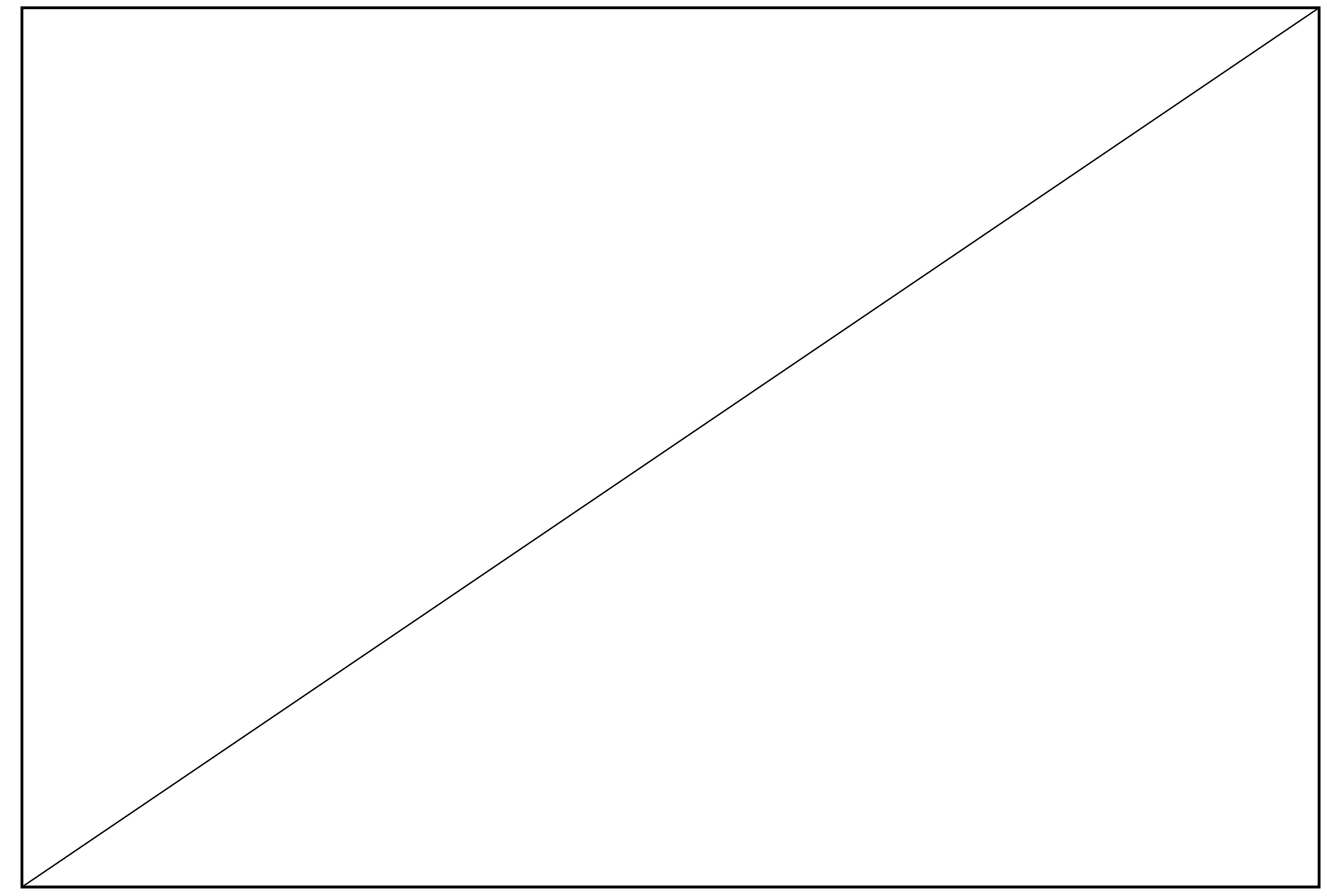

fig. 15 Simon Starling, Project for a Masquerade (Hiroshima), 2011 (Hiroshima: Hiroshima City Museum of Contemporary Art). Installation view, Hiroshima City Museum of Contemporary Art, 2011 


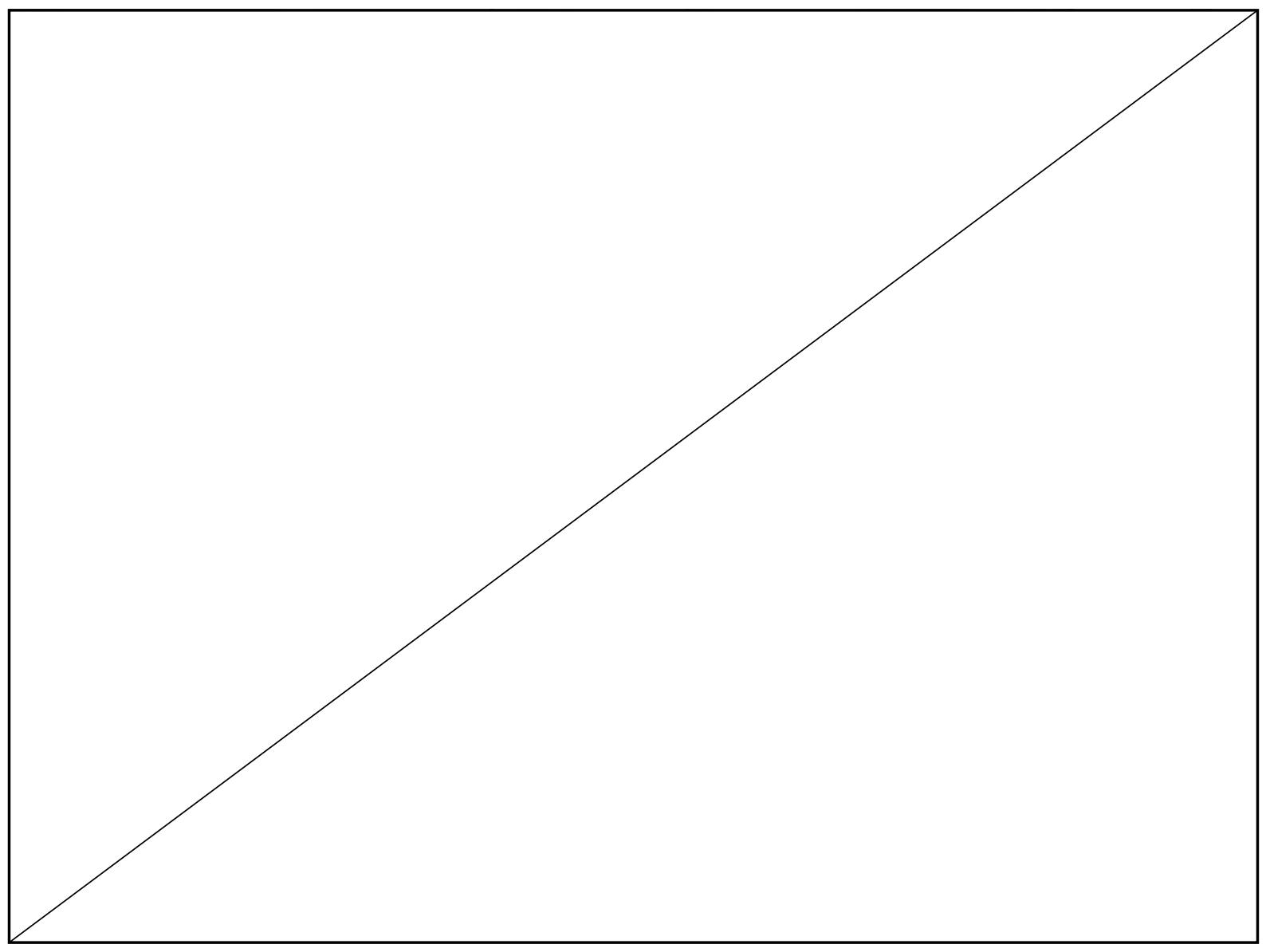

fig. 16 Simon Starling, The Long Ton, 2009. Installation view, Neugerriemschneider, Berlin, 2009 


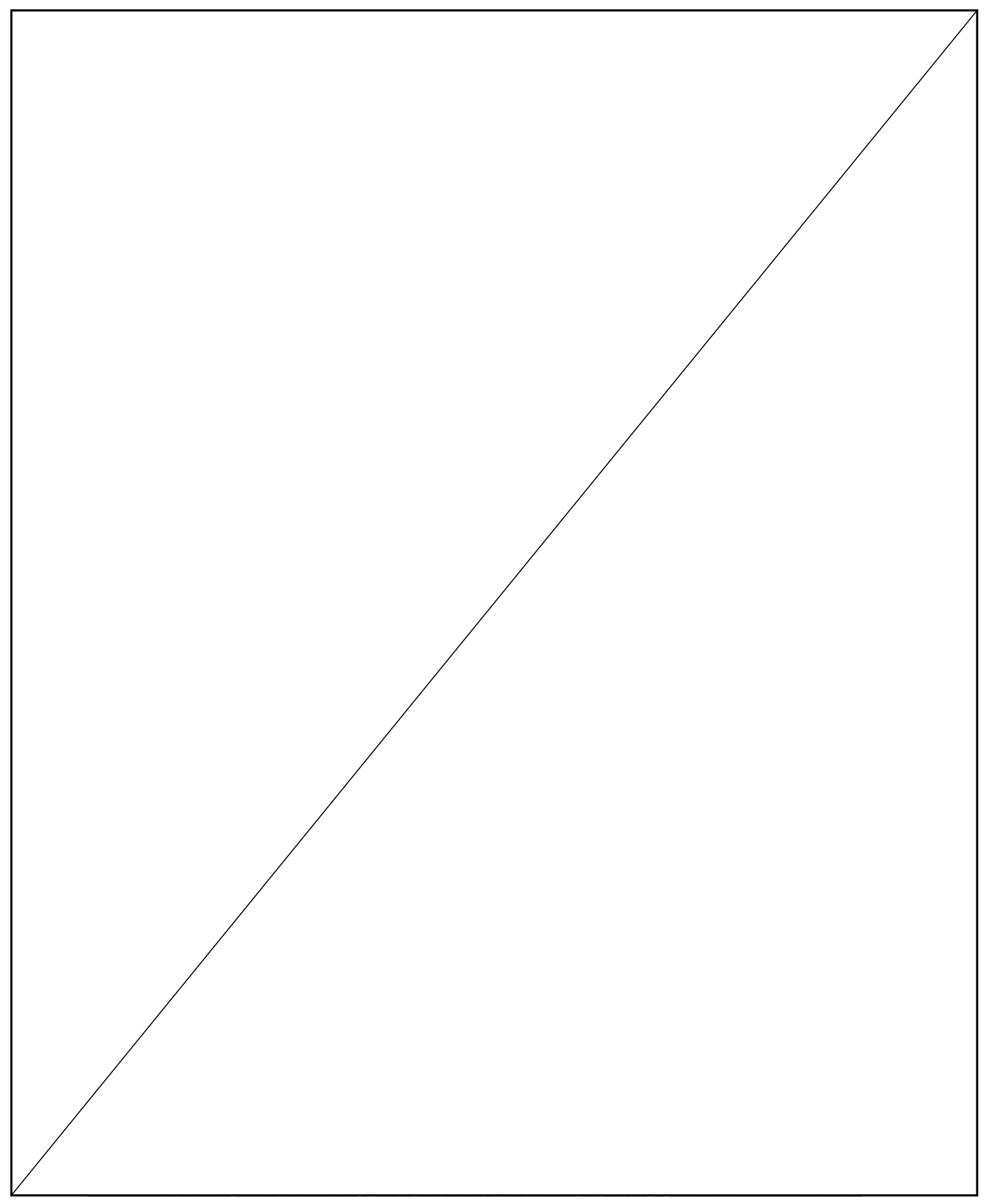

fig. 17 Sebastião Salgado, The Gold Mine, Brazil, 1986 (London: Tate Modern) 


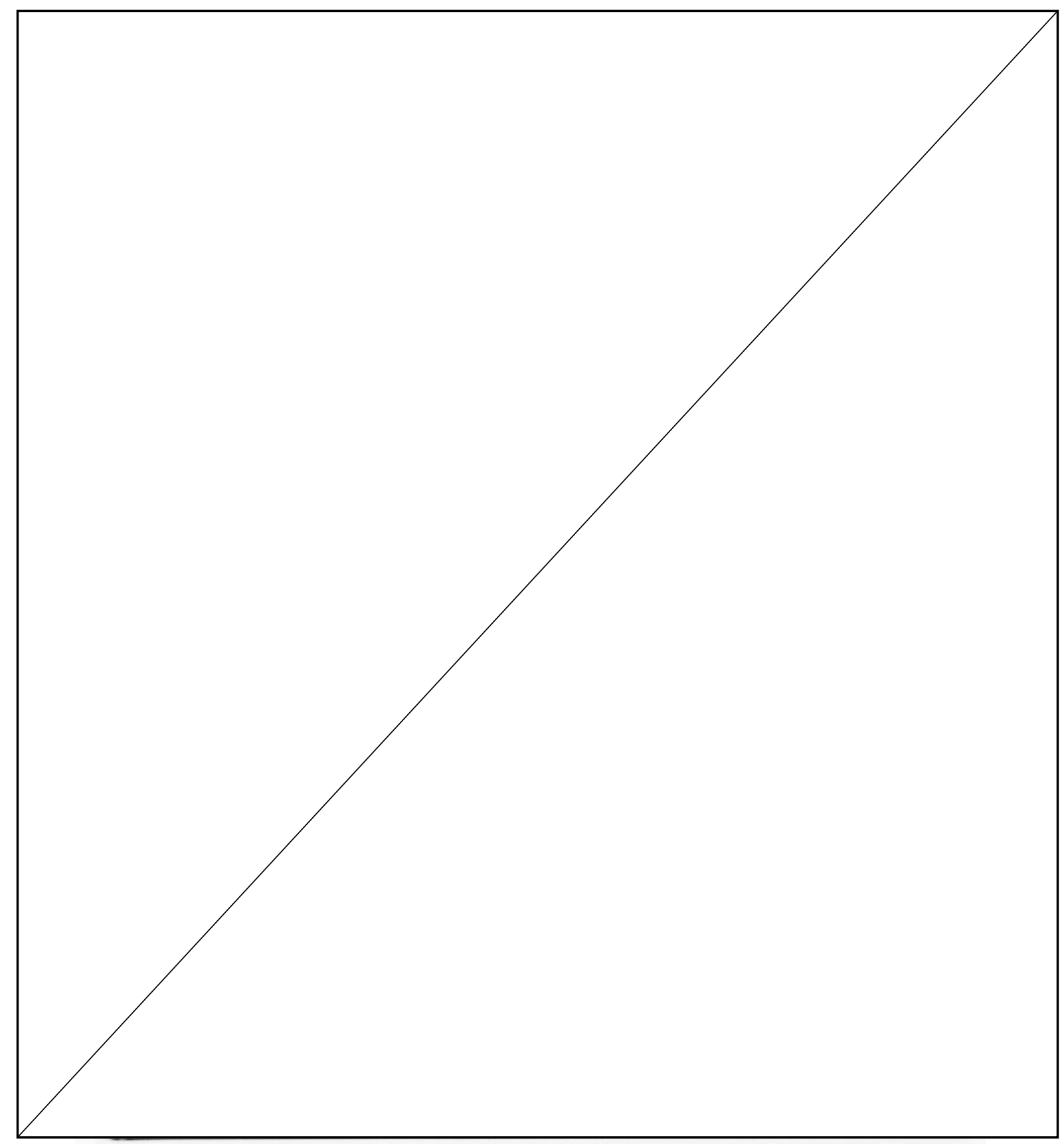

fig. 18 Michael Snow, Authorization, 1969 (Ottawa: National Gallery of Canada) 


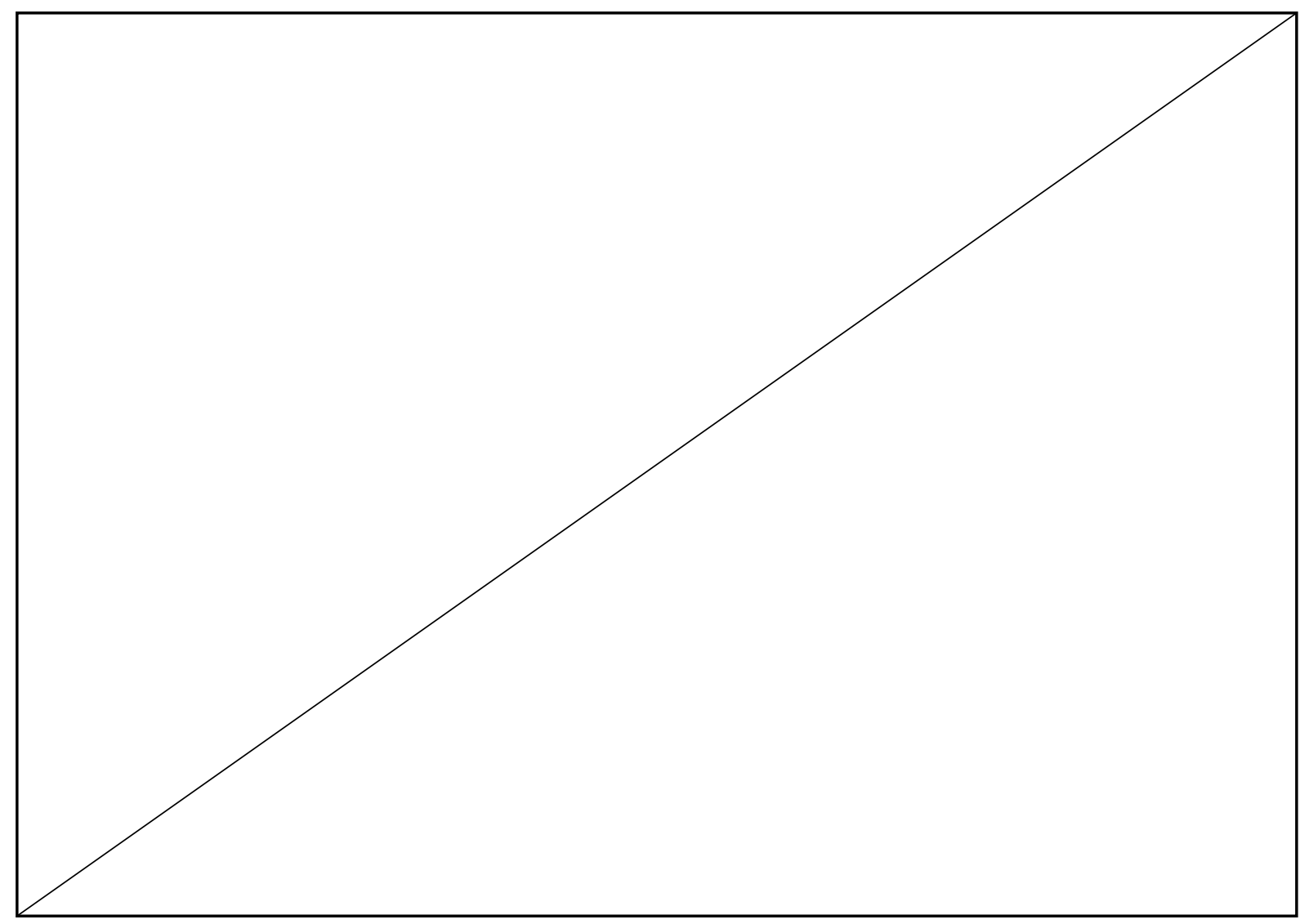

fig. 19 Simon Starling, Silver Salts, Platinum Salts, 2008 (Cologne: Ludwig Museum). Detail 


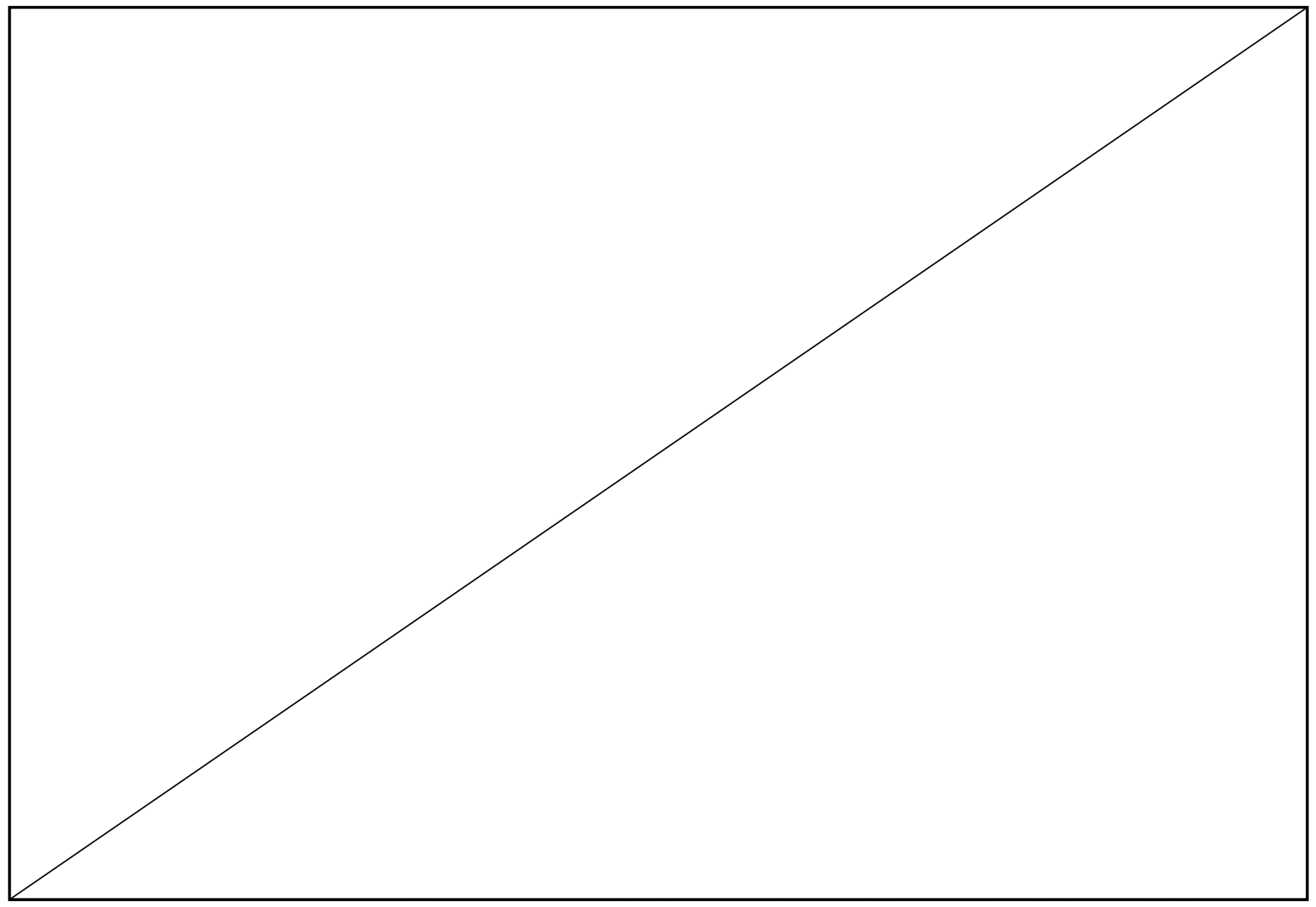

fig. 20 Simon Starling, The Nanjing Particles (After Henry Ward, View of C.T. Sampson's Shoe Manufactory, with the Chinese Shoemakers in working costume, North Adams and vicinity, circa 1875), 2008. Installation view, Massachusetts Museum of Contemporary Art, North Adams, 2008. 


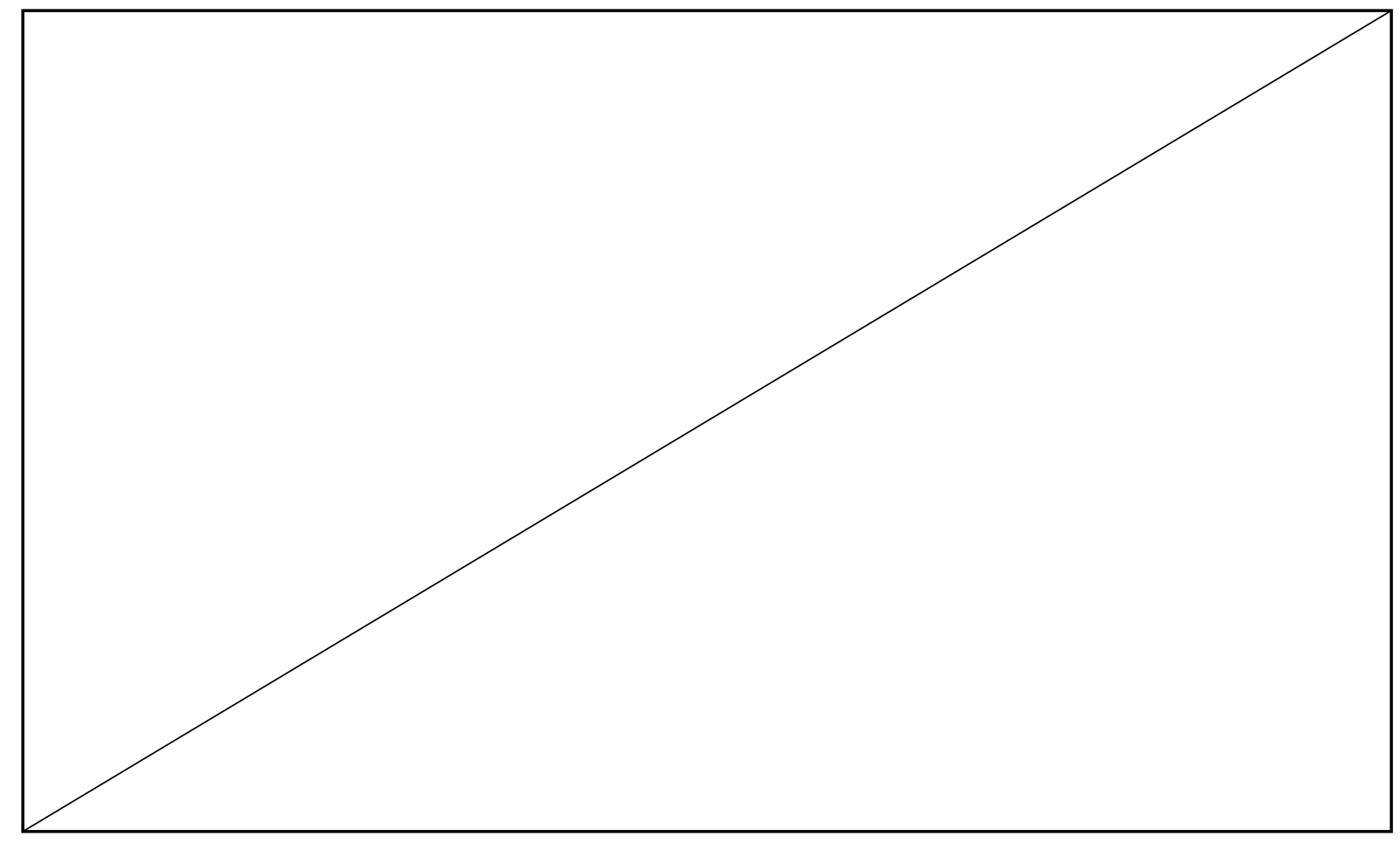

fig. 21 Simon Starling, The Nanjing Particles (After Henry Ward, View of C.T. Sampson's Shoe Manufactory, with the Chinese Shoemakers in working costume, North Adams and vicinity, circa 1875), 2008. Installation view, Massachusetts Museum of Contemporary Art, North Adams, 2008. 


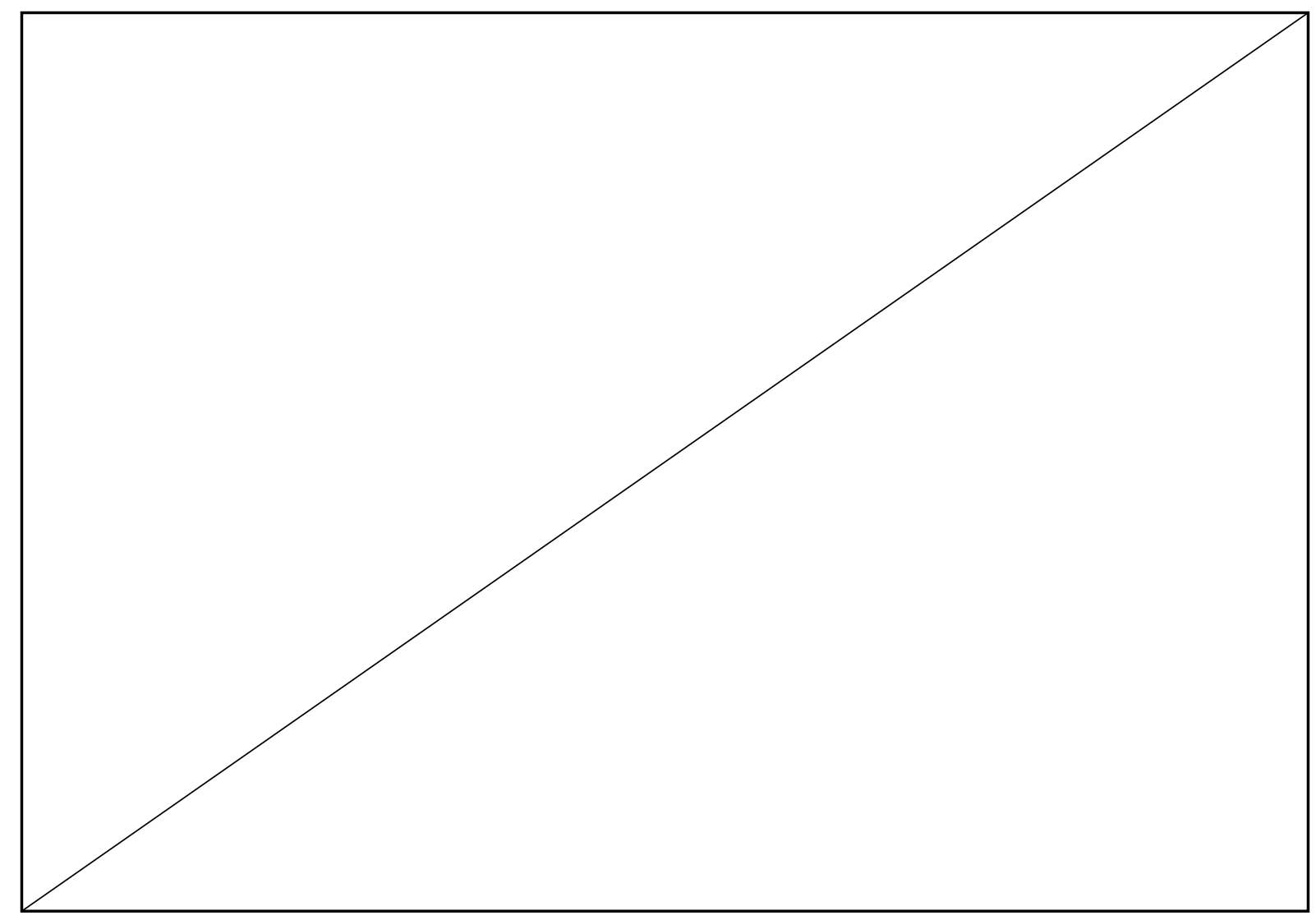

fig. 22 Simon Starling, One Ton II (Five handmade platinum/palladium prints of the Anglo American Platinum Corporation mine at Potgietersrus, South Africa, produced using as many platinum group metal salts as can be derived from one ton of ore), 2005 (Vancouver: Rennie Museum). Installation view, Centro de Arte Contemporáneo de Málaga, 2010 


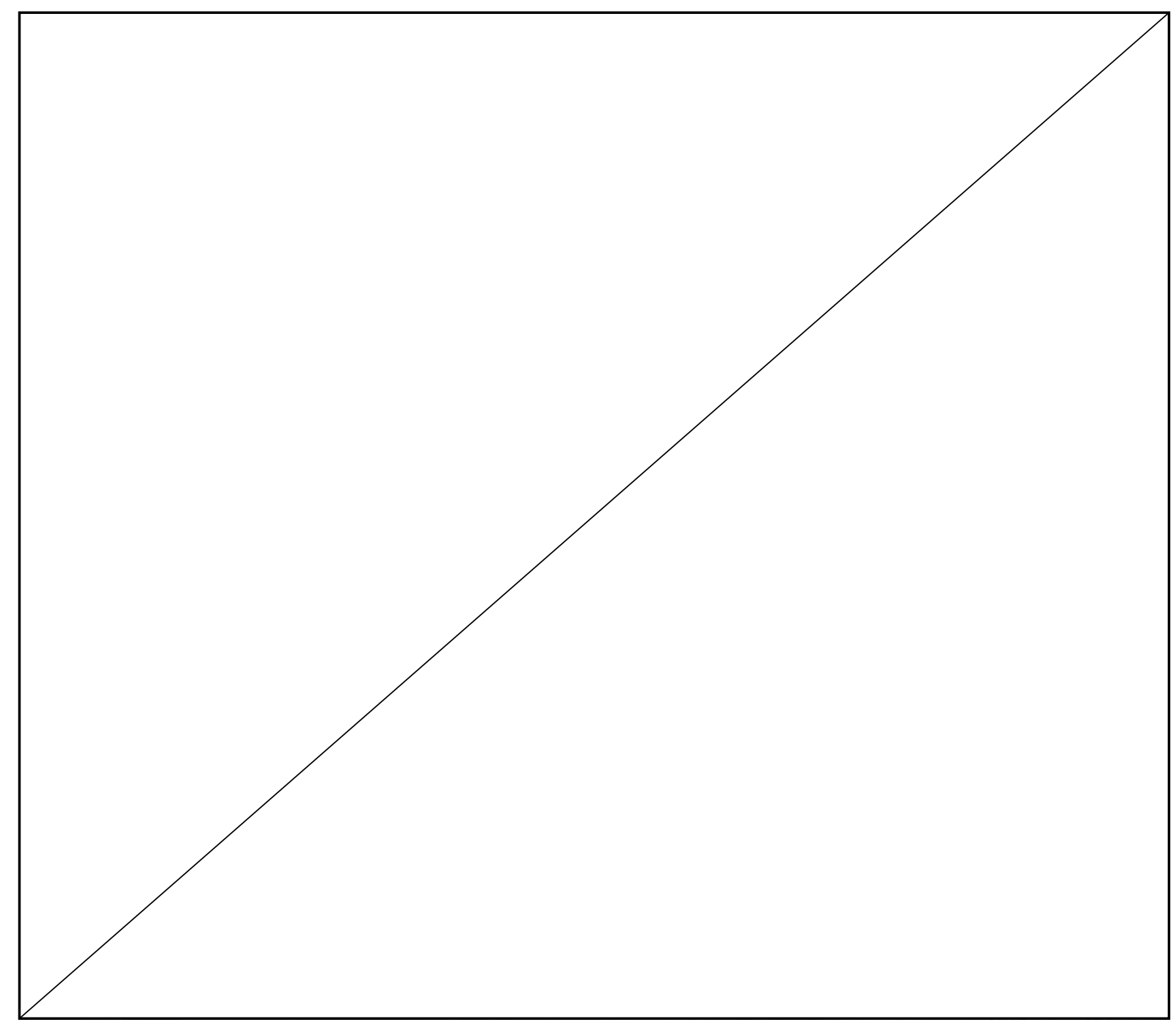

fig. 23 Simon Starling, One Ton II (Five handmade platinum/palladium prints of the Anglo American Platinum Corporation mine at Potgietersrus, South Africa, produced using as many platinum group metal salts as can be derived from one ton of ore), 2005 (Vancouver: Rennie Museum). Detail 


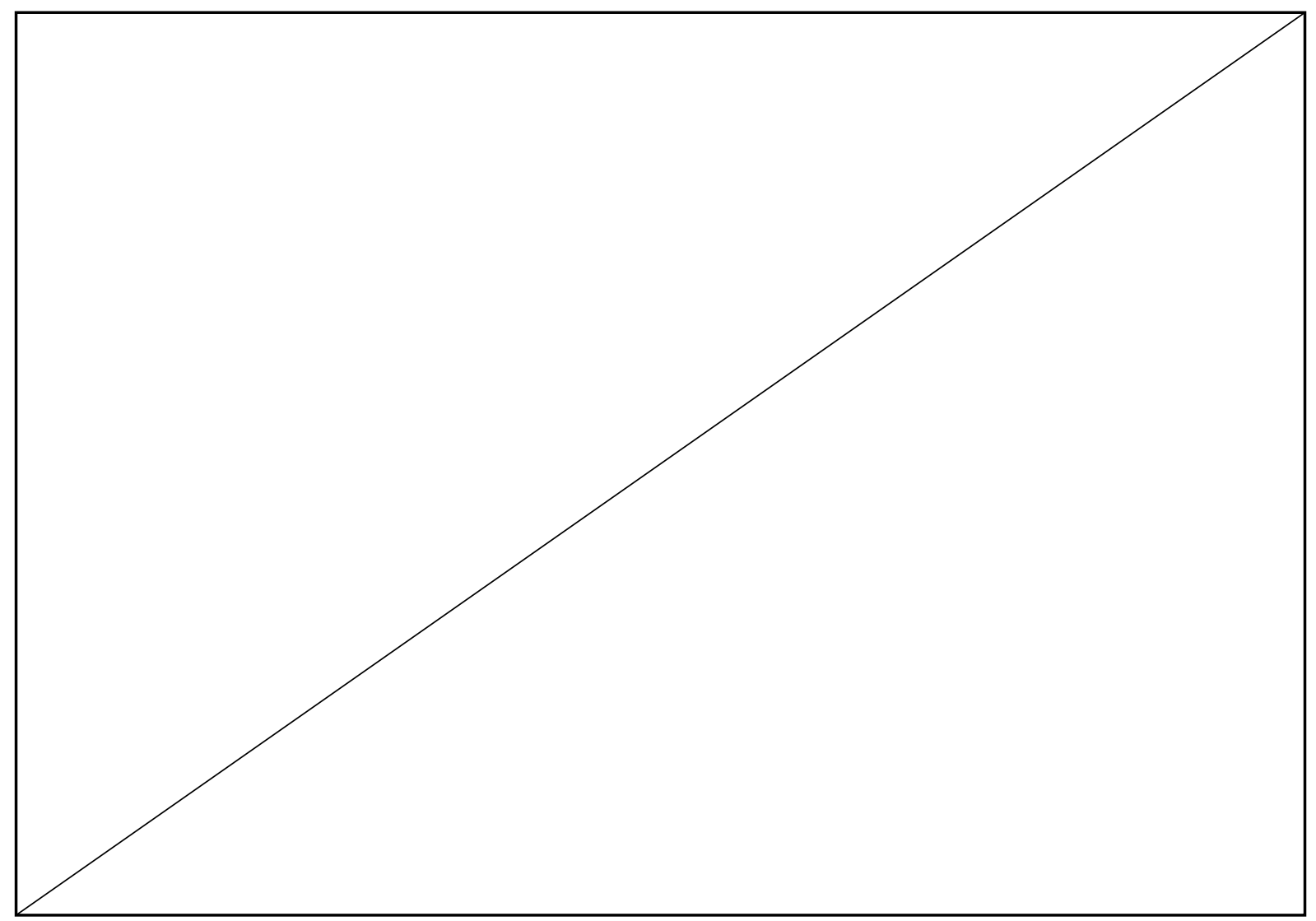

fig. 24 Edward Burtynsky, Nickel Tailings \#34, 1996 (Cleveland: Cleveland Museum of Art) 


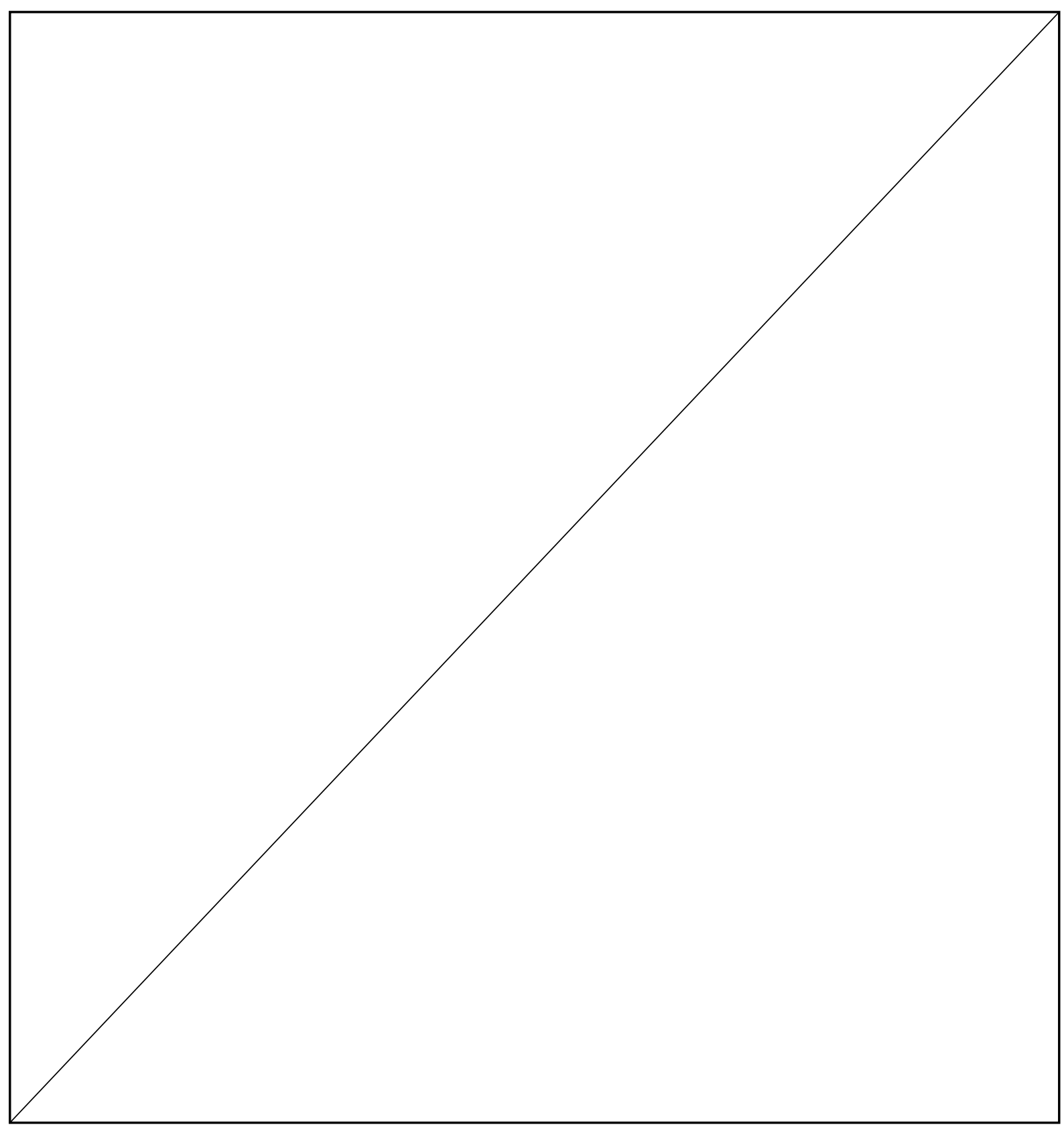

fig. 25 Bernhard and Hilla Becher, Winding Towers, 1966-97 (New York: Museum of Modern Art) 


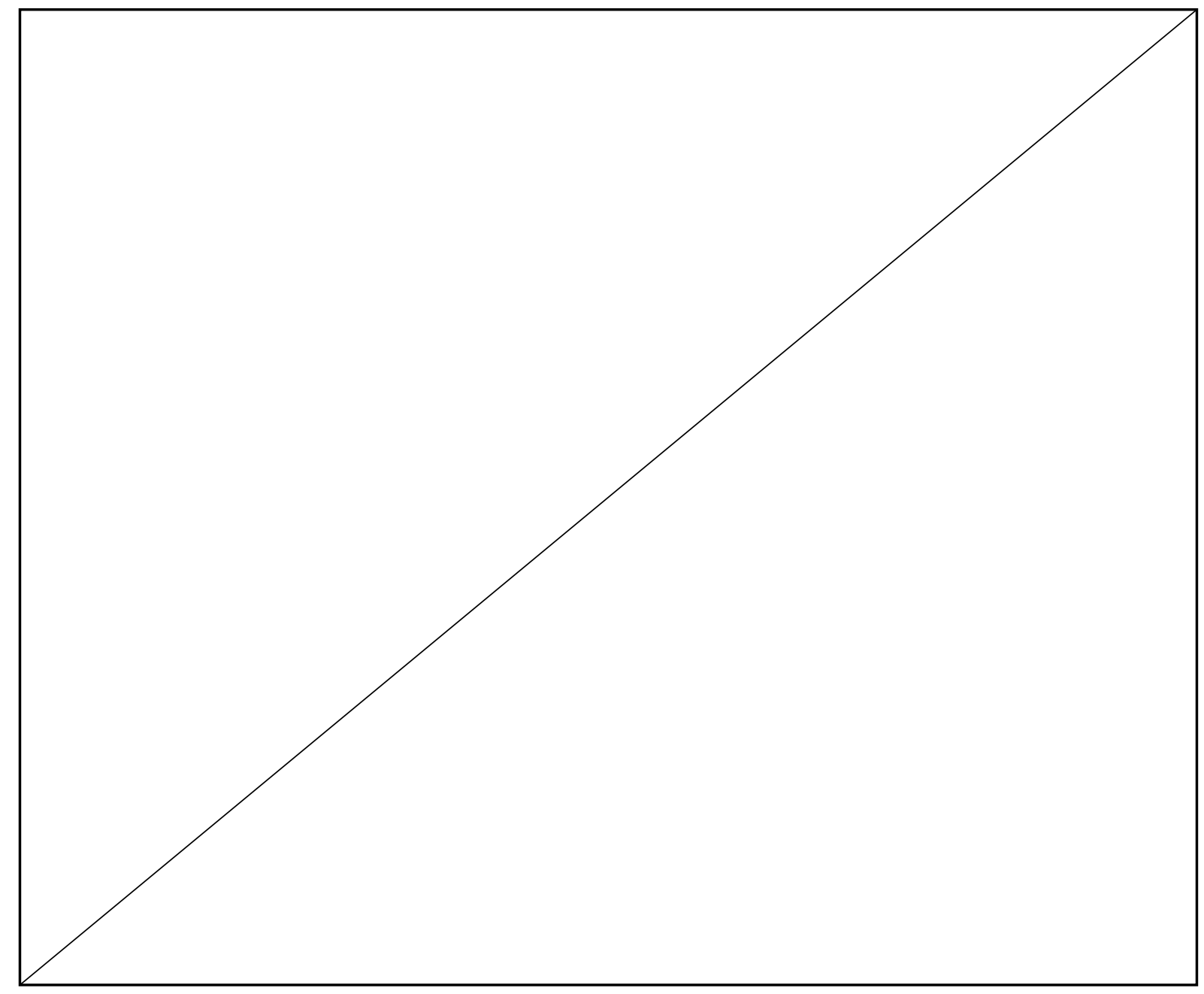

fig. 26 Conor Clarke, Schkopau, Saalekreis, Sachsen-Anhalt, 2013 (Auckland: Two Rooms) 


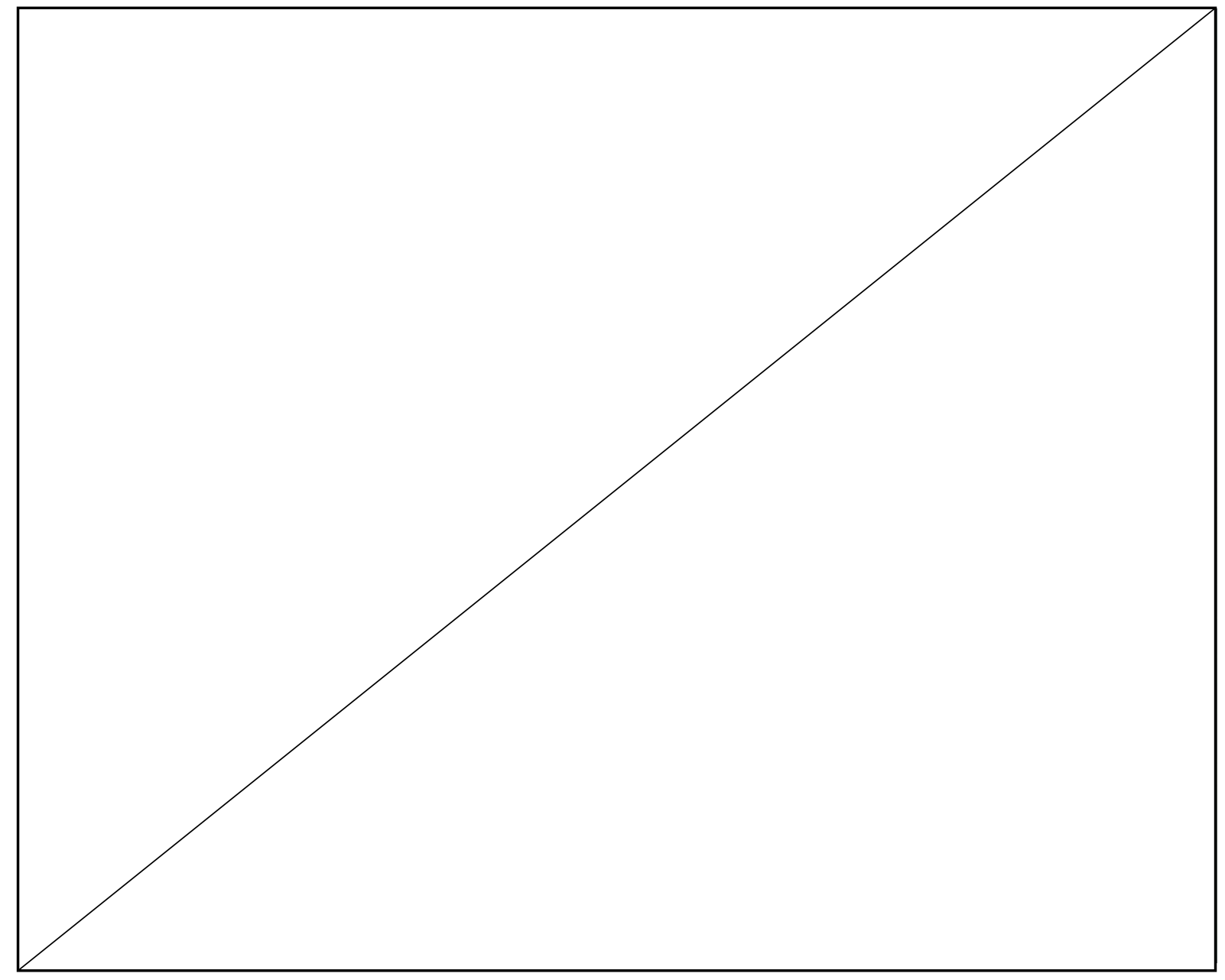

fig. 27 Conor Clarke, Duisburg-Hamborn, Nordrhein-Westfalen, 2014 (Auckland: Two Rooms) 


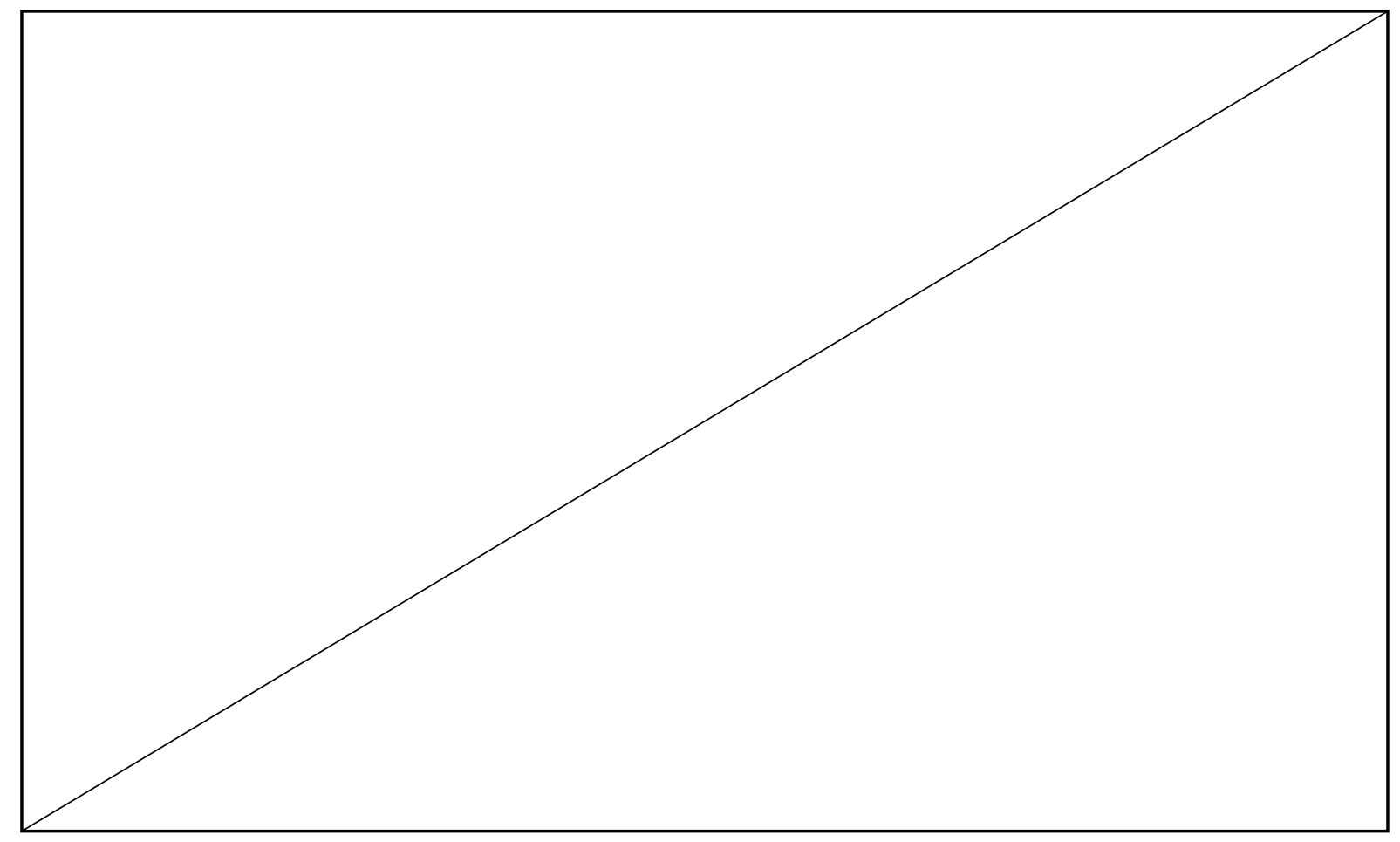

fig. 28 Conor Clarke, In Pursuit of the Object, at a Proper Distance, 2012-14. Installation view, Outer Space, Two Rooms, Auckland, 2014 


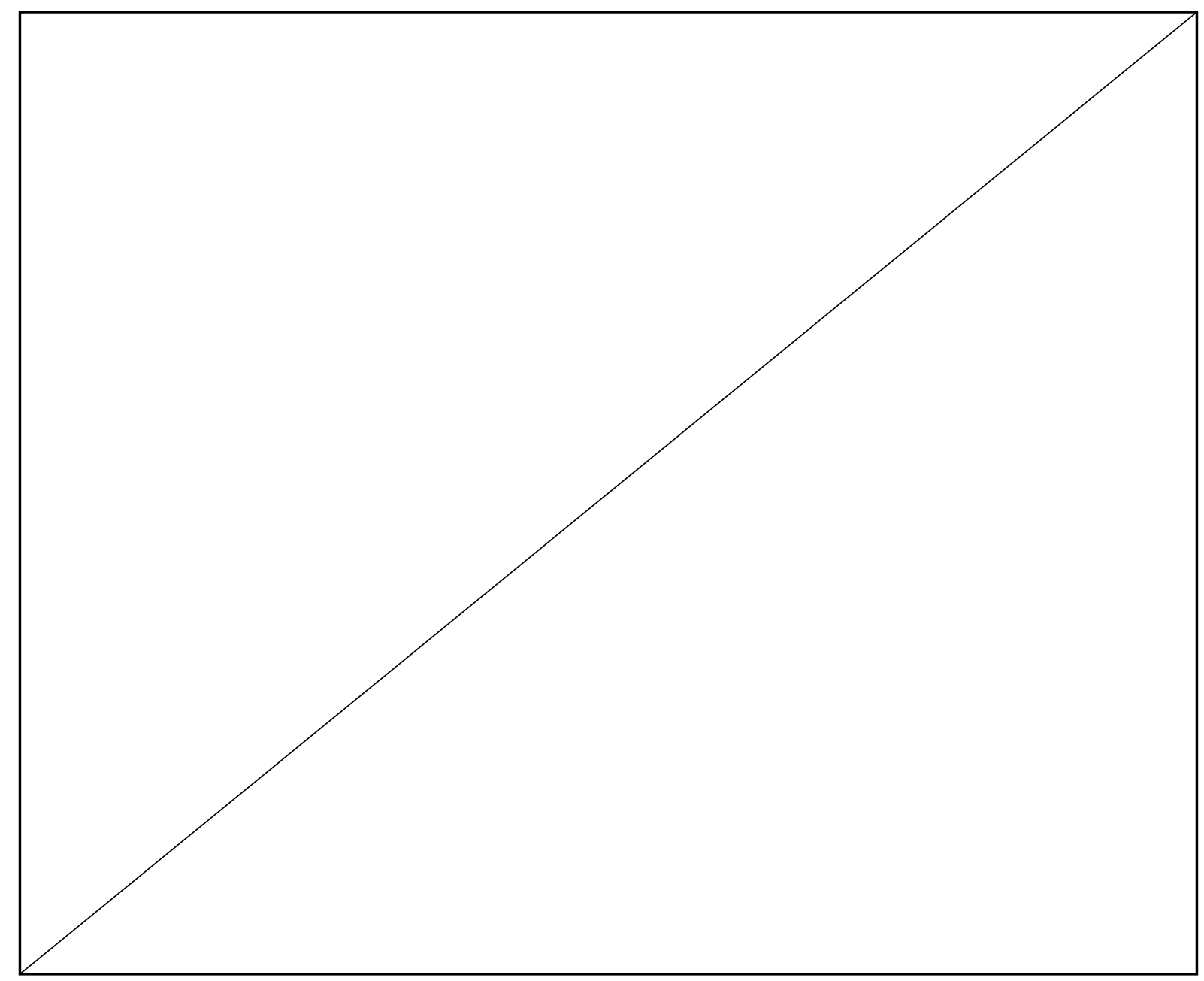

fig. 29 Conor Clarke, Peak III, Berlin, 2015 (Auckland: Two Rooms) 


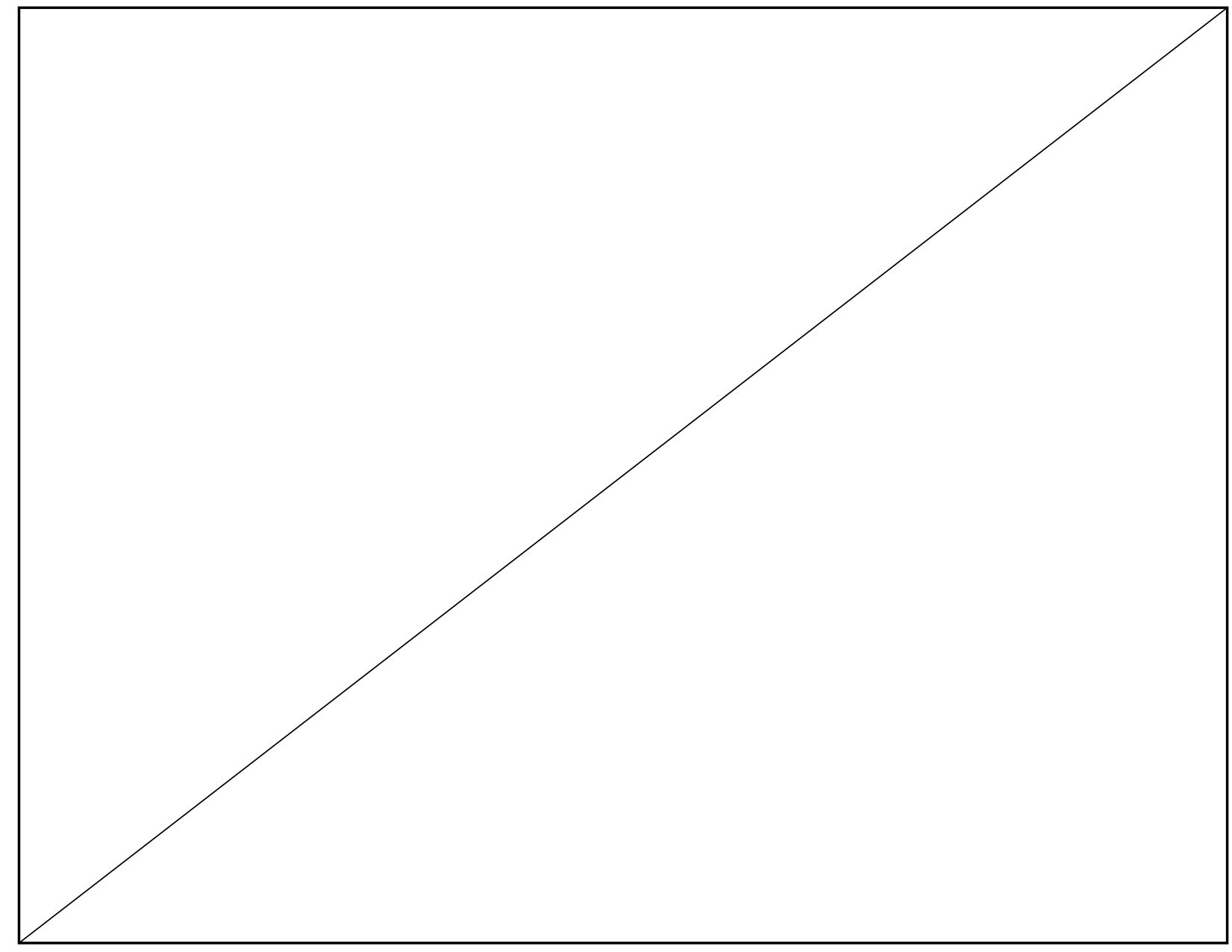

fig. 30 Conor Clarke, Peak I, Berlin, 2014 (Auckland: Two Rooms) 


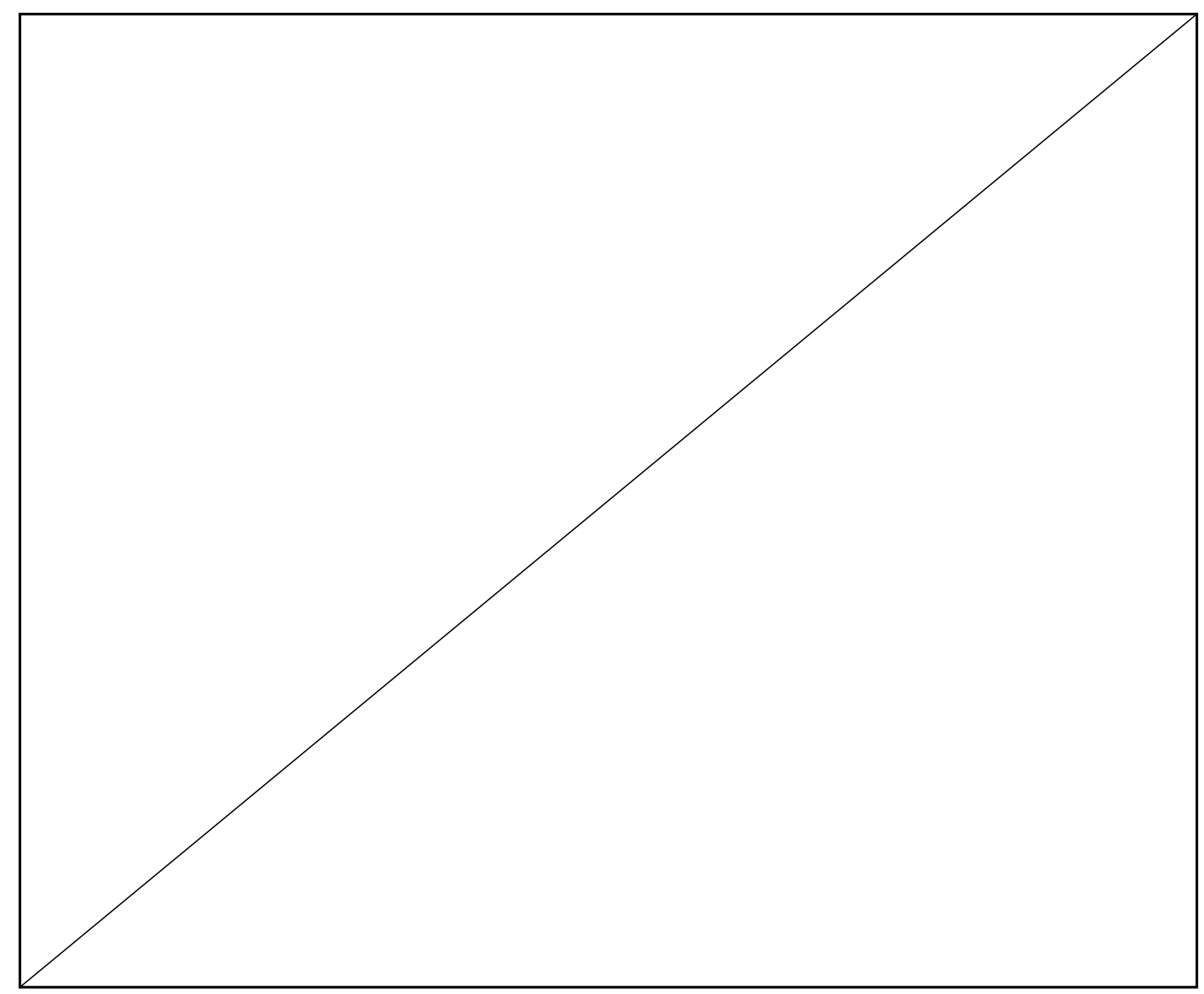

fig. 31 Conor Clarke, Peak II, Berlin, 2015 (Auckland: Two Rooms) 


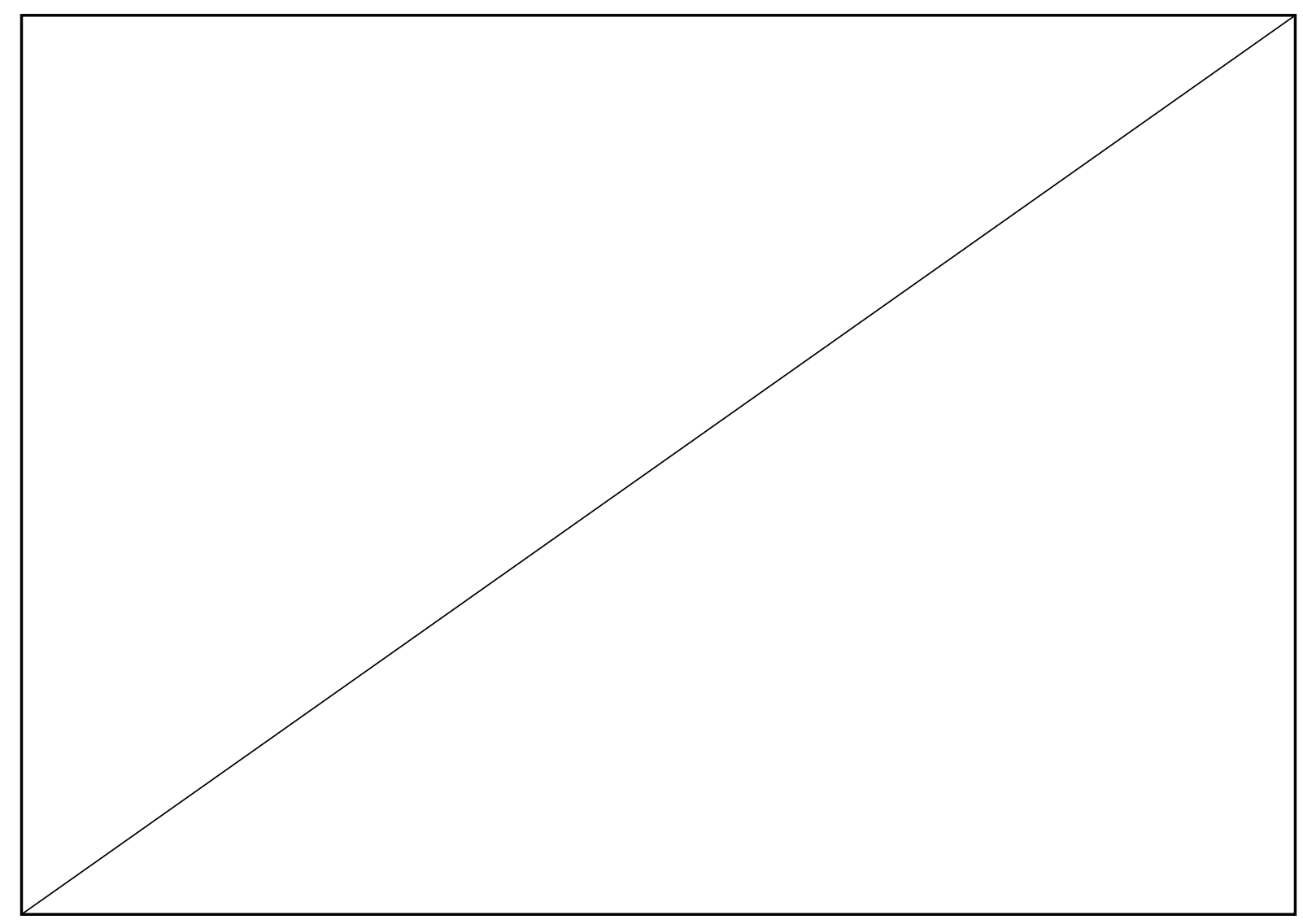

fig. 32 Conor Clarke, Landscape I, Berlin, 2014 (Auckland: Two Rooms) 


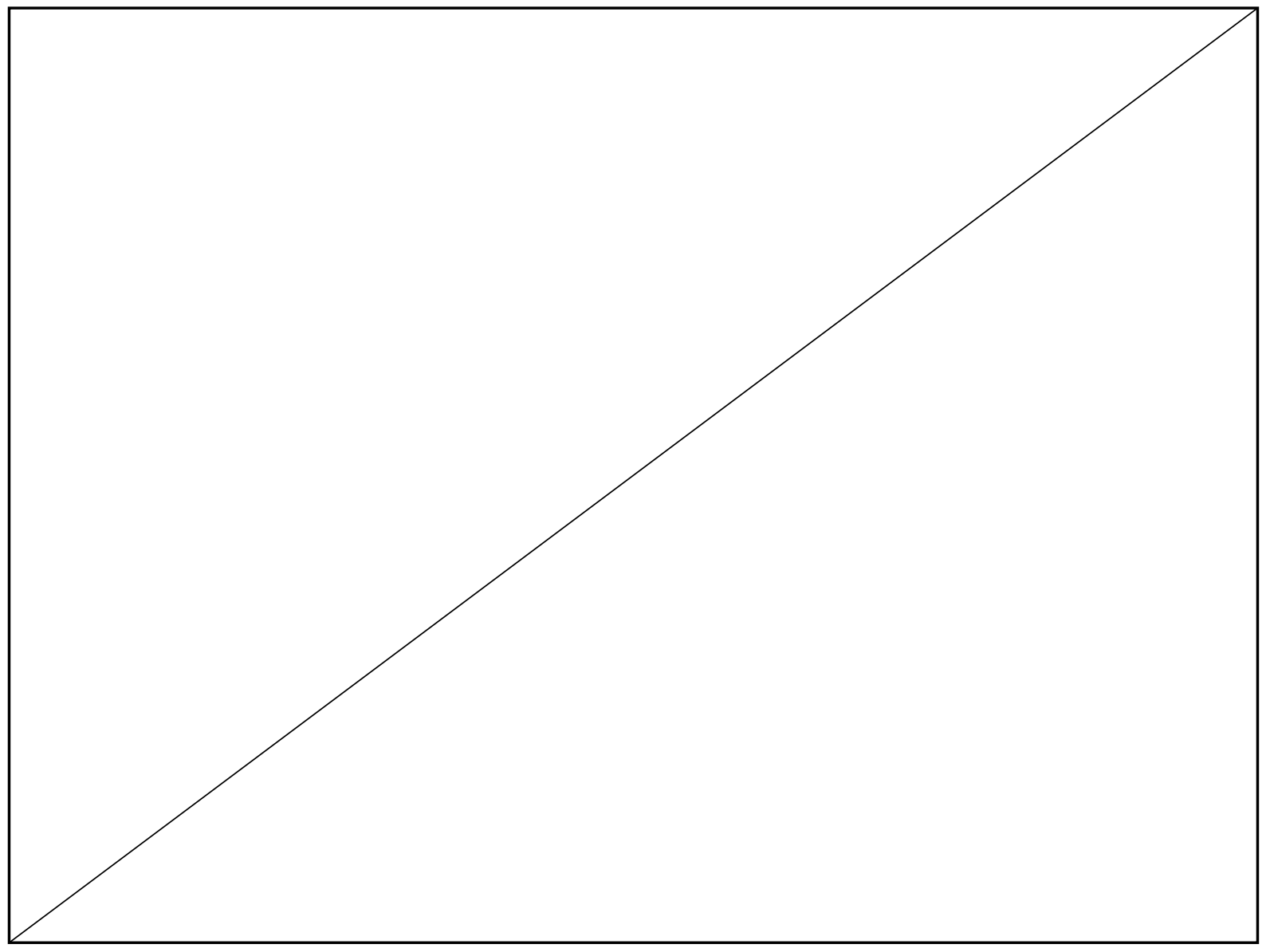

fig. 33 Conor Clarke, Scenic Potential, 2014-15. Installation view, Scenic Potential, Two Rooms, Auckland, 2015 


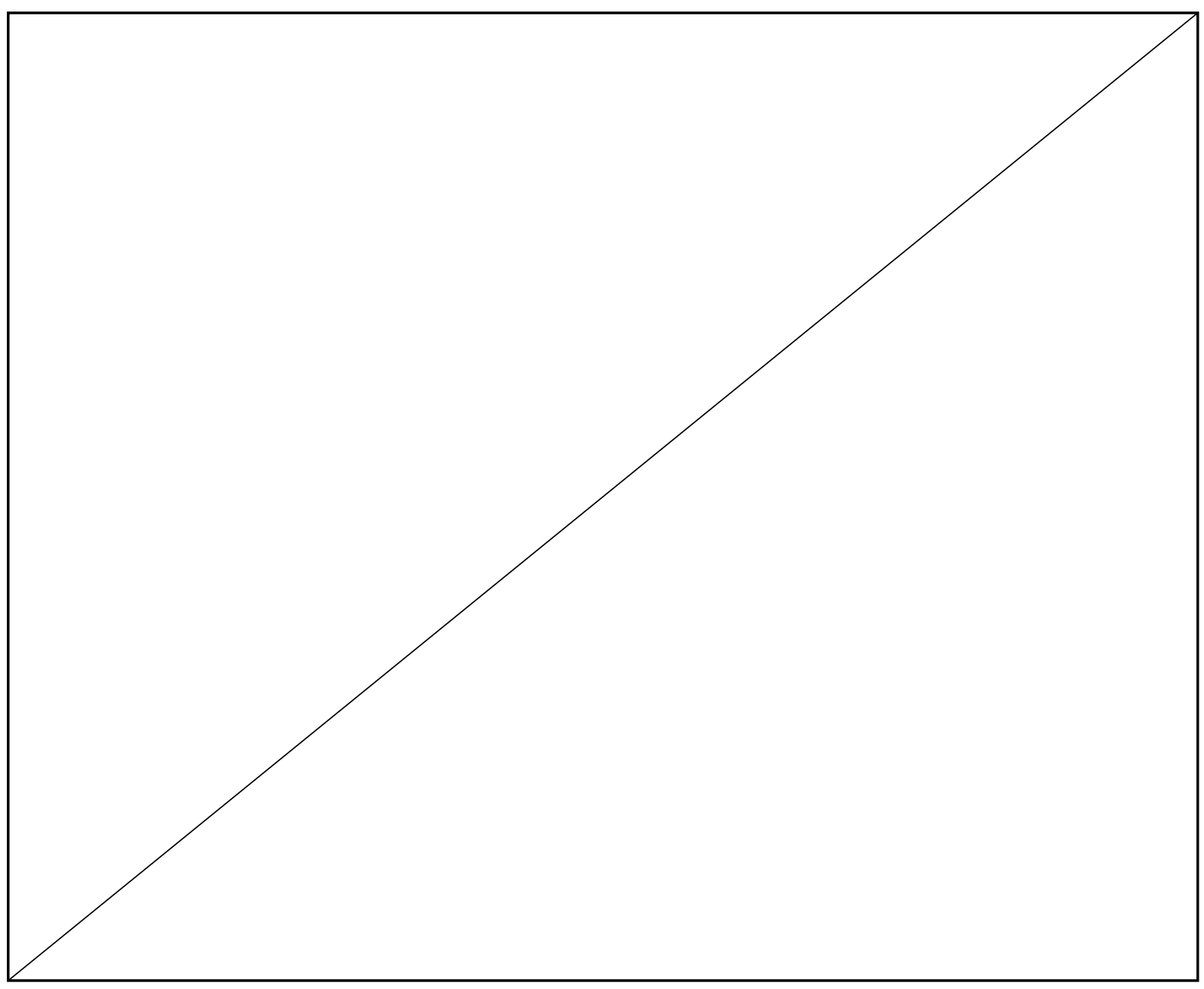

fig. 34 Edward Weston, Dunes, Oceano, 1936 (New York: Metropolitan Museum of Art) 
